\title{
DEGRADAÇÃO DA FRAÇÃO ORGÂNICA DE DIFERENTES RESÍDUOS E EFEITOS EM ALGUMAS PROPRIEDADES QUÍMICAS E FÍSICAS DE DOIS SOLOS
}

\author{
MARCOS CABRAL DE VASCONCELLOS BARRETTO \\ Engenheiro Agrônomo
}

Orientador. Prof. Dr. NADIR ALMEIDA DA GLÓRIA

Tese apresentada à Escola Superior de Agricultura "Luiz de Queiroz", da Universidade de São Paulo, para obtençăo do título de Doutor em Agronomia, Área de Concentraçäo: Solos e Nutriçăo de Plantas.

PIRACICABA

Estado de São Paulo - Brasil

Novembro - 1995 
Dados internacionais de Catalogação na Publicação (CIP)

Divisão de Biblioteca e Documentação - CAMPUS "LUIZ DE QUEYROZ"/USP

Barreto, Marcos Cabral de Vasconcellos

Degradação da fração orgânica de diferentes resíduos e efeitos

em algumas propriedades químicas e físicas de dois solos. Piracisaba, 1995.

106p. ilus.

Tese - ESALQ.

Bibl iografia.

1. Residuo orgânico en solo - Efeito 2. Solo - Propriedade físicoquímica I. Escola Superior de Agricultura Luiz de Queiroz, Piracicaba

CDD 631.41

630.209 


\section{DEGRADAÇÃO DA FRAÇÃO ORGÂNICA DE DIFERENTES RESÍDUOS E EFEITOS EM ALGUMAS PROPRIEDADES QUÍMICAS E FÍSICAS DE DOIS SOLOS}

\section{MARCOS CABRAL DE VASCONCELLOS BARRETTO}

Aprovada em: $19 / 12 / 1995$

Comissão julgadora:

Prof. Dr. Nadir Almeida da Glória

Prof. Dr. Maria Emília Mattiazzo-Prèzotto

Prof. Dr. Paulo Leonel Libardi

Prof. Dr. Wandêley José de Melo

Prof. Dr. Celso Augusto Fessel Graner

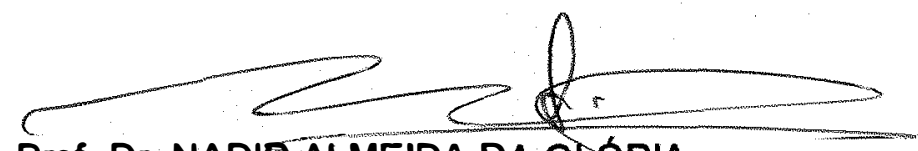

Prof. Dr. NADIR ALMEIDA BA GIǴRIA Orientador 
A

Ana Lúcia

\section{OFEREÇO}

Aos meus pais

Gil e llma

DEDICO 


\section{AGRADECIMENTOS}

Ao Professor Nadir Almeida da Glória, pela orientação dedicada e segura, pela amizade e pelo exemplo.

À Professora Maria Emília Mattiazzo, pela amizade e por todo carinho que dedicou a este trabalho.

Ao Professor Paulo Leonel Libardi, pelos valiosos ensinamentos e por saber ser irmão dos seus alunos.

Ao Professor Arnaldo Antônio Rodella, pela paciência nas explicações de procedimentos analíticos.

Ao colega Raimundo Nonato de Assis Júnior, pela ajuda prestada na execução deste trabalho.

À Universidade Federal de Sergipe, pela oportunidade de realização deste curso.

À CAPES/PICD, pela bolsa de estudos concedida.

Ao corpo de professores e funcionários do Setor de Química Analítica, Departamento de Química - ESALQ/USP, pela amizade que sempre me dedicaram.

A todos os colegas de pós-graduação, queridos amigos, pelos bons momentos que me proporcionaram. 


\section{SUMÁRIO}

Página

RESUMO vii

SUMMARY ix



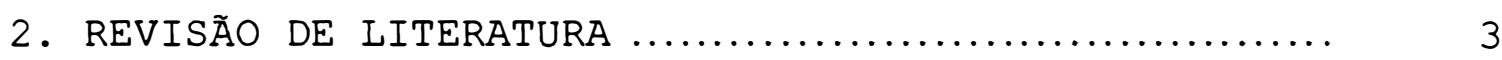

2.1. Decomposição de materiais orgânicos no solo. 3 2.1.1. Métodos de avaliação ................... 3

2.1.2. Degradação da fração orgânica ........... 5

2.2. Efeitos da aplicação de materiais orgânicos em propriedades do solo $\ldots \ldots \ldots \ldots \ldots \ldots \ldots \ldots \ldots . . .6$

2.2.1. Observações gerais $\ldots \ldots \ldots \ldots \ldots \ldots \ldots \ldots \ldots . . .6$

2.2.2. Efeito na capacidade de troca catiônica do solo ............................ 9

2.2.3. Efeito no conteúdo de metais pesados do solo e na sua fitodisponibilidade.

2.2.4. Efeito na capacidade de retenção de

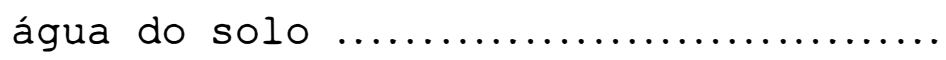

2.2.4.1. Medição da capacidade de retenção de água do solo ........

3. MATERIAL E MÉTODOS

3.1. Comparação de três sistemas de respirome-

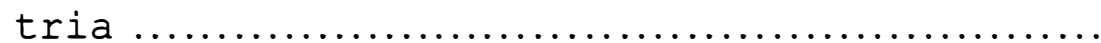

3.2. Estudo de degradação da fração orgânica de diferentes resíduos no solo .....................



3.2.2. Materiais orgânicos .................... 28

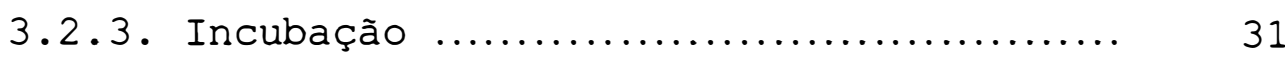


Página

3.3. Avaliação de efeitos da aplicação dos resíduos em propriedades do solo .................. 34

3.3 .1 . Observações gerais .................... 34

3.3.2. Determinação da CTC dos solos .......... 35

3.3.3. Estudo da fitodisponibilidade de metais nos solos e avalição de

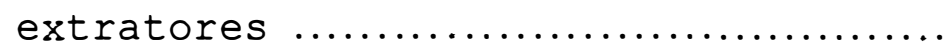

3.3.4. Determinação da capacidade de retenção de água dos solos e dos resíduos.

3.3.5. Cálculos da distribuição de poros no solo ..................................... 40

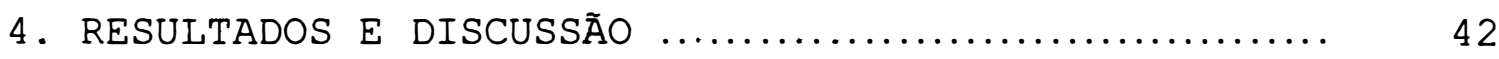

4.1. Comparação de três sistemas de respirometria. 42

4.2. Decomposição de quatro resíduos orgânicos

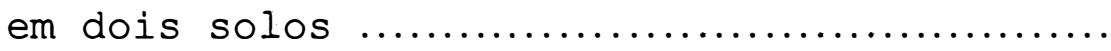

4.3. Efeitos da aplicação dos resíduos sobre propriedades do solo.......................... 52

4.3.1. Observações gerais $\ldots . \ldots \ldots \ldots \ldots \ldots \ldots \ldots . . .62$

4.3.2. Efeito na capacidade de troca catiô-

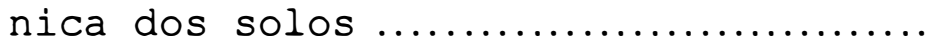

4.3.3. Efeito no conteúdo de metais pesados do solo e na sua fitodisponibilidade.

4.3.4. Efeito na capacidade de retenção de

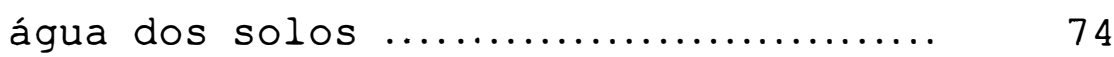

4.4. Considerações finais ...................... 84

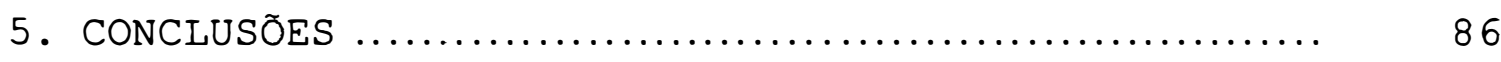

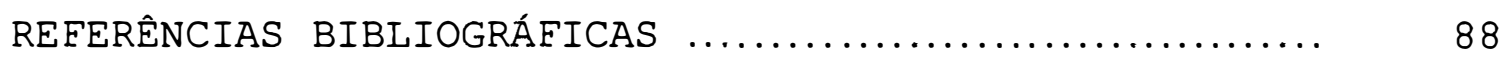

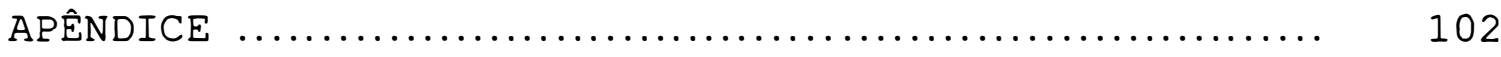




\title{
DEGRADAÇĀO DA FRAÇĀO ORGÂNICA DE DIFERENTES RESÍDUOS \\ E EFEITOS EM ALGUMAS PROPRIEDADES QUIIMICAS \\ E FISICAS DE DOIS SOLOS
}

\author{
Autor: MARCOS CABRAL DE VASCONCELLOS BARRETTO \\ Orientador: Prof. Dr. NADIR ALMEIDA DA GLORIA
}

\section{RESUMO}

Este trabalho teve como objetivo estudar a decomposição de diferentes resíduos orgânicos aplicados em dois solos e os efeitos desta adição em atributos químicos e físicos destes, com ênfase para pH, CTC, fitodisponibilidade de metais pesados e capacidade de retenção de água.

Estudo prévio foi desenvolvido visando eleger um sistema para determinação de perdas de carbono do solo na forma de $\mathrm{CO}_{2}$. A partir deste, optou-se pelo uso de câmaras sem circulação forçada de ar, pela sua equivalência com o sistema dinâmico, desde que se empregasse intervalos adequados de abertura para aeração.

Uma vez definido o sistema de respirometria, incubaram-se torta de filtro, composto de lixo, lodo proveniente do tratamento de efluentes petroquímicos e lodo de esgoto, com amostras de dois solos, a saber: Latossolo Vermelho-escuro, LE, (Typic Haplorthox) e Areia Quartzosa distrófica, AQ, (Typic Quartzipsament). As doses empregadas

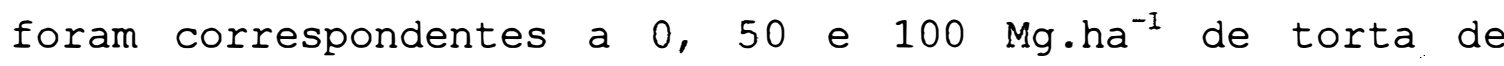
filtro e, para os demais resíduos, quantidades equivalentes a esta em carbono.

O período de incubação teve a duração de 60 dias. Finda esta fase foram separadas amostras de terra 
para análises diversas e para a implantação do estudo de fitodisponibilidade de metais pesados, conduzido com plantas de arroz (Oriza sativa, L.). Os dados de remoção de metais pelas plantas foram comparados com extrações feitas com soluções de DTPA 0,05M, $\mathrm{HCl} 0,1 \mathrm{M}$ e $\mathrm{Ca}\left(\mathrm{NO}_{3}\right)_{2}$ 0,05M.

Os resultados obtidos mostraram que a velocidade de decomposição dos residuos, nos dois solos, apresentou-se na seguinte ordem: torta de filtro > lodo de esgoto $\cong$ composto de lixo > lodo petroquímico. O aumento das doses provocou o decréscimo das taxas de decomposição dos materiais nos solos.

A adição dos resíduos provocou elevação do pH e condutividade elétrica, bem como aumentos nos teores de nutrientes e na saturação por bases dos solos. Quanto a alterações da CTC a pH7, observou-se que estas ocorreram, principalmente, em função de mudanças no pH do solo. Para a CTC determinada com soluções não tamponadas, observaram-se diferenças apenas no solo arenoso.

$\mathrm{Na}$ avaliação da fitodisponibilidade de metais pesados, as soluções de DTPA $0,05 \mathrm{M}$ e $\mathrm{HCl}$ 0,1M mostraram-se eficientes, com relação a cádmio, níquel, crômio, e cobre, não mostrando eficiência quanto ao zinco. O $\mathrm{Ca}\left(\mathrm{NO}_{3}\right)_{2}$ não extraiu metais em quantidades detectáveis. Os metais $\mathrm{Cd}, \mathrm{Ni}$ e $\mathrm{Cr}$ mostraram fitodisponibilidade a partir de concentrações, no solo, de respectivamente, 0,15, 2,97 e $4,29 \mathrm{mg} \cdot \mathrm{kg}^{-1}$ no $L E \mathrm{e}$, na $A Q$, a partir de $0,12,2,33 \mathrm{e} \mathrm{3,35}$ $\mathrm{mg} \cdot \mathrm{kg}^{-1}$.

A capacidade de retenção de água, determinada a tensões variando de 1 a $15 \mathrm{kPa}(0,1$ a $1,5 \mathrm{~m}$ $\left.\mathrm{H}_{2} \mathrm{O}\right)$, mostrou que a adição de residuos orgânicos promoveu o seu aumento no solo argiloso. Já no solo arenoso, este efeito não ficou evidente. 


\title{
ORGANIC MATTER DECOMPOSITION OF DIFFERENT WASTES AND \\ EFFECTS ON SOME CHEMICAL AND PHYSICAL PROPERTIES \\ OF TWO SOILS
}

\author{
Author: MARCOS CABRAL DE VASCONCELLOS BARRETTO \\ Adviser: Prof. Dr. NADIR ALMEIDA DA GLÓRIA
}

\section{SUMMARY}

The objective of this work was to study the decomposition of different organic wastes applied to two soils and the effects of this addition on soil chemical and physical properties, specifically pH, CEC, phytoavailability of heavy metals, and water retention capacity.

A previous work was carried out to select a system to determine carbon losses from soil as $\mathrm{CO} 2$. This test led to use chambers without forced air circulation provided that the openings of chambers for aeration were adequate.

After the definition of the respirometry system, filter cake, compost of municipal solid waste, sludge from petrochemical effluent treatments, and sewage sludge were incubated with samples of two soils: Typic Haplorthox and Typic Quartzipsament. The doses used were 0 , 50, and $100 \mathrm{Mg} \cdot \mathrm{ha}^{-1}$ for the filter cake and the equivalent carbon quantities for the other wastes.

The incubation period lasted 60 days. After that period soil samples were collected for several analyses and the set up of an experiment on phytoavaila- 
bility of heavy metals to be conducted with rice (Oriza sativa, I.). Data of metals uptake by plants were compared to the extractions made with solutions of DTPA $0.05 \mathrm{M}, \mathrm{HCl}$ $0.1 \mathrm{M}$, and $\mathrm{Ca}(\mathrm{NO} 3) 20.05 \mathrm{M}$.

The results showed that the rate of wastes decomposition in both soils was in the following order: filter cake > sewage sludge $\cong$ urban waste compost > petrochemical sludge. The increase of doses led to a decrease in the rates of decomposition in the soils.

The addition of wastes caused increase of $\mathrm{pH}$, electrical conductivity, nutrient contents and base saturation of soils. CEC changes at pH7 were observed to occur, mainly due to $\mathrm{pH}$ changes of the soil. For CEC determined with non-buffered solutions, differences occurred only in the sandy soil.

In the phytoavailability evaluations of heavy metals, DTPA $0.05 \mathrm{M}$ and $\mathrm{HCl} 0.1 \mathrm{M}$ solutions proved to be efficient for the detection of cadmium, nickel, chromium, and copper, but not efficient for zinc. $\mathrm{Ca}\left(\mathrm{NO}_{3}\right)_{2}$ did not extract metals in detectable amounts. $\mathrm{Cd}, \mathrm{Ni}$, and Cr showed phytoavailability from concentrations in the soil of $0.15,2.97$, and $4.29 \mathrm{mg.} \mathrm{kg}^{-1}$, respectively, in Haplorthox and from $0.12,2.33$, and $3.35 \mathrm{mg} \cdot \mathrm{kg}^{-1}$, in Quartzipsament.

The water retention capacity, was determined for tensions ranging from 1 to $15 \mathrm{kPa}\left(0.1\right.$ to $\left.1.5 \mathrm{~m} \mathrm{H}_{2} \mathrm{O}\right)$. Results showed that it is increased with the addition of organic wastes in clay soil. Such effect was not evident in sandy soil. 


\section{INTRODUÇÃO}

Segundo MANAHAN (1990), poluente é uma substância presente no ambiente em concentração maior que a natural, como resultado da atividade humana, e que causa um efeito prejudicial sobre este. Ainda para este autor, contaminante é tudo que causa uma variação na composição normal de um ambiente.

Considerando o ambiente solo, ou o sistema solo-planta, a adição de defensivos, fertilizantes, corretivos ou resíduos diversos enquadra-se, conceitualmente, como um ato de contaminação, e, de alguma forma, qualquer destas intervenções possui um potencial poluidor. Assim sendo, no trato de questões ambientais, inclusive as voltadas para a agricultura, deve-se buscar a maximização dos benefícios e a minimização dos riscos, diante da inevitabilidade de alterações no meio, decorrentes da atividade humana.

Uma forma tradicional de intervenção no ambiente solo é o uso agrícola de resíduos orgânicos, de origem vegetal ou animal, prática milenar que sempre visou à reposição de nutrientes retirados pelas culturas e a melhoria de alguns atributos do solo.

Atualmente, o crescimento das cidades e a expansão industrial promovem a produção de grandes quantidades de resíduos, entre os quais, vários de natureza orgânica, que podem ser submetidos a processos de 
tratamento, visando à diminuição do seu potencial poluidor, do volume de material a descartar e facilitar a sua disposição final. No entanto, apesar da redução de volume, as quantidades de materiais são ainda muito grandes, tornando a possibilidade de aplicação ao solo para uso agrícola uma alternativa interessante. Neste caso, ocorre uma alteração de enfoque a respeito do uso da matéria orgânica, visto que, tão grande quanto a utilidade desta como melhoradora de solos, é a importância destes como meio favorável ao consumo da carga orgânica dos resíduos, ou seja, como fator de preservação da qualidade ambiental.

Embora a adição de resíduos orgânicos possa causar benefícios ao solo, a grande diversidade destes materiais exige que se quantifique os efeitos desta prática, entre estes, a persistência do material adicionado e alterações físicas e químicas do solo decorrentes da sua aplicação.

Diante do enfoque apresentado, os objetivos deste trabalho foram, utilizando dois solos de diferentes texturas, comparar a velocidade de decomposição de quatro resíduos orgânicos (composto de lixo, lodo de esgoto, lodo de origem petroquímica e torta de filtro, produzida por usinas de açúcar) e quantificar o efeito desta aplicação na capacidade de retenção de água dos solos e sobre alguns atributos químicos, com ênfase para $\mathrm{pH}$, capacidade de troca catiônica e fitodisponibilidade de metais pesados. 


\section{REVISÃO DE LITERATURA}

Ao considerar o solo como meio depurador de resíduos orgânicos (GLÓRIA 1992), é necessário que se faça uma abordagem levando em conta dois aspectos principais. O primeiro, relativo a benefícios decorrentes da sua aplicação, tais como elevação do pH, aumento da CTC, adição de nutrientes, melhoria das propriedades físicas e incremento da atividade biológica no solo. O segundo aspecto, este limitante quanto a taxas de aplicação ou mesmo quanto à conveniência de se dispor certos materiais em solos, diz respeito à presença de metais pesados, salinidade e sodicidade, presença de substâncias orgânicas tóxicas, presença de organismos patogênicos e também à acidificação do solo.

Nesta revisão, é feita breve discussão sobre a decomposição de materiais orgânicos aplicados a solos e efeitos de ordem química e física relacionados com esta prática.

\subsection{Decomposição de materiais orgânicos no solo}

\subsubsection{Métodos de avaliação}

A avaliação da taxa de decomposição de materiais orgânicos adicionados a solos fornecem dados úteis para orientar o seu manejo. Estas observações podem 
ser feitas em campo ou em laboratório sob condições controladas.

- Ensaios em campo permitem avaliar comportamentos em escala real e em geral baseiam-se em determinações do carbono do solo em diversas fases do experimento (TESTER, 1990) ou medições do $\mathrm{CO}_{2}$ produzido pelo solo. Quanto a estas, segundo NAGANAWA et al. (1989), a maior variedade de fatores intervenientes nestas condições pode dificultar a quantificação de efeitos específicos. Em estudo conduzido em campo por estes autores foi determinada alta correlação entre temperatura do solo e taxa de respiração. No entanto, ao observar a relação da taxa de respiração com teor de matéria orgânica do solo, as grandes variações de temperatura impediram determinações precisas deste efeito, levando à opção, para este caso, por medições em laboratório.

Medidas das emanações de gás carbônico a partir de amostras de terra incubadas com materiais orgânicos em condições de laboratório, dentro de respirômetros, são as mais utilizadas para avaliar a atividade biológica do solo, tanto para cálculos de biomassa microbiana (JENKINSON $\varepsilon$ POWLSON, 1976; GRISI, 1984; SPARLING, 1992) como para determinação de taxas de decomposição de materiais adicionados. Estudos desta natureza permitem, segundo CERRI et al. (1994), obter em pouco tempo informações seguras sobre o comportamento de materiais orgânicos no solo. Os tipos de respirômetros geralmente utilizados podem ser divididos em fechados e dinâmicos. Estes últimos possuem um sistema de circulação forçada de ar. Nos dois casos a maneira mais comum de coletar $\circ \mathrm{CO}_{2}$ consiste na sua absorção por soluções alcalinas. 
Os respirômetros fechados consistem de vasos de variados tamanhos e formatos, nos quais se acondicionam os materiais a ser estudados, sendo abertos periodicamente para promover a aeração do sistema elou troca da solução coletora de $\mathrm{CO}_{2}$. Em geral derivam do sistema proposto por BARTHA $\mathcal{E}$ PRAMER (1965) e, pelo baixo custo e facilidade de operação, são utilizados extensivamente, como por exemplo, por ZIBILSKE (1987), CASARINI et al. (1988), FINE et al. (1989) e HADAS $E$ PORTNOY, (1994).

Nos sistemas chamados dinâmicos, como 0 proposto por BOWER et al. (1958), faz-se passar uma corrente de ar isento de $\mathrm{CO}_{2}$ através dos recipientes onde estão as amostras. Desta forma a aeração pode ser contínua, embora haja casos em que é feita de forma intermitente. São de construção mais complexa e onerosa. Utilização deste sistema foi feita, entre outros, por JENKINSON (1977), MINHONI et al (1990), SMITH $\mathcal{E}$ HADLEY, (1990), e CERRI et al. (1994).

Visando definir a adoção de um dos métodos citados, será feito neste trabalho um estudo prévio comparando a eficiência destes dois sistemas e ainda de um outro método, utilizando respirômetros semi- abertos.

\subsubsection{Degradação da fração orgânica.}

- A decomposição de materiais orgânicos adicionados a solos, sob condições adequadas de umidade e aeração, é função de vários fatores, entre os quais sobressaem-se: taxa de aplicação, composição do resíduo e temperatura ambiente.

Ao incorporar palha de azevém seca $e$ finamente moída a amostras de dois solos com teores de 
carbono de 2,73 e 0,97\%, JENKINSON (1977) observou que as perdas de $\mathrm{C}-\mathrm{CO}_{2}$, proporcionais às doses, eram independentes das quantidade de carbono adicionadas, que foram de 1,26, 2,52 e $5,05 \mathrm{~g} \cdot \mathrm{kg}^{-1}$. HERNANDEZ et al. (1988) aplicaram restos de videira, estercos de galinha e de porco, lixo urbano e lodo de esgoto em quantidades suficientes para elevar o teor de carbono, de um solo argiloso, de 0,73 para 1,5\%; após seis meses, o teor de carbono orgânico das parcelas tratadas com esterco de galinha, lixo e lodo de esgoto apresentavam-se menores que a testemunha, enquanto os demais possuíam valores semelhantes a esta; também a relação $\mathrm{C} / \mathrm{N}$ do solo decresceu. Estas observações evidenciam a ação do material orgânico adicionado alterando o comportamento do carbono nativo do solo.

Doses elevadas de resíduos, contudo, podem fazer com que os materiais decomponham-se mais lentamente. Em estudo conduzido por ZIBILSKE (1987) foi aplicado lodo de indústria de celulose nas proporções de 0, 17, 33, 67, $133 \mathrm{e} 267 \mathrm{~g}$ por $\mathrm{kg}$ de solo. As perdas percentuais de carbono para a dose de $17 \mathrm{~g} \cdot \mathrm{kg}^{-1}$ foram de $64,8 \%$ enquanto que na dose de $267 \mathrm{~g} \cdot \mathrm{kg}^{-1}$ foram de apenas 16,7\%. Atribuiu este efeito à elevada relação $\mathrm{C} / \mathrm{N}$ do material, ...que aplicado em grande quantidade no solo não encontrou nitrogênio suficiente para promover sua mineralização. Avaliando efeitos da aplicação de doses de 30 a $180{\mathrm{Mg} \cdot \mathrm{ha}^{-1} \mathrm{de}}^{-1}$ esterco bovino em um solo argiloso, SOMMEREELDT et al. (1988) observaram que as menores taxas de decomposição ocorriam sempre nas parcelas que receberam as maiores doses. Se em termos de agricultura estes resultados podem ser interessantes, encarando o solo como meio de descarte de resíduos, a menor taxa de decomposição de grandes quantidades aplicadas pode ser um componente desfavorável, 
pois vai exigir maiores áreas para disposição dos materiais.

Quanto à composição do material a ser descartado, BOYLE $\varepsilon$ PAUL (1989), por exemplo, afirmam que os materiais orgânicos contidos no lodo de esgoto são mais persistentes no solo que o carbono nativo. Observam ainda, que a taxa de decomposição decresce com 0 aumento da quantidade adicionada. MINHONI et al. (1990) determinaram que o nitrogênio foi o fator limitante da decomposição de vinhaça, bagaço de cana e palha de milho incubadas em amostras de Latossolo Vermelho-amarelo.

Temperaturas ambientes mais altas incrementam a decomposição dos materiais orgânicos. ZIBILSKE (1987) determinou que perdas de carbono a $12^{\circ} \mathrm{C}$ eram metade das medidas a $25^{\circ} \mathrm{C}$ em solo que recebeu resíduo de elevada relação C/N. NAGANAWA et al. (1989) observaram que a taxa de decomposição de lodo de esgoto no solo dobrava a cada aumento de $10^{\circ} \mathrm{C}$ na temperatura.

A maioria dos trabalhos consultados informam que as maiores perdas de carbono no solo ocorrem nos primeiros dias após a adição dos materiais, tornando-se razoavelmente constantes a partir de duas a quatro semanas. Isto indica que é possível, em curtos intervalos de tempo, coletar informações acerca de tendências de comportamentos de materiais orgânicos aplicados a solos 


\subsection{Efeitos da aplicação de materiais orgânicos em propriedades do solo.}

\subsubsection{Observaçōes gerais.}

Resíduos orgânicos possuem na sua composição elementos essenciais às plantas e sua aplicação pode resultar no aumento dos teores de macro e micronutrientes do solo (TIESSEN et al., 1984; MCLAUGHLIN $\varepsilon$ CHAMPION, 1987 ; BROWN $\varepsilon$ BRUSH, 1992; HERNANDEZ et al., 1992; BEVACQUA $\varepsilon$ MELLANO, 1994). Entre os macronutrientes destaca-se o caso do nitrogênio, que embora tenha seus teores aumentados no solo, é a relação $\mathrm{C} / \mathrm{N}$ do material aplicado que vai determinar a sua disponibilidade, promovendo a imobilização pela biomassa microbiana do solo (SIMS, 1990), ou a liberação deste nutriente para o solo. Neste caso, deve ser considerado não apenas o fornecimento de $\mathrm{N}$ para as plantas como também o risco de poluição de aquíferos pela lixiviação de nitrato (BUCHANAN $\varepsilon$ GLIESSMAN, 1991).

Alterações no pH do solo são comuns após a adição de resíduos e serão comentadas junto com seus efeitos na CTC.

A condutividade elétrica dá uma indicação do acúmulo de sais no solo. Quando da aplicação de resíduos em solos, geralmente ocorre elevação deste valor (HAYES et al, 1990). Se o aumento da concentração de sais for devido à presença de $\mathrm{Na}^{+}$pode ocorrer dispersão de argilas e entupimento de poros do solo, o que vai diminuir a sua condutividade hidráulica, podendo causar encharcamento. Além da falta de oxigênio para as raízes, as plantas sofrerão também pelo aumento da pressão osmótica da solução do solo. Quanto à degradação da carga orgânica, o ambiente mais redutor vai tornar mais lento este processo. Todos 
estes problemas podem reduzir a vida útil da área de descarte. Observações em campo destes efeitos são relatadas por TEDESCO (1991) em locais de descarte de lodos de origem petroquímica. Nestes, houve drástica redução da taxa de infiltração de água no solo.

Tendo em vista os objetivos da presente pesquisa, os trabalhos revisados a seguir foram selecionados dando ênfase aos efeitos da aplicação de resíduos orgânicos sobre a CTC, fitodisponibilidade de metais pesados e retenção de água nos solos.

\subsubsection{Efeito na capacidade de troca catiônica do solo.}

decomposição e neossíntese no solo, chamada húmus, apresenta grande atividade de superficie, determinada pela dissociação de diversos radicais orgânicos presentes nos polímeros que a compõem (SPOSITO, 1989). Isto the confere uma capacidade de troca catiônica bem maior do que a de minerais de argila, contribuindo desta forma com parte significativa da CTC dos solos, principalmente daqueles nos quais predominam argilas de baixa atividade. No entanto, as cargas da matéria orgânica são dependentes do $\mathrm{pH}$, de modo que a sua contribuiçao será determinada pela condição de acidez do solo que a contém.

HELLING et al. (1964) estudaram o efeito, na CTC do solo, do $\mathrm{pH}$ da solução utilizada na sua determinação, relacionando-o com o conteúdo de argila e de matéria orgânica de 60 amostras de solos. Utilizaram soluções de bário tamponadas, com valores de pH ajustados a $2,5,3,5,5,0,6,0,7,0$ e 8,0 . Os valores médios de CTC determinados para a fração orgânica dos solos, em cada nivel de pH, foram de, respectivamente, 36, 73, 127, 131, 
163 e $213 \mathrm{cmol}_{\mathrm{c}} \cdot \mathrm{kg}^{-1}$, mostrando que do $\mathrm{pH} \mathrm{2,5}$ para $\circ \mathrm{pH} 8,0$ a CTC da matéria orgânica aumentou em seis vezes. No mesmo intervalo de $\mathrm{pH}$, a CTC da fração argila aumentou 1,7 vezes. Confirmaram, para a CTC da matéria orgânica, o seu caráter altamente dependente do pH. Em termos de contribuição para a CTC total do solo, esta participou com 19\% a pH 2,5 e com $40 \%$ a pH 7,0. Determinaram, ainda, dentro de cada nível de pH, elevadas correlações da CTC com conteúdo de argila e de matéria orgânica do solo. Ao incluirem nas regressões $\circ \mathrm{pH}$ original do solo, não ocorreu incrementos significativos nos coeficientes de correlação. Concluíram que os teores de argila e de carbono são parâmetros muito úteis para estimativas da CTC dos solos.

Nos trabalhos comentados a seguir o termo CTC refere-se a determinações feitas a pH7. Em casos diferentes, será especificado o método.

RAIJ (1969), avaliando a CTC de 22 perfis de solos do Estado de São Paulo, observou estreitas correlações entre esta e o carbono do solo, atribuindo à matéria orgânica contribuições de até $74 \%$ da CTC total. Notou, ainda que, nos solos estudados, além de a fração inorgânica apresentar CTC mais elevada a maiores valores de pH, também a fração orgânica seguia esta tendência. Assim sendo, a matéria orgânica não apenas influencia, mas, sofre a influência de alterações químicas do solo quanto à expressão deste atributo. Observa-se, portanto, que ao avaliar a contribuição decorrente da adição de materiais orgânicos na CTC do solo, quanto à correspondência deste parâmetro com o carbono adicionado, tem que se levar em conta as interações decorrentes desta prática.

SARKIS (1987), estudando efeitos da aplicação de lodo de esgoto a solos, concluiu que as flutuações observadas para a CTC estavam associadas a 
variações no pH do solo. Em outro trabalho, com amostras de solo arenoso e argiloso, incubadas durante um ano com composto de lixo na proporção de 2,5\% em peso, GIUSQUIANI et al. (1988) observaram sensíveis elevações nos teores de carbono em relação a amostras não tratadas. Já os valores de pH não mostraram alterações. Neste estudo, não se observou nenhuma alteração na CTC do solo.

Em solo de textura franco-siltosa com $\mathrm{pH}$ inicial de 5,4, NDAYEGAMIYE $\mathcal{E}$ CÔTÉ (1989) estudaram efeitos da aplicação de esterco bovino nas doses de 0, 20, 40 e 60 $\mathrm{Mg} \cdot \mathrm{ha}^{-1}$ e de esterco suíno líquido nas doses de 60 e 120 $\mathrm{m}^{3} \cdot \mathrm{ha}^{-1}$. Após dois anos, a aplicação do esterco suíno não resultou em alterações no solo quanto a pH, carbono e CTC. No caso do esterco bovino, apenas na maior dose houve aumento do carbono (2,1 para 3,1\%) e da CTC do solo (de 10,5 para $\left.12,1 \mathrm{cmol}_{\mathrm{c}} \cdot \mathrm{kg}^{-1}\right)$. Quanto ao $\mathrm{pH}$ no final do ensaio, - tratamento testemunha apresentou o valor de 6,4, igual às doses de 20 e $40 \mathrm{t} / \mathrm{ha}^{-1}$, tendo o solo do tratamento com 60 Mg.hat um valor de $\mathrm{pH}$ de 6,5 . Os autores atribuíram o aumento de CTC ao acréscimo de cargas negativas provenientes da matéria orgânica. Por outro lado, VIVEKANANDAN et al. (1991), trabalhando com amostras de solo argiloso nas quais foram aplicadas doses de lodo de esgoto nas proporções de $0,2,55,0$ e 7,5 g. $\mathrm{kg}^{-1}$, observaram aumento na CTC de $7,8 \mathrm{cmol}_{\mathrm{c}} \cdot \mathrm{kg}^{-1}$ na testemunha, para 10,5 na dose maior. O pH elevou-se de 4,9 para 7,5. Já a matéria orgânica do solo (calculada multiplicando o teor de carbono por 1,72$)$ manteve-se em torno de $24 \mathrm{~g} \cdot \mathrm{kg}^{-1}$ em todos os tratamentos.

Em estudo conduzido no campo por CAVALLARO et al. (1993) em um solo Podzólico de Porto Rico, foram aplicadas doses $0,8,16$ e $24 \mathrm{Mg} \mathrm{ha}^{-1}$ de lodo de esgoto, 
incorporadas até a profundidade de $15 \mathrm{~cm}$. Os dados para carbono do solo, $\mathrm{pH}$ em água e CTC, para a testemunha e a dose maior de lodo, foram os seguintes, respectivamente: carbono, 15,9 e $21 \mathrm{~g} \cdot \mathrm{kg}^{-1}$; CTC, 7,2 e $8,58 \mathrm{cmol}_{\mathrm{c}} \cdot \mathrm{kg}^{-1}$; $\mathrm{pH}$, 5,1 e 5,2. Os autores atribuem a elevação na CTC ao significativo aumento do carbono do solo, o qual, complexando alumínio, liberaria sítios de troca. No entanto, outros trabalhos relatam aumentos bem maiores de CTC com incrementos pequenos ou nulos do teor de carbono no solo, quando ocorreram significativas elevações do $\mathrm{pH}$. Neste trabalho, o que se observa é um pequeno aumento de CTC e uma pequena elevação de $\mathrm{pH}$, o que permite considerar que é marcante a contribuição na CTC, dada pela adição de materiais orgânicos, apenas quando esta promove a elevação do $\mathrm{pH}$ do solo.

Na maioria dos trabalhos avaliando a CTC do solo, utilizam-se métodos nos quais esta determinação é feita com o uso de soluções tamponadas, a pH7. Em revisão crítica sobre o tema, BACHE (1976) aponta como mais interessante o uso de soluções não tamponadas, ressaltando um método proposto por BASCOMB (1964) no qual se utiliza solução de $\mathrm{BaCl}_{2}$ para saturar as amostras, deslocando em seguida o bário adsorvido com solução de $\mathrm{MgSO}_{4}$. GILLMAN (1979) propôs um método para determinação da CTC ao pH do solo, modificado de BASCOMB (1964), utilizando ainda $\mathrm{BaCl}_{2}$ e $\mathrm{MgSO}_{4}$, testado em amostras de seis diferentes solos. Os resultados obtidos mostraram valores baixos, quando comparados com determinações feitas a pH7. O autor concluiu que $o$ uso da solução não tamponada produz resultados mais coerentes com a condição natural do solo. Uma aplicação deste método, visando avaliar efeitos da adição de materiais orgânicos a um solo, é comentada a seguir. 
RODELLA et al. (1995) estudaram a contribuição da CTC a pH7 da matéria orgânica adicionada ao solo sobre a CTC deste, tendo concluído que 32\% da СTC do solo podia ser explicada pela CTC do material orgânico. Ao incluir na regressão $\circ \mathrm{pH}$ do solo, $\bigcirc$ coeficiente de correlação passou para 78\%. No trabalho acima, amostras de Areia Quartzosa foram incubadas por noventa dias com turfa, bagaço de cana, torta de filtro, composto orgânico, vermicomposto, estercos de curral e de galinha e lodo de indústria de celulose. $O \mathrm{pH}$ do solo foi previamente ajustado em 4,9 e 6,4. A CTC foi determinada ao pH atual do solo, utilizando-se solução não tamponada de $\mathrm{BaCl}_{2}$. Os resultados mostraram que a turfa, embora possuísse uma CTC a pH7 bem maior que os outros materiais, promoveu um aumento insignificante na CTC do solo, o qual apresentou decréscimo no pH ao final da incubação. Os materiais que elevaram a CTC do solo também promoveram o aumento do seu $\mathrm{pH}$.

Diante dos resultados obtidos para CTC em função do método empregado na sua determinação, no presente estudo a CTC do solo será medida com 0 uso de soluções tamponada e não tamponada.

\subsubsection{Efeito no conteúdo de metais pesados do solo e na sua fito- disponibilidade.}

Assim como outras substâncias, os metais pesados podem ter expressa sua ação poluente de várias maneiras: sobre organismos do solo, em problemas de toxicidade às plantas e em transferência para a cadeia alimentar através dos vegetais ou da contaminação de aqüíferos. Portanto, para prevenir contra efeitos danosos 
ao ambiente decorrentes da aplicação de resíduos, é necessário o estudo do comportamento de metais pesados no solo, com vistas a reunir subsídios para a definição dos critérios de adição de materiais que os contenham.

CHANG et al. (1992), avaliando as normas que definem as taxas de aplicação de lodos de esgoto nos Estados Unidos, informam que os limites de acumulação prescritos para vários metais pesados foram definidos com base em critérios de fitotoxidade, os quais diferem entre plantas e variam com propriedades dos solos. Acentuam ainda a necessidade de informações mais precisas na literatura especializada. Apesar disto, recentemente foram definidas, naquele país, taxas de aplicação mais elevadas. WALLACE $\mathcal{E}$ WALLACE (1994) e MCBRIDE (1995) criticam os níveis recomendados, afirmando que a adsorção de metais em solos não é um fato permanente e estes podem vir a ser liberados a longo prazo. Acentuam ainda que as condições dos estudos de laboratório nem sempre se reproduzem em campo. Por outro lado, trabalhos deste tipo são úteis para a coleta de informações específicas e fornecem grande número de dados em pouco tempo. Deste modo, podem apontar diretrizes para estudos em escala real e fornecer dados preliminares que atendam, apesar de parcialmente, à urgência do problema gerado pela grande produção de resíduos nos tempos atuais. No Brasil, uma primeira aproximação foi proposta por MATTIAZZO $\varepsilon$ GLÓRIA (1995), baseada em estudos em laboratório, na qual taxas de aplicação de cádmio, cobre níquel e zinco são preconizadas em função do conteúdo de argila e do teor de óxidos de ferro e alumínio do solo.

Com relação à biodisponibilidade de metais pesados, o procedimento comumente utilizado para sua avaliação consiste na extração destes com vários tipos de soluções, tentando relacionar as concentrações determinadas 
com a absorção por plantas (ADRIANO, 1986). A eficiência dos extratores é dada pelo grau de correlação entre estas duas determinações. Os extratores consistem em geral de soluções de ácidos, agentes quelantes ou de sais neutros. Utiliza-se ainda misturas destas substâncias.

Extratores ácidos, entre estes Mehlich 1 $\left(\mathrm{H}_{2} \mathrm{SO}_{4} 0,05 \mathrm{~N}+\mathrm{HCl} 0,025 \mathrm{~N}\right), \mathrm{HCl} 0,05 \mathrm{~N}$ e $\mathrm{HCl} 0,1 \mathrm{~N}$, são muito utilizados em estudos de biodisponibilidade (BRAMS $\mathcal{E}$ ANTHONY, 1988; ROCA $\mathcal{E}$ POMARES, 1991; TAYLOR et al., 1992; HADDAD $\mathcal{E}$ EVANS, 1993). Quantidades de metais absorvidas por vegetais muitas vezes correlacionam-se com teores determinados nestas soluções, embora estas extraiam quantidades muito maiores, próximas do total aplicado ao solo.

O uso de agentes quelantes decorre da sua habilidade de deslocar metais ligados a radicais orgânicos. Entre estes ligantes destaca-se o DTPA (ácido dietilenotriamino-pentaacético) de aplicação proposta para Cu, Zn, Fe e Mn por LINDSAY $\varepsilon$ NORVELL (1978) para solos calcários. Em diversos trabalhos esta substância é utilizada para extrair outros metais além destes e em variados tipos de solos (VALDARES et al., 1983; KING $\varepsilon$ HAJJAR, 1990; MULCHI et al., (1991); SIKKA $\mathcal{E}$ KANSAL, 1995).

Soluções salinas não tamponadas de $\mathrm{NaNO}_{3}$, $\mathrm{Ca}\left(\mathrm{NO}_{3}\right)_{2}, \mathrm{CaCl}_{2}$ e outras extraem geralmente pequenas quantidades de metais, correspondendo às que se encontram no solo em solução ou fracamente adsorvidas. HÄNI $\mathcal{E}$ GUPTA (1985) afirmam que as quantidades removidas por estes extratores são semelhantes às retiradas pelas plantas. A possibilidade de aproximar as quantidades extraídas quimicamente daquelas absorvidas pelas plantas vem estimulando o uso destes extratores (SAVERBECK $\varepsilon$ STYPEREK, 
1985; PETRUZELLI et al., 1989; JING $\varepsilon$ LOGAN, 1992; SMILDE $\mathcal{E}$ LUIT, 1992) .

Utilizando amostras de quatro solos (Areia Quartzosa distrófica ( $A Q)$, Podzólico Vermelho-amarelo (PV), Terra Roxa estruturada (TR) e Latossolo Vermelho-escuro (LE)) com valores de $\mathrm{pH}$ ajustados em torno de 4,2, 5,2 e 6,2, MATTIAZZO-PREZOTTO (1994) estudou 0 efeito da aplicação de soluções contendo $\mathrm{Cd}, \mathrm{Cr}, \mathrm{Ni}, \mathrm{Cu}$ e $\mathrm{Zn}$, em duas doses, na absorção destes metais por plantas de arroz e a sua correspondência com quantidades extraídas por soluções $0,05 \mathrm{M}$ de DTPA a pH7,2, $\mathrm{HCl} 0,1 \mathrm{M}$ e $\mathrm{Ca}\left(\mathrm{NO}_{3}\right)_{2}$ 0,05 M. Os resultados mostraram que a presença de metais prejudicou seriamente o desenvolvimento das plantas na areia Quartzosa e moderadamente no PV. Nos solos TR e LE o desenvolvimento foi prejudicado apenas quando da adição da maior dose de metais. Para $\bigcirc$ solo $A Q$ as análises de tecido vegetal, apresentadas apenas para $\mathrm{Cu}, \mathrm{Ni}$ e $\mathrm{Zn}$, revelaram maiores quantidades totais de metais nas parcelas que apresentavam menor desenvolvimento, para a dose maior de metais. Os valores na dose menor foram semelhantes à testemunha, fato atribuído à maior produção de matéria seca nestas. Avaliando a relação entre as quantidades retiradas pelas plantas e aquelas extraídas pelas soluções observou-se que as menores correlações para os três extratores foram determinadas no solo $\mathrm{AQ}$, aumentando nos demais solos na seguinte ordem: $\mathrm{PV}<\mathrm{TR}<\mathrm{LE}$. Nestes, destacou-se 0 extrator salino $\left(\mathrm{Ca}\left(\mathrm{NO}_{3}\right)_{2}\right)$ com os maiores coeficientes de correlação. Convém considerar que estas melhores correlações podem ter sido obtidas em decorrência de ter-se adicionado ao solo os metais na forma de sais.

Aproveitando amostras de solo incubadas com quatro diferentes materiais orgânicos, no presente trabalho será conduzido um estudo de biodisponibilidade, utilizando 
a mesma planta e os mesmos extratores empregados no trabalho comentado acima, visando avaliar diferenças no comportamento de $\mathrm{Cd}, \mathrm{Cr}, \mathrm{Cu}, \mathrm{Ni}$ e $\mathrm{Zn}$, quando aplicados não na forma de sais, mas como contaminantes de resíduos orgânicos.

\subsubsection{Efeito na capacidade de retenção de água do solo}

Diversos são os trabalhos que relacionam matéria orgânica com atributos físicos do solo, tais como densidade, porosidade, estabilidade dos agregados, condutividade hidráulica e retenção de água (WILLIAMS $\mathcal{E}$ COOKE, 1961; KIRKHAM, 1974; KHALEEL et al., 1981; COSTA, 1983; MBAGWU, 1989; FORTUN et al., 1989; RICCI et al. 1993). A seguir serão feitas algumas considerações tentando discernir capacidade de retenção de água da sua disponibilidade para as plantas, como resultado da aplicação de materiais orgânicos em solos.

Em trabalho feito por BouYoucos (1939), amostras de $100 \mathrm{~g}$ de sete solos, com textura variando de arenosa a argilosa, foram misturadas a quantidades de 0, 2, $4,6,8,10$ e 12 gramas de solo orgânico, turfa e esterco de curral, secos e moídos. Em seguida, determinou-se a umidade equivalente, considerada como capacidade de campo, e o ponto de murcha permanente. Os valores obtidos pela diferença entre estas duas medidas forneceram os dados de água disponível. Os resultados mostraram, para todos os solos, a elevação da quantidade de água disponível com o aumento da dose do material aplicado, tendo sido este efeito mais pronunciado nos solos de texturas mais arenosas.

Da maneira como foi conduzido o ensaio acima, mediu-se apenas a transferência de um atributo do 
resíduo para as amostras de terra. As determinações foram feitas imediatamente após a mistura dos materiais, sem que houvesse um período de incubação. Assim, não foram observados efeitos das transformações da matéria orgânica no solo. As maiores respostas dos solos arenosos podem até ser atribuídas à sua originalmente menor capacidade de retenção de água. A diluição, na terra, da capacidade de retenção de água do resíduo, mostrou diferenças maiores. Na realidade, é a interação física, química e biológica do material orgânico com o solo que vai determinar o comportamento resultante, o qual vai variar também de acordo com a textura do solo.

KLUTE E JACOB (1949) observaram elevação na capacidade de retenção de água em um solo de textura média que recebeu aplicacões de estercos durante 25 anos, bem como um aumento na estabilidade dos agregados e decréscimo na densidade do solo. Estes efeitos, no entanto, não se traduziram em aumento da água disponível, calculada pela diferença entre os pontos extremos das curvas de retenção de água.

Em estudo conduzido em campo por EPSTEIN et a1. (1976) foram aplicadas doses de 0,40, 80, 160 e 240 $\mathrm{Mg} \cdot \mathrm{ha}^{-1}$ de lodo de esgoto, "in natura" ou compostado com lixo urbano, em solo de textura franco-siltosa. Periodicamente era determinada a umidade do solo e ao final do ensaio foram determinadas curvas de retenção de água entre tensões de 33 a $1500 \mathrm{kPa}(0,33$ e 15 atm). Os resultados mostraram valores de umidade do solo mais altos nas parcelas tratadas com os residuos. As curvas de retenção foram diferentes entre parcelas não tratadas e as que receberam lodo "in natura" ou compostado, este último resultando em valores menores que para o lodo "in natura" a tensões menores que $100 \mathrm{kPa}\left(10 \mathrm{~m} \mathrm{H} \mathrm{H}_{2} \mathrm{O}\right)$. Os dados 
apresentados referem-se à dose de $240 \mathrm{Mg} \cdot \mathrm{ha}^{-1}$, 0 que permite supor que nos níveis mais baixos os efeitos não foram evidentes. Considerando como água disponível a diferença de umidade volumétrica entre as tensões de 33 e $1500 \mathrm{kPa}$, foram determinados valores de 12,5\% base volume para a testemunha e $14,5 \%$ e $18,5 \%$ para os tratamentos com lodo compostado e "in natura", respectivamente.

Resultados semelhantes da aplicação de materiais orgânicos em solos argilosos são também reportados por WEIL $\mathcal{E}$ KROONTJE (1979) e GIUSQUIANI et al. (1995). Já em solos arenosos, o comportamento parece ser diferente.

Estudo em campo conduzido por TESTER (1990) em solo contendo 97\% de areia, no qual foi aplicado lodo de

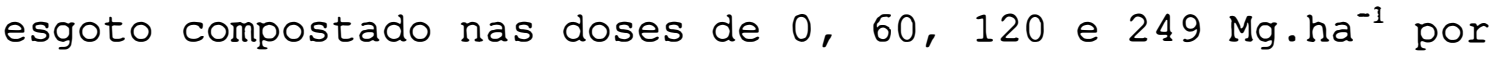
5 anos, mostrou valores de umidade do solo, no campo, tanto mais altos quanto maiores as doses de residuo. Efeitos inversos foram notados para densidade do solo. O autor afirma que a maior umidade se traduz em maior disponibilidade de água neste solo. Neste trabalho, confunde-se retenção com disponibilidade e faz-se uma associação desta com a densidade do solo, inferência que não se confirma em outros estudos, inclusive anteriores a este.

GUPTA et al. (1977), trabalhando em solo contendo $90,1 \%$ de areia ao qual aplicaram $0,112,225,450$ e $900 \mathrm{Mg} \cdot \mathrm{ha}^{-1}$ de lodo de esgoto, observaram que a densidade do solo decresceu linearmente com 0 aumento da dose e notaram alterações na distribuição de poros. Também reportam um aumento linear em função da dose para a água retida à tensão de $1500 \mathrm{kPa}$. Por outro lado, considerando como água disponível aquela retida entre as tensões de 10 e $1500 \mathrm{kPa}$, não foram observadas diferenças, mostrando a 
ausência de efeito da matéria orgânica na disponibilidade de água para as plantas neste solo. A observação das curvas apresentadas mostra que esta ausência de diferenças pode ser observada não apenas com a subtração de pontos extremos da curva de retenção, mas também entre pontos intermediários e ainda entre pontos situados na "faixa mais úmida" da curva, ou seja, a tensões em torno de $10 \mathrm{kPa}(0,1$ atm ou $1,0 \mathrm{~m}$ de coluna de água).

OBREZA \& REEDER (1994) ao aplicarem de 13 a $112 \mathrm{Mg} \cdot \mathrm{ha}^{-1}$ de três tipos de composto de lixo urbano a um solo muito arenoso da Flórida, observaram aumentos na capacidade de retenção de água e na produção de tomate e melão irrigados. Entretanto, um decréscimo significativo de produção ocorreu quando a irrigação foi diminuída da taxa de 1,25 para 1,0 e 0,75 vezes a evapotranspiração das culturas, o que sugere a ausência da contribuição da matéria orgânica na disponibilidade de água neste estudo.

Os trabalhos analizados indicam que a matéria orgânica do solo não pode ser tomada, apenas por sí, como um indicador da disponibilidade de água para as plantas. EPENIBU $\varepsilon$ NWADIALO (1993), com amostras de 22 solos, determinaram correlação de apenas 0,22\% entre o teor de matéria orgânica e a água disponível destes solos. Embora OBI $\varepsilon$ EBO (1995) tenham determinado correlação de $0,96 \%$ para água disponível em função da dose de esterco de galinha aplicada em um solo arenoso, os valores expressos em termos de armazenagem, tendo sido de $75 \mathrm{~mm}$ para a testemunhá e de $85 \mathrm{~mm}$ para o solo tratado, não chegam a indicar uma grande contribuição.

Apesar de nem sempre haver uma relação direta entre matéria orgânica e disponibilidade de água, os benefícios físicos que esta traz ao solo não devem ser subestimados. Os minerais do solo possuem um calor 
específico de $0,46 \mathrm{cal} \cdot \mathrm{g}^{-1}$, enquanto este valor para a matéria orgânica humificada é de 0,60 (BAVER et al.,1972). A sua incorporaçao vai elevar o calor específico do solo e isto pode retardar o seu aquecimento e diminuir a perda de água por evaporação. Por outro lado, um aumento da capacidade de retenção de água vai diminuir o seu movimento no perfil de solo, reduzindo a lixiviação de nutrientes e de substâncias tóxicas.

\subsubsection{Medição da capacidade de retenção de água do solo}

Fundamentos teóricos acerca da dinâmica da água no solo bem como métodos para a sua quantificação podem ser encontrados de forma detalhada em IIBARDI (1995). Com vistas à definição de procedimentos a serem adotados na presente pesquisa é feita a seguir uma abordagem sumária a respeito do tema.

$\mathrm{Na}$ medição da capacidade de retenção de água pelos solos a determinação de curvas características de umidade dá uma idéia da capacidade do solo como reservatório de água para as plantas dentro de uma larga faixa de disponibilidade, em intervalo correspondente a tensões entre zero e $15 \mathrm{~atm}(1500 \mathrm{kPa})$. Por outro lado, é comum que sejam feitas medidas considerando a umidade de amostras em equilíbrio com a pressão atmosférica. Medidas como estas, feitas em laboratório com pequenas amostras, podem levar a inferências não muito condizentes com uma situação de campo, visto que, neste, o contínuo de um perfil de solo faz com que estejam atuando forças de outra magnitude. É o caso de um maior potencial gravitacional no campo do que em amostras que, em geral, têm de 2 a $3 \mathrm{~cm}$ de altura. Isto faz com que parte da água em equilíbrio com 
uma amostra não submetida a uma tensão em laboratório tenha uma permanência efêmera em um perfil de solo, onde poderá estar sendo rapidamente drenada, estando, portanto, mais distante de uma situação de equilíbrio. No entanto, medidas como estas são muitas vezes consideradas correspondentes à capacidade de campo. Esta, como conceito, merece uma certa atenção.

Conforme proposto por VEIHMEYER $\mathcal{E}$ HENDRICKSON (1931), capacidade de campo é a "quantidade de água retida pelo solo depois que o excesso tenha sido drenado e a taxa de movimento tenha decrescido acentuadamente, o que geralmente ocorre dois a três dias depois de uma chuva ou irrigação em solos permeáveis de estrutura e textura uniformes".

$$
\text { Discutindo este conceito, REICHARDT (1988) }
$$

acentua a dificuldade de se quantificar o que é excesso de água e diminuição acentuada do seu movimento. Lembra ainda que, ao contemplar o movimento da água no solo, a definição refere-se a um comportamento dinâmico do perfil e não a uma característica intrínseca. Informa, também, que entre os procedimentos de laboratório utilizados para determinar a "capacidade de campo" é comum equilibrar amostras com tensões de 6,10 ou $33 \mathrm{kPa}(6 / 100,1 / 10$ e 1/3 de atmosfera ou $0,60,1,0$ e $3,3 \mathrm{~m} \mathrm{H}_{2} \mathrm{O}$ ), considerando as duas primeiras como mais adequadas.

A faixa de umidade correspondente a tensões de 6 a $10 \mathrm{kPa}$ de fato encontra grande correspondência com observações de campo. Por exemplo, LIBARDI $\mathcal{E}$ SAAD (1994) em trabalho no qual faziam balanço hídrico para cultura de feijão em Latossolo Roxo de textura muito argilosa, determinaram $\circ$ valor de $8 \mathrm{kPa}\left(0,8 \mathrm{~m} \mathrm{H}_{2} \mathrm{O}\right)$ para a tensão coorespondente à capacidade de campo neste solo. 
A partir destas observações, optou-se, no presente estudo por se efetuar medidas da retenção de água pelos solos tratados com residuos orgânicos em uma faixa de tensão compreendida entre 1 e $15 \mathrm{kPa}\left(0,1\right.$ e 1,5 $\left.\mathrm{m} \mathrm{H}_{2} \mathrm{O}\right)$, procedimento este de fácil implementação com o uso de funis de placa porosa.

A capacidade de retenção de água de materiais orgânicos é geralmente determinada saturando a amostra e deixando em seguida escorrer o excesso de água (KIEHL, 1985). Desta forma, determina-se a quantidade de água contida na amostra em equilíbrio com a pressão atmosférica. Além deste método, neste trabalho as amostras serão também submetidas a uma tensão de $10 \mathrm{kPa}(1,0 \mathrm{~m}$ de coluna de água), visando observar se os dados obtidos por um destes procedimentos relacionam-se com efeitos da aplicação de resíduos na retenção de água do solo. 


\section{MATERIAL E MÉTODOS}

\subsection{Comparação de três sistemas de respirometria.}

Visando eleger um modelo de respirômetro para ser utilizado nesta pesquisa, foi realizado um estudo comparativo de três sistemas: dinâmico, fechado e semiaberto. Para testá-los, utilizaram-se, como substrato, amostras de $500 \mathrm{~g}$ de Terra Roxa estruturada, nas quais foram aplicadas, como fonte de carbono, torta de filtro rotativo, proveniente da fabricação do açúcar de cana, na quantidade de $33 \mathrm{~g}$ por vaso. Esta dose corresponde a $40 \mathrm{Mg} \cdot \mathrm{ha}^{-1}$, fazendo-se o cálculo considerando a massa de solo de 1 ha a $5 \mathrm{~cm}$ de profundidade $\left(\rho=1200 \mathrm{~kg} \cdot \mathrm{m}^{-3}\right)$. Para os três sistemas testados, descritos a seguir, foram utilizados potes de vidro com capacidade para 1,5 I com tampa plástica. Detalhes de cada conjunto são apresentados na Figura 1.

No sistema dinâmico, faz-se passar um fluxo de ar isento de $\mathrm{CO}_{2}$ através dos vasos, contendo o material a ser estudado. Esta retirada do $\mathrm{CO}_{2}$ do ar é feita previamente, fazendo o mesmo borbulhar em solução de $\mathrm{NaOH} a$ 50\%. Em seguida, o ar é ainda borbulhado em água destilada e descarbonatada para promover sua hidratação. Após estes dois procedimentos, $O$ ar segue através de tubos plásticos para ser injetado nos vasos. Depois de circular pelos vasos - ar contendo $\mathrm{O}^{\mathrm{CO}_{2}}$ emanado das amostras passa por dois frascos de $100 \mathrm{ml}$, montados em série, contendo quantidades 
conhecidas de solução de $\mathrm{NaOH}$ que retém o gás carbônico na forma de $\mathrm{Na}_{2} \mathrm{CO}_{3}$. O uso de dois frascos com a solução alcalina foi adotado para garantir que todo $\circ \mathrm{CO}_{2}$ fique retido.

No sistema fechado, dentro dos vasos contendo a mistura solo + torta, foi colocado um recipiente plástico com a solução de $\mathrm{NaOH}$, apoiado sobre dois pedaços de mangueira plástica para evitar contato com o solo. Periodicamente os vasos eram abertos para troca de solução e aeração do sistema.

O sistema semi-aberto foi montado de maneira idêntica ao fechado, sendo que, nas tampas dos vasos, foi aberto um orifício de $5 \mathrm{~mm}$ de diâmetro para permitir trocas gasosas com o ambiente. Neste orifício, era colocado um chumaço de lã de vidro.

A troca das soluções coletoras de $\mathrm{CO}_{2}$ foi feita em intervalos idênticos para os três sistemas, tendo sido espaçados no decorrer do estudo para observar, nos sistemas fechado e semi-aberto, o efeito do aumento dos intervalos de aeração na taxa de respiração. Estas observações foram comparadas com as feitas no sistema dinâmico, que recebe um suprimento constante de oxigênio. As trocas foram efetuadas após os seguintes dias: 1, 2, 3, 4, 6, 10 e 17. Para cada um dos três sistemas foram feitas provas em branco, em conjuntos montados sem a mistura solo + torta. Os tratamentos foram montados em laboratório num delineamento inteiramente casualizado com três repetições.

Uma vez substituídos os recipientes contendo as soluções coletoras, estes eram tampados até o momento da determinação do carbono retido. Esta era feita da seguinte maneira: primeiramente, provocava-se a precipitação do carbonato, na forma de $\mathrm{BaCO}_{3}$, adicionando-se solução de $\mathrm{BaCl}_{2}$ 1N. Em seguida, o excesso de $\mathrm{NaOH}$ ou seja, a fração 
não consumida na reação com $\circ \mathrm{CO}_{2}$, era titulada com solução padronizada de $\mathrm{HCl}$. O cálculo da quantidade de carbono foi efetuado de acordo com seguinte expressão:

$$
\text { mg } C=\left(V_{B}-V_{A}\right) \cdot N \cdot 3
$$

onde:

$$
\begin{aligned}
\mathrm{V}_{\mathrm{B}}= & \text { volume de solução de } \mathrm{HCl} \text { gasto na titulação da } \\
& \text { prova em branco }(\mathrm{ml}) . \\
\mathrm{V}_{\mathrm{A}}= & \text { volume de solução de } \mathrm{HCl} \text { gasto na titulação da } \\
& \text { amostra }(\mathrm{m} 1) . \\
\mathrm{N}= & \text { Concentração normal da solução de } \mathrm{HCl} . \\
3= & \text { massa de } 1 \text { e.mg de carbono }(\text { considerando o núme- } \\
& \text { ro de oxidação como sendo }=4) .
\end{aligned}
$$



Figura 1. Aspecto da montagem dos respirômetros em sistema dinâmico, semi-aberto e fechado. 
O ensaio foi conduzido à temperatura ambiente do laboratório. Para os três sistemas manteve-se o volume de $50 \mathrm{ml}$ de solução de $\mathrm{NaOH}$ (no sistema dinâmico, $25 \mathrm{ml}$ em cada frascol. A concentração desta solução, no início do estudo, foi $1 \mathrm{~N}$, sendo reduzida no seu decorrer, à medida que diminuíam as perdas de $\mathrm{CO}_{2}$ do solo, com vistas a diminuir erros de titulação. As titulações foram feitas dentro dos mesmos recipientes que continham as soluções, evitando-se assim, dispêndio de tempo com sua transferência ou retirada de alíquotas.

\subsection{Estudo da degradação da fração orgânica de diferentes resíduos no solo.}

A partir de estudo prévio, a partir do qual optou-se pelo uso de respirômetros fechados, foram instalados, no Laboratório de Química Ambiental do Departamento de Química - ESALQ/USP, dois experimentos, incubando amostras de dois solos com quatro resíduos orgânicos de diferentes origens, conforme descrição a seguir. O delineamento experimental foi fatorial com quatro resíduos e três doses, com três repetições.

\subsubsection{Solos.}

Os solos utilizados foram Latossolo Vermelho-escuro, LE, (Typic Haplorthox) e Areia Quartzosa distrófica, AQ, (Typic Quartzipsament) retirados da camada de 0 a $20 \mathrm{~cm}$ de área de canavial da Usina Costa Pinto, Piracicaba - SP. A Tabela 1 apresenta a composição granulométrica destes solos. Valores referentes à retenção de água, bem como parâmetros químicos, são apresentados no capítulo Resultados e Discussão, referindo-se aos tratamentos-testemunha. 
Tabela 1. Composição granulométrica dos solos empregados.

\begin{tabular}{|c|c|c|c|c|}
\hline \multirow{2}{*}{ Solo } & \multicolumn{2}{|c|}{ Areia } & \multirow{2}{*}{ Silte } & Argila \\
\cline { 2 - 5 } & Grossa & Fina & S. kg \\
\hline LE & 187 & 476 & 102 & 235 \\
AQ & 399 & 484 & 49 & 68 \\
\hline
\end{tabular}

\subsubsection{Materiais orgânicos.}

Os resíduos aplicados às amostras de solos foram os seguintes:

- Torta de filtro: Resíduo da agroindústria canavieira, coletado na Usina Costa Pinto, Piracicaba, SP.

- Composto de lixo: Proveniente da usina de compostagem do Município de São José do Rio Preto, SP

- Lodo petroquímico: Resultante do tratamento aeróbico de efluentes orgânicos do Pólo Petroquímico de Camaçari, BA, fornecido pela CETREL S.A. - Empresa de Saneamento Ambiental (detalhes da obtenção: FONTES LIMA $\mathcal{E}$ ALVES FERREIRA (1992)).

- Lodo de esgoto:

Coletado na Estação de Tratamento de Efluentes da SABESP em Barueri - SP. 
A Tabela 2 apresenta valores de umidade e da capacidade de retenção de água destes materiais. O método de determinação é descrito no ítem 3.3.4. Na Tabela 3, encontram-se os dados de análises químicas. Estas, para macronutrientes (exceto nitrogênio) e metais pesados, foram feitas a partir da digestão nítrico-perclórica dos materiais secos e moídos. O fósforo foi determinado por colorimetria, potássio e sódio por fotometria de chama de emissão e os demais elementos por espectrofotometria de absorção atômica. O nitrogênio foi determinado através da digestão sulfúrica das amostras seguidas de destilação em meio alcalino. As análises de carbono foram feitas por volumetria de oxi-redução, com dicromato de potássio em meio ácido, a quente. A CTC dos materiais foi determinada através da saturação das amostras com solução de $\mathrm{HCl}$, seguida do desiocamento do $\mathrm{H}^{+}$adsorvido pelo íon $\mathrm{Ca}^{2+}$ fornecido por solução de acetato de cálcio a pH7, segundo método descrito em WILLIAMS (1984), modificado por RODELLA $\varepsilon$ ALCARDE (1994).

Tabela 2. Valores de umidade dos materiais orgânicos utilizados, em três diferentes condições.

\begin{tabular}{|c|c|c|c|}
\hline \multirow{3}{*}{ Material } & \multirow{3}{*}{$\begin{array}{c}\text { Umidade } \\
\text { original } \\
\mathrm{g} \cdot \mathrm{kg}^{-1}\end{array}$} & \multicolumn{2}{|c|}{ Umidade $\mathrm{x}$ tensão } \\
\hline & & $(\mathrm{CR})^{*}$ & $10 \mathrm{kPa}^{*}$ \\
\hline & & \multicolumn{2}{|c|}{$\mathrm{g} \cdot \mathrm{kg}^{-1}$} \\
\hline Torta de filtro & 767,6 & 6665 & 3452 \\
\hline Composto de lixo & 33,8 & 1330 & 739 \\
\hline Lodo petroquímico & 380,0 & 1842 & 1361 \\
\hline Lodo de esgoto & 732,5 & 3680 & 2177 \\
\hline
\end{tabular}


Tabela 3. Alguns parâmetros químicos relativos aos materiais orgânicos utilizados ${ }^{(1)}$.

\begin{tabular}{|c|c|c|c|c|c|}
\hline Parâmetro & Unidade & $\begin{array}{c}\text { Torta } \\
\text { de } \\
\text { Filtro }\end{array}$ & $\begin{array}{c}\text { Composto } \\
\text { de } \\
\text { lixo }\end{array}$ & $\begin{array}{l}\text { Lodo } \\
\text { petro- } \\
\text { químico }\end{array}$ & $\begin{array}{c}\text { Lodo } \\
\text { de } \\
\text { esgoto }\end{array}$ \\
\hline $\mathrm{C}$ & $\mathrm{g} \cdot \mathrm{kg}^{-1}$ & 347,3 & 140,0 & 200,2 & 213,8 \\
\hline $\mathrm{C} / \mathrm{N}$ & -- & 25,2 & 11,0 & 4,7 & 8,8 \\
\hline $\mathrm{pH} \quad \mathrm{H}_{2} \mathrm{O} \quad(1: 5)$ & --- & 5,5 & 7,5 & 8,2 & 10,1 \\
\hline СТC $\mathrm{pH} 7$ & $\mathrm{cmol}_{\mathrm{c}} \cdot \mathrm{kg}^{-1}$ & 41,3 & 42,8 & 35,9 & 45,2 \\
\hline $\mathrm{Cd}$ & \multirow{12}{*}{$\mathrm{mg} \cdot \mathrm{kg}^{-1}$} & 1,8 & 5,6 & 5,8 & 18,9 \\
\hline $\mathrm{Cr}$ & & 14,5 & 114,0 & 43,3 & 545,2 \\
\hline $\mathrm{Cu}$ & & 53,7 & 195,7 & 196,7 & 799,6 \\
\hline $\mathrm{Ni}$ & & 37,2 & 45,1 & 96,7 & 378,3 \\
\hline $\mathrm{Zn}$ & & 131 & 565 & 1355 & 2036 \\
\hline $\mathrm{Fe}$ & & 10857 & 36493 & 6705 & 37960 \\
\hline $\mathrm{Mn}$ & & 900 & 308 & 153 & 323 \\
\hline $\mathrm{P}$ & & 550 & 182 & 430 & 492 \\
\hline K & & 2332 & 5136 & 1172 & 794 \\
\hline $\mathrm{Na}$ & & 159 & 4695 & 8455 & 681 \\
\hline $\mathrm{Ca}$ & & 25814 & 15812 & 106471 & 99390 \\
\hline $\mathrm{Mg}$ & & 3977 & 1638 & 2092 & 2306 \\
\hline
\end{tabular}

(1): Valores expressos no material seco a $65^{\circ} \mathrm{C}$. 


\subsubsection{Incubação}

A Tabela 4 contém a descrição dos tratamentos empregados na incubação dos solos com os quatro resíduos orgânicos. A incubação das amostras de terra foi feita em vasos de vidro com altura de $17 \mathrm{~cm}$ e diâmetro de $12 \mathrm{~cm}$, utilizando massas de $0,90 \mathrm{~kg}$ de Latossolo Vermelhoescuro e $1,15 \mathrm{~kg}$ para a Areia Quartzosa distrófica, resultando, nos dois casos, numa coluna de solo de 7,5 cm.

As doses aplicadas, para torta de filtro,

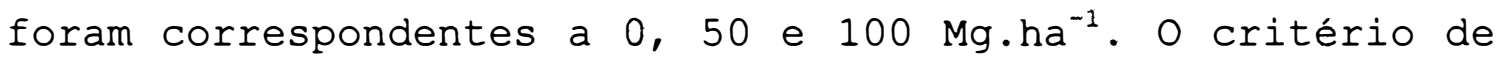
cálculo utilizado considerou como sendo de $20 \mathrm{~cm}$ a profundidade de incorporação dos materiais no campo. Assim, após fazer o cálculo da quantidade a aplicar no vaso, levando em conta a sua área, fez-se um desconto em função da profundidade de $7,5 \mathrm{~cm}$ do solo no vaso, resultando nas quantidades de 18,75 e $37,5 \mathrm{~g}$ de torta por vaso para as

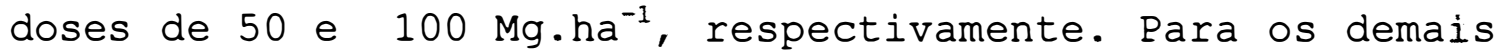
resíduos foram aplicadas quantidades equivalentes em carbono àquelas aplicadas na forma de torta de filtro.

Para cada parcela experimental foram pesadas porções de solo e de resíduo. Em seguida, misturou-se intimamente os residuos aos solos e acondicionaram-se as misturas nos vasos. Estes permaneceram abertos por uma noite, após o que procedeu-se ao umedecimento das parcelas, com quantidades correspondentes a $80 \%$ da capacidade de retenção de água dos solos, previamente determinada, sem que se descontasse a umidade contida nos resíduos. Imediatamente após o umedecimento, foi colocado dentro de cada vaso um recipiente plástico, contendo $20 \mathrm{ml}$ de solução de $\mathrm{NaOH}$ para coletar $\circ \mathrm{CO}_{2}$ liberado.

A concentração da solução de $\mathrm{NaOH}$ utilizada para receber $\circ \mathrm{CO}_{2}$, no início do estudo, foi $1 \mathrm{M}$. No 
decorrer do experimento, acompanhando a taxa de liberação de $\mathrm{CO}_{2}$ pelo solo, soluções mais diluídas foram sendo empregadas. Este procedimento foi adotado visando reduzir erros analíticos. O ensaio teve a duração de 60 dias. Neste período a abertura dos vasos para aeração e troca da solução coletora de $\mathrm{CO}_{2}$ foi feita diariamente nos primeiros 20 dias e a cada dois dias no intervalo restante.

Imediatamente após serem retirados dos vasos, os recipientes contendo a solução coletora eram tampados e conduzidos para a determinação do carbono nela retido, segundo procedimento anteriormente descrito. Os dados relativos às perdas diárias de $\mathrm{CO}_{2}$ foram expressos em miligramas de carbono e, a taxa de decomposição dos diversos materiais em função da dose aplicada, em $\mathrm{mg}$ de C por grama aplicada. Foram feitas, também, determinações dos teores de carbono nos solos após a incubação.

Ao final do período de incubação, foram retiradas, utilizando-se anéis metálicos, amostras não deformadas do solo dos vasos para a determinação de parâmetros relativos à retenção de água. Amostras úmidas foram ainda retiradas e congeladas para análises do nitrogênio total e mineral. O solo restante foi posto para secar ao ar sendo depois utilizado para outras determinações analíticas e no estudo de biodisponibilidade de metais pesados. 


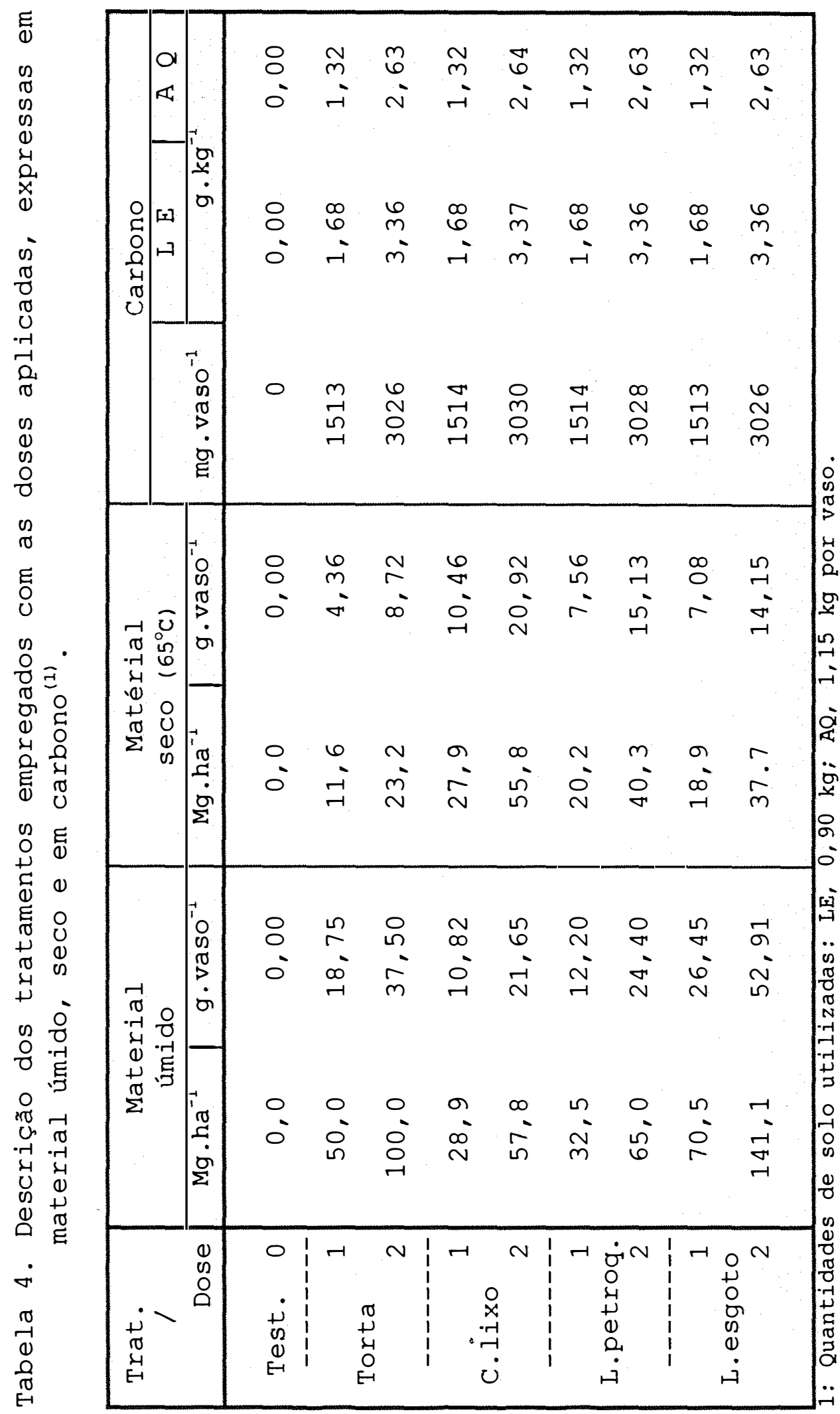




\subsection{Avaliação de efeitos da aplicação dos residuos em propriedades do solo.}

\subsubsection{Observações gerais.}

Amostras de solo seco ao ar provenientes do estudo de degradação da carga orgânica dos resíduos tiveram medidos os seus valores $\mathrm{pH}$ em $\mathrm{CaCl}_{2}$ e em água na proporção 1:2,5. Na suspensão de solo + água foi feita também a medição da condutividade elétrica. Análises de $\mathrm{P}, \mathrm{K}, \mathrm{Ca}$, Mg, $\mathrm{H}+\mathrm{Al}$ e $\mathrm{Al}$, foram feitas segundo métodos descritos por RAIJ et al. (1987).

As análises de carbono foram feitas por volumetria de oxi-redução, a quente, utilizando amostras de $5 \mathrm{~g}$ de solo seco ao ar. O balanço de perdas de carbono, baseado na análise do solo, foi feito utilizando a expressão a seguir:

$$
\mathrm{Pd}=\frac{\text { dose }+ \text { Cft }- \text { Cfp }}{\text { dose }} \times 1000
$$

onde:

$$
\begin{aligned}
\mathrm{Pd}= & \text { perdas de carbono, em } \mathrm{mg} \text { por } \mathrm{g} \text { de } \mathrm{C} \text { aplicado } \\
\text { Cft = } & \text { concentração final de } \mathrm{C} \text { na testemunha }\left(\mathrm{g} \cdot \mathrm{kg}^{-1}\right) \\
\mathrm{Cfp}= & \text { concentração final de } \mathrm{C} \text { na parcela }\left(\mathrm{g} \cdot \mathrm{kg}^{-1}\right) \\
\text { dose }= & \text { quantidade de carbono aplicada na parcela, } \\
& \text { expressa em } \mathrm{g} \text { por } \mathrm{kg} \text { de solo. }
\end{aligned}
$$

Para as análises de nitrogênio, utilizaramse as amostras coletadas e congeladas no final do ensaio. 0 nitrogênio total foi determinado em amostras submetidas a digestão sulfúrica seguida de destilação em meio alcalinizado com solução de $\mathrm{NaOH}$ a $50 \%$. O nitrogênio mineral $\left(\mathrm{NO}_{3}{ }^{-}+\mathrm{NH}_{4}{ }^{+}\right)$foi determinado em amostras de $10 \mathrm{~g}$ 
fazendo sua extração com $50 \mathrm{ml}$ de solução de $\mathrm{KCl} 2 \mathrm{~N}$. Do extrato obtido, $25 \mathrm{ml}$ foram foram submetidos a destilação em meio alcalino (com $\mathrm{NaOH}$ a 50\%) acrescentando-se liga de Devarda, visando reduzir o nitrato para a forma amoniacal. A amônia era então recebida em solução de ácido bórico e determinada pela titulação deste com solução padronizada de ácido sulfúrico.

\subsubsection{Determinação da CTC dos solos.}

A CTC foi determinada, em amostras de $2 \mathrm{~g}$ de solo seco ao ar, por dois métodos: a $\mathrm{pH} 7$ e ao $\mathrm{pH}$ atual do solo.

Para a determinação da CTC a pH7, utilizouse método descrito por GLÓRIA et al. (1965), que consiste da saturação das amostras com 0 íon $\mathrm{Ca}^{2+}$, utilizando-se solução de acetato de cálcio 1N a pH7, da lavagem da fração não adsorvida com solução hidroalcoólica, seguida do deslocamento do cálcio adsorvido, pelo íon $\mathrm{NH}_{4}{ }^{+}$de uma solução de acetado de amônio a pH7. O valor da concentração de cálcio no extrato é então utilizado para o cálculo da CTC.

A CTC ao $\mathrm{pH}$ atual das amostras foi determinada segundo método proposto por BASCOMB (1964) modificado por GILLMAN (1979), utilizando soluções não tamponadas. Neste método, os sítios de troca do solo são saturados com bário, fornecido por solução de $\mathrm{BaCl}_{2}$. Este ín é depois deslocado pelo magnésio presente em solução de $\mathrm{MgSO}_{4}$. Determinando-se a concentração final da solução de magnésio, calcula-se a quantidade deste metal adsorvida pelo solo, que fornecerá o valor da CTC. 


\subsubsection{Estudo da fitodisponibilidade de metais pesados nos solos e avaliação de extratores.}

Utilizando amostras dos solos incubados com os quatro resíduos nas diversas doses, conforme descrito no ítem 3.2.3 (Tabela 4) foram montados dois experientos em esquema "Neubauer" conforme descrito por CATANI $\mathcal{E}$ BERGAMIN FILHO (1961) utilizando como planta-teste o arroz (Orisa sativa, L.) variedade IAC-165.

Em placas de Petri, foram colocados $10 \mathrm{~g}$ de solo proveniente de cada tratamento misturado com $40 \mathrm{~g}$ de areia lavada e calcinada. Colocaram-se, então, em cada conjunto 25 sementes de arroz pré-germinadas, cobrindo-as em seguida com $20 \mathrm{~g}$ de areia lavada e calcinada. Os conjuntos foram então umedecidos e pesados. Esta pesagem era repetida diariamente, fazendo-se a reposição da água perdida.

Aos nove dias da implantação ensaio foram adicionados, a cada vaso, $5 \mathrm{ml}$ de solução nutritiva com a seguinte concentração: $\mathrm{N}, 210 \mathrm{mg} \cdot \mathrm{kg}^{-1} ; \mathrm{P}, 117 \mathrm{mg} \cdot \mathrm{kg}^{-1}$ e $\mathrm{K}$, $447 \mathrm{mg} \cdot \mathrm{kg}^{-1}$. O ensaio teve a duração de 14 dias, tendo sido então as plantas retiradas e lavadas com água corrente, com solução 0,1 M de $\mathrm{HCl}$ e com água deionizada. Em seguida, as plantas foram postas para secar em estufa a $40^{\circ} \mathrm{C}$ até peso constante. Após a secagem, foram submetidas a digestão nítrico-perclórica, sendo determinadas, nos extratos, as concentrações de $\mathrm{Cd}, \mathrm{Cr}, \mathrm{Cu}, \mathrm{Ni}$ e $\mathrm{Zn}$, por espectrofotometria de absorção atômica. Com estes dados foram calculadas as quantidades totais de metais absorvidas pelas plantas em cada parcela experimental.

Visando observar a correspondencia da absorção de metais pelas plantas com os teores determinados nas amostras de solo, foram preparados extratos a partir da 
suspensão de $10 \mathrm{~g}$ de terra com $50 \mathrm{ml}$ de três diferentes diferentes soluções: $\mathrm{HCl} 0,1 \mathrm{M}, \mathrm{Ca}\left(\mathrm{NO}_{3}\right)_{2} 0,05 \mathrm{M}$ e DTPA 0,05 M. As supensões foram agitadas, e, em seguida, deixadas em repouso por 24 horas. Após este período as suspensões eram agitadas novamente, filtradas, sendo os extratos submetidos à leitura dos teores de metais em espectrofotômetro de absorção atômica. A solução de DTPA 0,05 M era também 0,1 M em $\mathrm{CaCl}_{2}$, visando evitar a turbidez do extrato. No entanto, devido à presença de matéria orgânica solúvel, foi necessário fazer a digestão nítrico-perclórica dos extratos em DTPA para possibilitar as determinações dos metais.

\subsubsection{Determinação da capacidade de retenção de água dos solos e dos resíduos.}

No final da fase de incubação dos solos com os resíduos, foram retiradas amostras, não deformadas, introduzindo em cada vaso anéis metálicos com $4,8 \mathrm{~cm}$ de diâmetro e altura em torno de $3 \mathrm{~cm}$, previamente tarados, acoplados a um tubo de igual diâmetro. Uma vez retiradas as amostras, colocou-se na base dos anéis um pedaço de tecido fixado por uma tira de borracha para sustentar o solo coletado. Procedeu-se, em seguida, à saturação das amostras durante 48 horas. Após este processo estas foram colocadas sobre as placas porosas dos funis de Haynes, às quais foram aplicas tensões de $0,1,0,2,0,5,1,0$ e 1,5 metros de coluna de água $(1,2,5,10$ e $15 \mathrm{kPa})$. As amostras eram submetidas a cada tensão por um período de 48 horas, suficiente para que se atingisse um estado de equilíbrio. Após este tempo, foram pesadas, novamente saturadas e submetidas a uma nova tensão. A Figura 2 mostra os conjuntos de funis utilizados neste procedimento. 
38 .

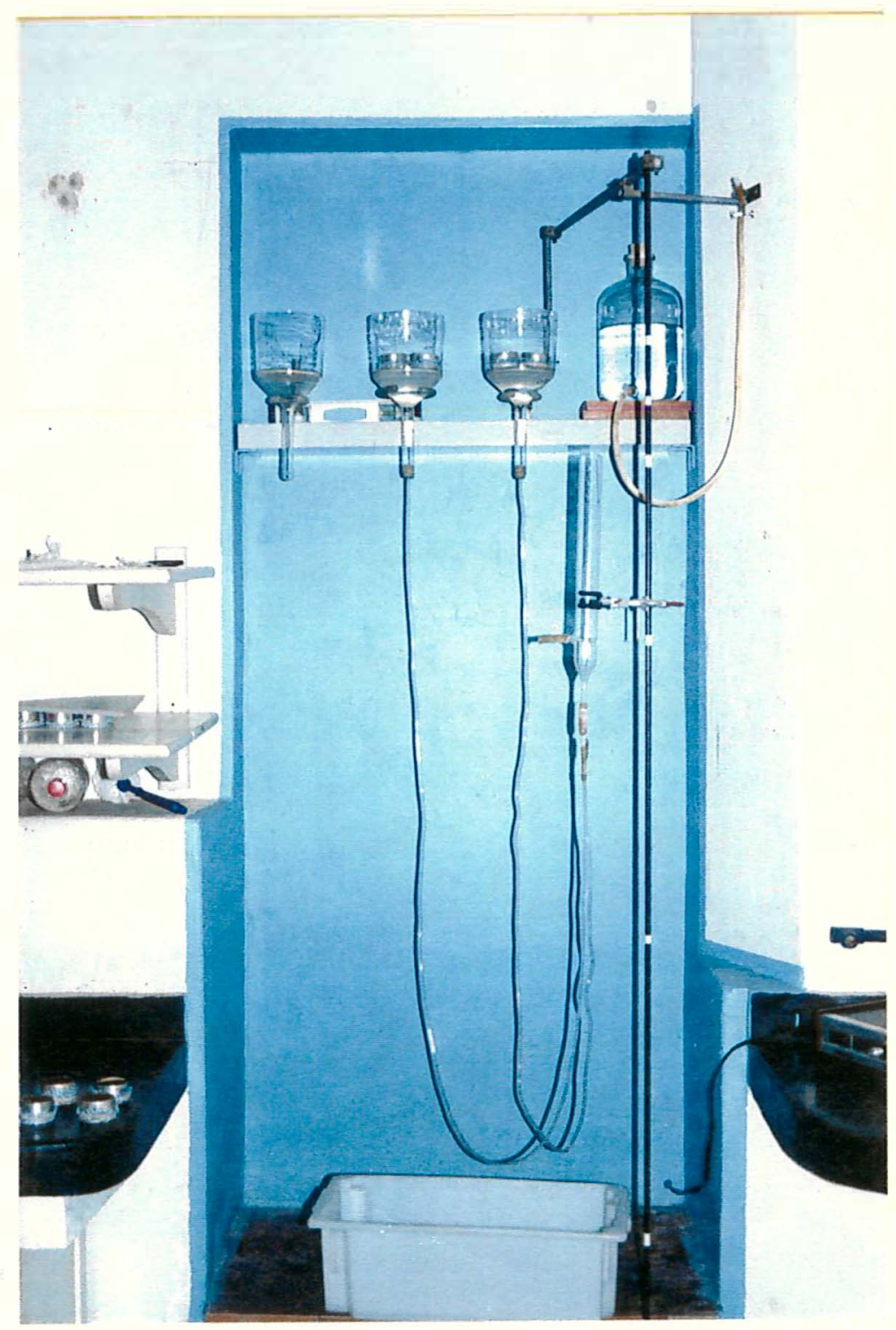

Figura 2. Vista dos conjuntos de funis de placa porosa utilizados na determinação da capacidade de retenção de água. 
Ao final das medições, as amostras foram postas para secar a $110^{\circ} \mathrm{C}$ até peso constante, ainda dentro dos anéis. Os valores das massas de solo, seco e úmido às varias tensões, foram utilizados para os cálculos da água retida, expressa como umidade volumétrica $(\theta)$, em $\mathrm{cm}^{3}$ de água por $\mathrm{cm}^{3}$ de solo.

Para a determinação da capacidade de retenção de água dos resíduos, utilizaram-se, também, os funis de placa porosa. Como o volume dos materais orgânicos varia com a umidade, estes valores foram expressos em termos de massa. As amostras foram submetidas apenas a uma tensão de $10 \mathrm{kPa}\left(1 \mathrm{~m} \mathrm{H} \mathrm{H}_{2} \mathrm{O}\right)$, sendo determinada também a capacidade de retenção de água das amostras em equilíbrio com a pressão atmosférica (CR). A preparação das amostras foi feita seguindo um procedimento diferente do adotado para solos, conforme descrição a seguir:

Em bequeres de $80 \mathrm{ml}$, foram colocadas quantidades dos resíduos em volume de aproximadamente 40 ml. Em seguida, adicionou-se água até o volume de $60 \mathrm{ml}$, misturando a suspensão com o auxílio de um bastão de vidro. Adicionaram-se, ainda, dois ou três cristais de timol para interromper qualquer atividade biológica. Esta suspensão foi deixada em repouso por seis horas. Após este tempo o conteúdo dos copos sofreu uma nova agitação sendo então transferido, na sua totalidade, para anéis de pvc, previamente tarados, tendo em uma das extremidades um pedaço de tecido, fixado por uma tira de borracha. Esses tubos substituíram os anéis metálicos utilizados para as amostras de terra. Suas dimensões eram: diâmetro, $5 \mathrm{~cm}$; altura, $6 \mathrm{~cm}$. A maior altura, neste caso, é necessária para que $o$ anel possa receber todo o conteúdo do bequer onde os resíduos foram saturados, evitando, assim, que ocorresse 
segregação de componentes da amostra, quando da sua transferência. Feito este procedimento, as amostras eram deixadas em repouso por 24 horas, drenando o excesso de água. Após este tempo anotava-se o peso do conjunto, para ser utilizado no cálcu-lo da CR. As amostras foram então colocadas nos funis de placa porosa, ressaturadas dentro dos mesmos e, em seguida, foi aplicada a tensão de 1,0 m de coluna de água (10 kPa).

Após o período em que as amostras entravam em equilíbrio com a placa, geralmente de dois a três dias, estas eram retiradas, pesadas, e postas para secar a $65^{\circ} \mathrm{C}$ até peso constante. Com os valores obtidos nas pesagens foram feitos os cálculos de umidade, expressos em $g$ de $\mathrm{H}_{2} \mathrm{O}$ por $\mathrm{kg}$ de matéria seca.

\subsubsection{Cálculos da distribuição de poros no solo.}

Expressando a afinidade do solo pela água como equivalente a uma ascenção desta em um tubo capilar de área circular, a tensão da água no solo seria dada pela seguinte equação:

onde:

$$
h=\frac{2 \sigma \cdot \cos \alpha}{\rho \cdot g \cdot r}
$$

$$
\begin{aligned}
& \mathrm{h}=\text { tensão em } \mathrm{cm} \mathrm{H}_{2} \mathrm{O} \\
& \sigma=\text { viscosidade da água }=71,97 \cdot 10^{-3} \mathrm{~N} \cdot \mathrm{m}^{-1} \\
& \alpha=\text { ângulo de contato }=360^{\circ} \Rightarrow \cos \alpha=1 \\
& \rho=\text { densidade da água }=1 \mathrm{~g} \cdot \mathrm{cm}^{-3} \\
& \mathrm{~g}=\text { aceleração da gravidade }=980 \mathrm{~cm} \cdot \mathrm{s}^{-2} \\
& r=\text { raio do capilar }
\end{aligned}
$$


Desta forma, observa-se que, conhecendo-se a - valor da tensão aplicada, pode ser calculado o diâmetro máximo dos poros que contêm a água determinada a uma dada tensão. Relacionando-se este valor de umidade volumétrica com a porosidade total, determina-se que frações desta são correspondentes a um volume de poros com diâmetros menores ou iguais a um determinado valor.

Para a obtenção desses valores a porosidade total foi calculada pela relação entre a densidade do solo e densidade das particulas, determinadas em cada parcela experimental. 


\section{RESULTADOS E DISCUSSÃO.}

\subsection{Comparação de três sistemas de respirometria.}

A Eigura 3 mostra as quantidades de carbono coletadas na forma de $\mathrm{CO}_{2}$ pelo sistema dinâmico, fechado e semi-aberto. Nos primeiros quatro dias observa-se que os sistemas dinâmico e fechado apresentam valores praticamente idênticos, indicando que, no ambiente dos vasos sem circulação forçada de ar, havia oxigênio suficiente, não limitando, assim, o processo de oxidação da matéria orgânica. Neste período, quanto ao sistema semi-aberto, embora este tenha diferido significativamente dos demais apenas no primeiro dia, observa-se que as quantidades de $\mathrm{CO}_{2}$ coletadas são sempre mais baixas, devido a uma possível passagem de $\mathrm{CO}_{2}$ para fora dos vasos através do orifício existente em suas tampas.

No sexto dia de coleta, os sistemas fechado e semi-aberto tinham permanecido tampados por 48 horas. Os dados de coleta apresentados para estes mostram-se significativamente inferiores ao do sistema dinâmico. Estando no início da fase experimetal, período no qual as taxas de decomposição são elevadas, o ar contido nos vasos fechados foi insuficente para prover oxigênio na quantidade requerida pelos organismos do solo. No sistema semi-aberto, pode ter havido alguma entrada de ar, embora menor que a 
necessária. Porém, a fuga de $\mathrm{CO}_{2}$ do ambiente do vaso torna inadequado o uso deste sistema.

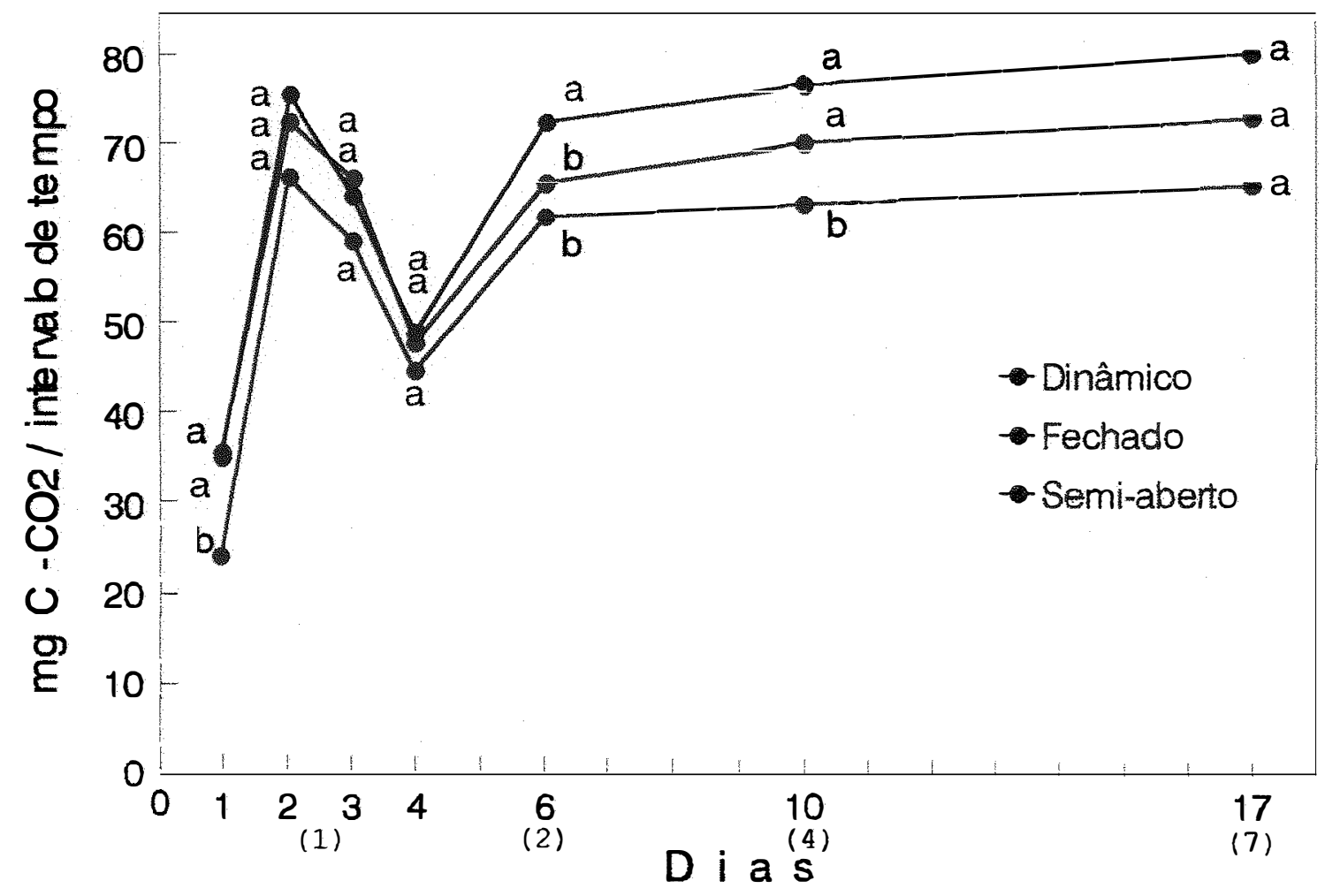

Letras iguais indicam ausência de diferenças significativas pelo teste de Tukey a 5 o entre sistemas.

Números entre parêntesis referem-se ao intervalo de troca da solução absorvedora de $\mathrm{CO} 2$, em dias.

Figura 3. Quantidades de carbono, provenientes de amostras de Terra Roxa estruturada tratadas com doses iguais de torta de filtro, recuperadas na forma de $\mathrm{CO}_{2}$ por três diferentes sistemas e com diferentes intervalos de coleta. 
As medições feitas a intervalos de quatro e sete dias (dias 10 e 17) mostram comportamentos semelhantes aos observados no dia 6 , com quantidades de $\mathrm{C}-\mathrm{CO}_{2}$ sempre maiores no sistema dinâmico, seguidas do fechado e semiaberto. Embora só tenha ocorrido neste período um caso de diferença estatística (semi-aberto, dia 10), a soma de todas as diferenças, quando da totalização das perdas, irá produzir valores muito distantes entre sí. Desta forma, O uso de sistema semi-aberto bem como o espaçamento dos intervalos de aeração para este e para o sistema fechado pode ser uma fonte de graves imprecisões no balanço das perdas de carbono do solo.

Diante dos resultados apresentados concluise que os sistemas dinâmico e fechado são equivalentes, desde que, neste último, mantenham-se intervalos de aeração de acordo com a demanda de oxigênio existente no decorrer do experimento. Esta constatação fez com que se definisse, para o estudo de degradação de resíduos no solo apresentado a seguir, o uso de respirômetros fechados com coletas diárias nos 20 primeiros dias, e, apartir de então, a cada dois dias, com as perdas de $\mathrm{C}-\mathrm{CO}_{2}$ apresentando valores abaixo de $20 \mathrm{mg}$ de carbono por dia.

\subsection{Decomposição de quatro resíduos orgânicos em dois solos.}

O comportamento das perdas de carbono na forma de $\mathrm{CO}_{2}$ no decorrer dos 60 dias da incubação dos solos com os resíduos é apresentado nas figuras 4 e 5 . Os valores médios observados, de perdas diárias e totais, encontram-se na Tabela 20 do APÊNDICE. Na Figura 4, constam as observações relativas aos primeiros vinte dias. De acordo com os diversos trabalhos já citados, também neste estudo o pico das perdas ocorreu no início do ensaio, neste caso aos 
dois dias. Isto se deve à rápida decomposição de substâncias orgânicas mais simples presentes nos materiais, fato confirmado pelas maiores taxas observadas para a torta de filtro. Esta, usada como referência por ser um material de decomposição mais rápida e de natureza menos complexa devido a resultar do processamento de um único material, a cana-de-açúcar, foi a que apresentou as maiores taxas de decomposição, seguida do lodo de esgoto, composto de lixo e lodo petroquímico. Este último, mostrou ser o mais estável no solo. Isto pode ser devido à eficiência do tratamento dos efluentes que o originaram e também a questões relacionadas com a natureza destes efluentes, oriundos, entre outras, de indústrias de polímeros orgânicos. O composto de lixo e o lodo de esgoto, que resultam de misturas de produtos de variadas origens apresentaram comportamentos intermediários entre a torta de filtro e o lodo petroquímico.

Decorridos 20 dias de incubação já havia ocorrido a maior parte das perdas de carbono medidas neste ensaio. Para os dois solos e os quatro resíduos estudados, as perdas neste período variaram de 52 a $66 \%$ das totais, inclusive para os tratamentos-testemunha. Isto mostra que estudos de curta duração podem fornecer informacões úteis sobre tendências de comportamentos de materiais orgânicos no solo.

A Eigura 5 mostra o comportamento dos quatro resíduos entre os dias 22 e 60 do ensaio. Vale lembrar que os valores observados referem-se a coletas feitas a cada dois dias. Para melhor visualização, a escala dos gráficos foi expandida em duas vezes em relação à figura anterior. 

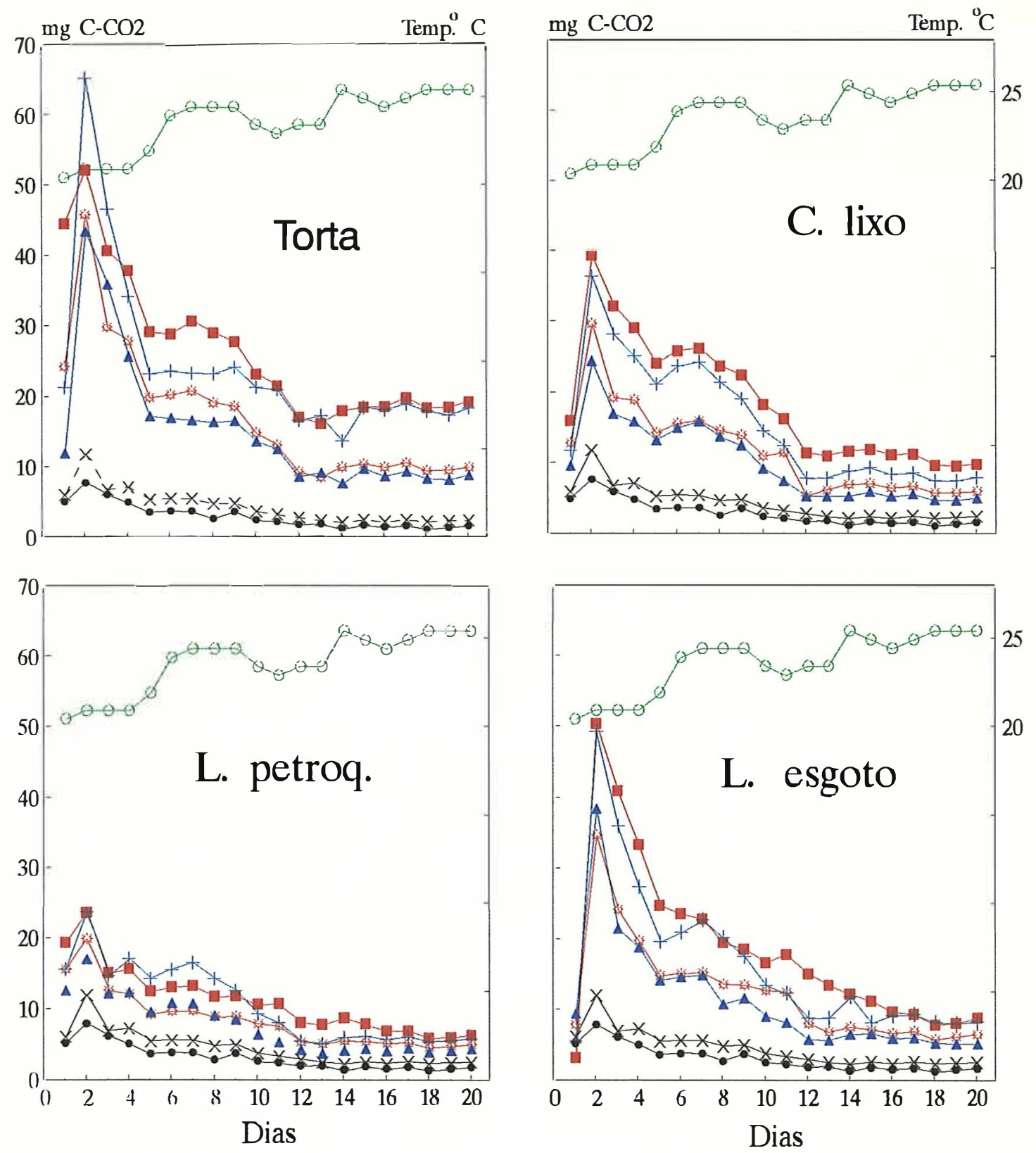

Dose 1 LE

+ Dose 2 LE Dose 1 AQ

Dose 2 AQ

Temp. media - Test. LE $\nsucc$ Test. AQ

Figura 4. Perdas diárias de carbono, na forma de $\mathrm{CO}_{2}$, em amostras de dois solos tratadas com quatro diferentes materiais orgânicos, nos primeiros 20 dias da incubação. 

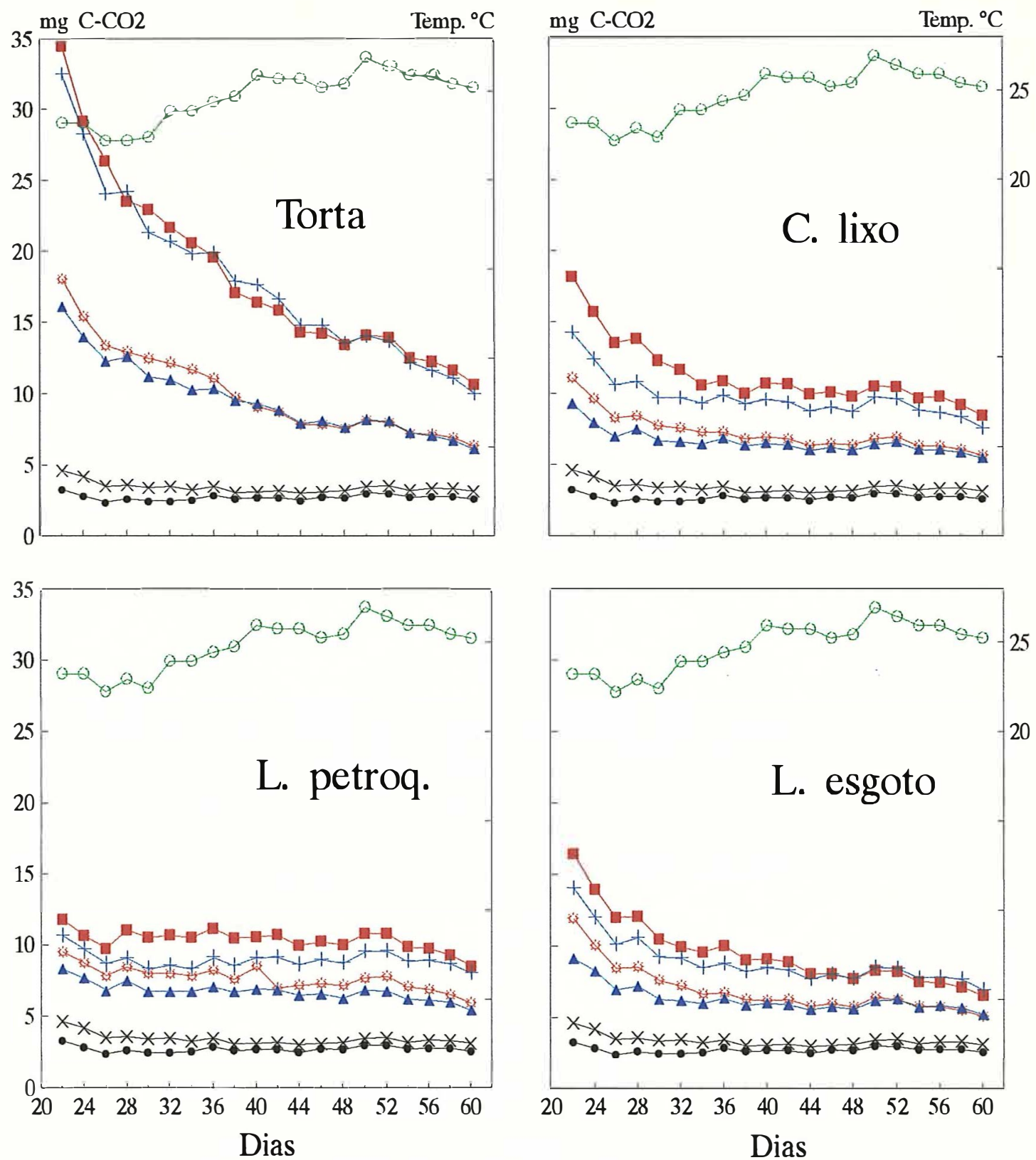

\begin{tabular}{|c|c|c|c|}
\hline A Dose 1 LE & + Dose 2 LE & Dose 1 AQ & Dose 2 AQ \\
\hline$\ominus$ Temp. media & - Test. LE & × Test. AQ & \\
\hline
\end{tabular}

Figura 5. Perdas de carbono na forma de $\mathrm{CO}_{2}$ em amostras de dois solos tratadas com quatro diferentes materiais orgânicos, medidas a intervalos de dois dias entre $\circ 20^{\circ}$ e $\circ 60^{\circ}$ dia da incubação. 
Neste intervalo do experimento, observa-se que as perdas tendem a assumir um comportamento constante, apresentando, contudo, valores sempre mais altos para as maiores doses e distantes do tratamento testemunha, mostrando que apenas em estudos de maior duração pode ser determinado o tempo com que o solo retorna à sua condiçào original.

O efeito da temperatura ambiente é observado pelas oscilações das taxas de respiração no decorrer do ensaio. No entanto, embora provocando algumas alterações, a elevação da temperatura não chegou a modificar a tendência geral de perdas decrescentes de carbono.

Os solos utilizados no estudo mostraram comportamentos semelhantes quanto às perdas de carbono, tendo Areia Quartzosa ( $\mathrm{QQ}$ ) apresentado valores levemente superiores ao Latosso Vermelho-escuro (LE) inclusive nas testemunhas. Assim, ao se descontar dos tratamentos os valores determinados nas testemunhas, os dois solos mostram comportamentos praticamente idênticos quanto a perdas determinadas por respirometria, conforme será visto a seguir.

A Tabela 6 apresenta os teores de carbono nas amostras de solo ao final do ensaio e valores de perdas em relação à dose de C aplicada, calculadas de duas maneiras: a partir de resultados de análise de solo e do carbono recuperado por respirometria. Quanto a esta, observa-se que as perdas máximas no periodo experimental foram de 29\% do carbono aplicado na forma de torta de filtro. De uma forma geral, as perdas ocorreram na seguinte ordem: torta > lodo de esgoto $\cong$ composto de lixo > lodo petroquímico. 
Tabela 5. Teores de carbono em dois solos após 60 dias de incubação com diferentes materiais orgânicos e comparação de perdas de $C$ em função da dose aplicada, determinadas por análise do solo e por respirometria.

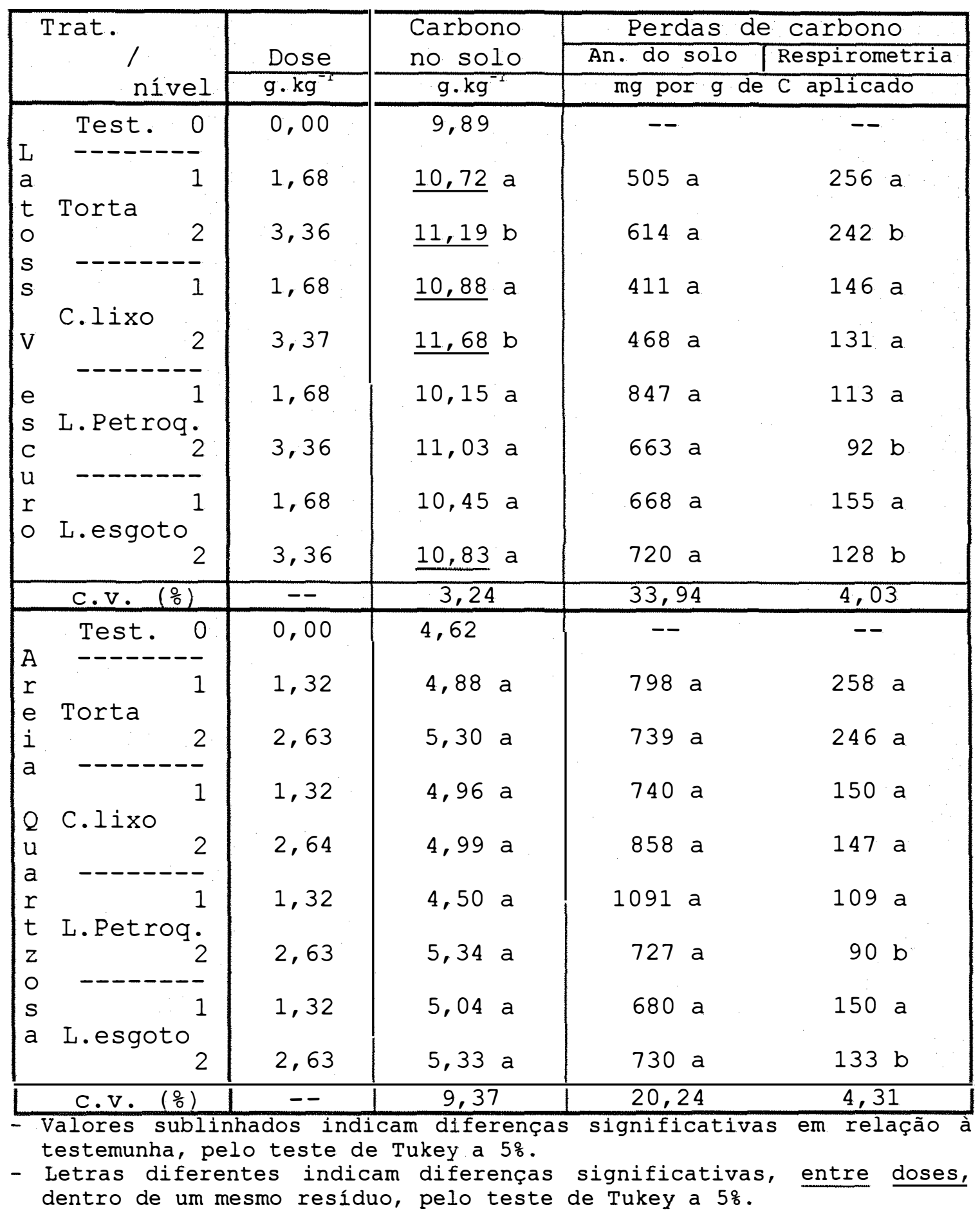


Com relação ao efeito da dose aplicada na taxa de decomposição, observa-se no solo LE que estas, determinadas por respirometria, foram significativamente maiores na dose 1 do que na dose 2 para torta de filtro, lodo petroquímico e lodo de esgoto. Para o solo AQ, estas diferenças ocorreram apenas para o lodo petroquímico e lodo de esgoto. Mesmo onde não ocorreu significância estatística os valores foram menores na dose 2, permitindo supor que a taxas de aplicação maiores que as utilizadas neste estudo, - efeito seria ainda mais pronunciado. Estas observações encontram-se de acordo com vários dos trabalhos feitos sobre esse tema e indicam que, caso seja desejável altas taxas de decomposição, os resíduos devem ser adicionados aos solos em pequenas doses.

Os resultados de análise de carbono no solo apresentados na Tabela 5 mostram, para o solo LE, valores mais altos nos tratamentos que receberam residuos do que nas testemunhas. Estas diferenças são significativas para torta de filtro e composto de lixo nas duas doses e para o lodo de esgoto na dose 2. Nos dois primeiros casos, dentro de cada resíduo, a dose 2 é significativamente maior que a dose 1. É interessante notar que os maiores teores de carbono no solo encontram-se justamente nos tratamentos que apresentaram as maiores perdas deste elemento, medidas por respirometria. Deste modo, as perdas calculadas com base na análise do solo mostram um comportamento inverso ao determinado por coleta de $\mathrm{CO}_{2}$. No solo $\mathrm{AQ}$ não se observam diferenças entre tratamentos.

Comparando os valores de perdas de carbono nota-se que aquelas calculadas a partir da análise do solo são muito maiores do que as medidas por respirometria, chegando inclusive a indicar (no solo AQ, lodo petroquímico, dose 2$)$ que todo o carbono aplicado foi 
decomposto, tendo sido consumido também parte de C nativo do solo. Os elevados coeficientes de variação mostram a pouca confiabilidade destes dados. Esta baixa precisão decorre das quantidades muito pequenas de carbono adicionadas na forma de resíduos em proporção da massa de solo. Observando as doses aplicadas, nota-se que a maior delas é de 3,37 miligramas de C para um quilograma de solo. Deste modo, as amostras de $5 \mathrm{~g}$ de solo seco empregadas na análise, embora maiores que as geralmente empregadas (2 g), tiveram, na dose maior, um acréscimo de apenas 0,016 g de carbono. É possível que o método analítico não seja suficientemente sensivel para avaliar efeitos de adições tão pequenas de carbono como estas.

Os dados analíticos apresentados referem-se a amostras de solo seco ao ar. Isto permitiria supor que tivesse ocorrido grandes perdas de $C$ após o final da incubação, durante a secagem. No entanto, análises feitas em amostras congeladas ao final do ensaio mostraram resultados semelhantes, invalidando esta hipótese.

Estas observações permitem considerar que a respirometria é um método mais adequado para a avaliação das taxas de decomposição de materiais orgânicos adicionados aos solos. 


\subsection{Efeitos da aplicação dos resíduos sobre algumas propriedades dos solos.}

\subsubsection{Observações gerais.}

A Tabela 6 apresenta os valores de $\mathrm{pH}$ em água, em $\mathrm{CaCl}_{2}$ e de condutividade elétrica dos solos nos diversos tratamentos. Os resultados das análises para macronutrientes (exceto $\mathrm{N}$ ), $\mathrm{H}+\mathrm{Al}$ e $\mathrm{Al}$ encontram-se na Tabela 7. Para os valores $\mathrm{pH}$, observa-se que as maiores elevações ocorreram nas amostras de solo tratadas com os resíduos mais alcalinos (vide Tabela 3, p.30), efeito este mais evidente nos dados de $\mathrm{pH}$ em $\mathrm{CaCl}_{2}$. Mesmo nos tratamentos com torta de filtro, residuo cujo pH era 5,5, portanto menor que $O \mathrm{pH}$ inicial dos solos ( LE e $A Q=6,9)$, observa-se uma diminuição da acidez. Isto se deve às reações de decomposição da matéria orgânica, conforme descrito por MATTIAZZO E GLÓRIA (1987):

$$
\text { Material orgânico -----> } \quad \mathrm{CO}_{2}+\mathrm{H}_{2} \mathrm{O}+\mathrm{n} \text { é }
$$

Os elétrons liberados são recebidos pelo oxigênio do ar:

$$
4 \text { é }+\mathrm{O}_{2}----->2 \mathrm{O}^{2-}
$$

Como o ion $\mathrm{O}^{2-}$ é um ávido receptor de prótons, vai neutralizar H+ da solução:

$$
2 \mathrm{O}^{2-}+4 \mathrm{H}^{+}----->\quad 2 \mathrm{H}_{2} \mathrm{O}
$$

A neutralização pode ocorrer também de forma direta:

$$
\mathrm{n} \text { é }+\mathrm{n} \mathrm{H}^{+}---->\mathrm{n} / 2 \mathrm{H}_{2}^{0}
$$


Tabela 6. Valores de $\mathrm{pH}$ em água e em $\mathrm{CaCl}_{2}$ e de condutividade elétrica em dois solos tratados com quatro diferentes materiais orgânicos.

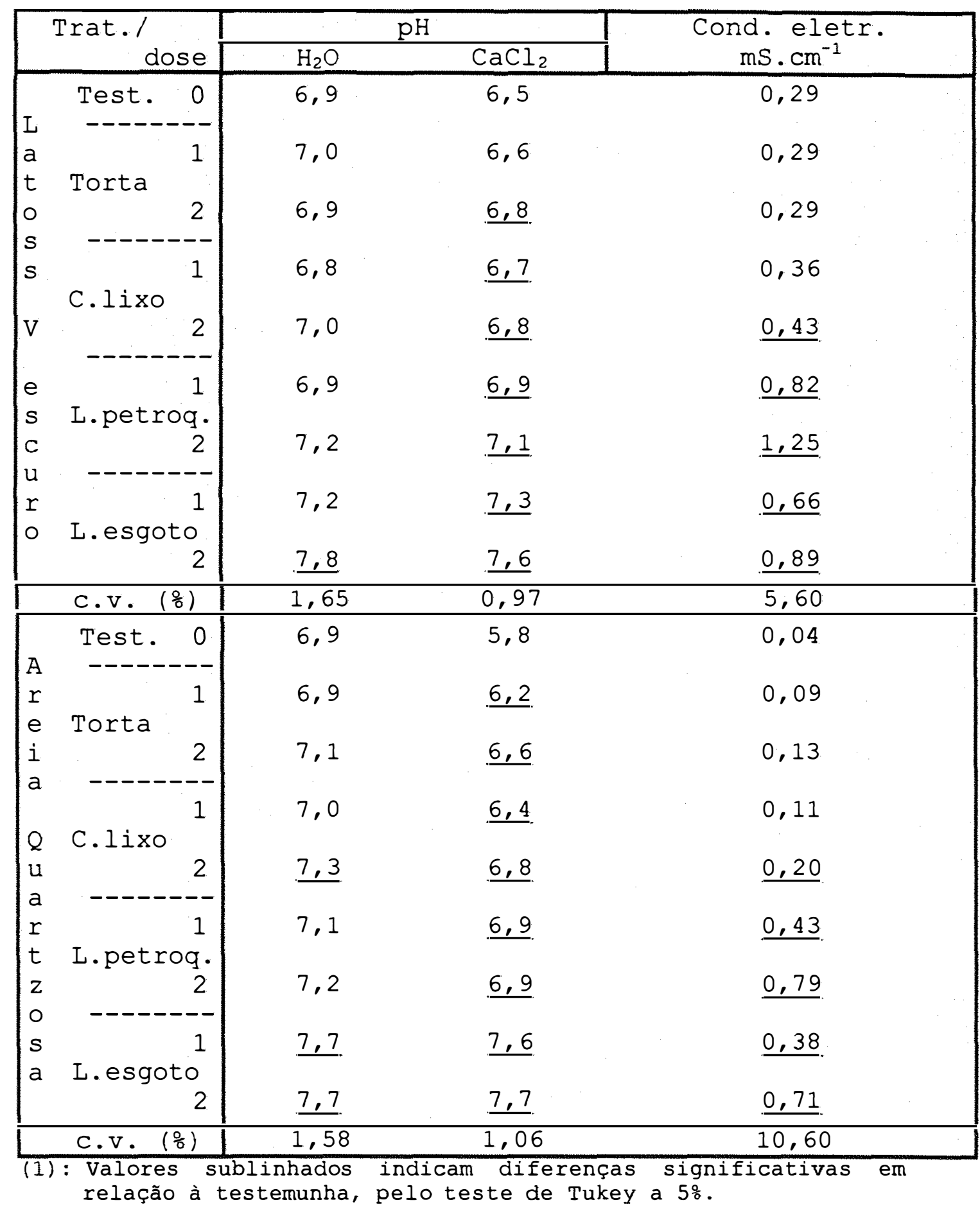


O efeito das mudanças no $\mathrm{pH}$ vai se traduzir em outros atributos do solo, como a CTC, discutida adiante. Quanto à condutividade elétrica, com exceção das duas doses torta de filtro e composto de lixo na dose 1, todos os outros tratamentos provocaram elevações significativas dos seus valores. Estes foram determinados em supensões 1:2,5 aproveitando aquelas utilizadas para medir $\circ \mathrm{pH}$ em água. Deste modo, não podem ser comparados com parâmetros determinados em pastas de saturação, não permitindo, portanto, afirmações seguras sobre o grau de salinização. Por outro lado, os valores obtidos mostram uma tendência relacionada com este processo, confirmando a necessidade de se levar em conta este fator, quando da adição de certos resíduos aos solos, para prevenir contra efeitos danosos decorrentes da salinização, como os relatados por TEDESCO (1991) em áreas de descarte de residuos de origem petroquímica.

Os dados constantes da Tabela 7 revelam aumentos dos teores de $\mathrm{P}, \mathrm{K}, \mathrm{Ca}$ e $\mathrm{Mg}$ nos solos, proporcionais às concentrações destes elementos nos resíduos aplicados. Observa-se, ainda, diminuições significativas da acidez titulável $\left(\mathrm{H}^{+}+\mathrm{Al}^{3+}\right)$, com conseqüente aumento na saturação por bases, indicando, assim, alguns efeitos benéficos da adição dos materiais orgânicos aos solos neste estudo.

Os resultados obtidos para teores de nitrogênio total e mineral $\left(\mathrm{NO}_{3}{ }^{-}+\mathrm{NH}_{4}{ }^{+}\right)$nos solos constam $\mathrm{da}$ Tabela 8. Nesta, para $\circ \mathrm{N}$ total, só foram observadas diferenças, em relação à testemunha, na dose 2 de lodo petroquímico no $\mathrm{LE}$ e dose 1 de lodo de esgoto e composto de lixo no solo $\mathrm{AQ}$. Isto decorre da variabilidade dos resultados que se explica, em parte, pelas rápidas transformações que este elemento sofre no solo. Já para o 
nitrogênio mineral, observa-se que a aplicação de lodo petroquímico, no solo LE, promoveu aumentos significativos dos seus teores. A torta de filtro na dose 1 ocasionou um decréscimo significativo, não observado na dose 2. No solo $A Q$, além do lodo petroquímico, também o lodo de esgoto promoveu aumentos significativos dos teores de $\mathrm{NO}_{3}{ }^{-}+\mathrm{NH}_{4}{ }^{+}$. $\mathrm{O}$ alto valor observado para a dose 2 de torta neste solo, tendo em vista a relação $\mathrm{C} / \mathrm{N}$ (ver Tabela 3, p.30) deste material, pode ser atribuído apenas a problemas de amostragem, uma vez que que a tendência geral foi a de os resíduos com menor relação $\mathrm{C} / \mathrm{N}$ contribuirem para as maiores elevações dos teores de $\mathrm{N}$ mineral no solo.

De um modo geral, os efeitos observados para nitrogênio mineral são coerentes com as doses aplicadas, calculadas a partir da concentração do elemento nos resíduos empregados neste estudo. A produção de formas minerais de $\mathrm{N}$ foi mais marcante no solo $\mathrm{AQ}$, mostrando que, neste, é maior o risco de lixiviação de nitrato.

As diferenças das relações $\mathrm{C} / \mathrm{N}$ dos solos, nos diversos tratamentos, não apresentaram significância estatística, fato também ligado à variação dos dados, não permitindo, portanto, que se façam inferências a respeito. 
Tabela 7. Concentrações $\mathrm{P}, \mathrm{K}, \mathrm{Ca}, \mathrm{Mg}, \mathrm{H}+\mathrm{Al}, \mathrm{Al}$ e valores de soma de bases, valor $T$ e saturação por bases em dois solos incubados com quatro diferentes materiais orgânicos.

\begin{tabular}{|c|c|c|c|c|c|c|c|c|c|c|}
\hline & Trat. & $\mathrm{P}$ & $\mathrm{K}$ & $\mathrm{Ca}$ & $\mathrm{Mg}$ & $\mathrm{H}+\mathrm{Al}$ & $\mathrm{Al}$ & $\bar{S}$ & $\mathrm{~T}$ & $\overline{\mathrm{V}}$ \\
\hline & dose & $\mathrm{mg} \cdot \mathrm{kg}^{-1}$ & & & $\mathrm{cmol}$ & +1.100 & & & & $(\%)$ \\
\hline & Test. 0 & 43 & 0,59 & 5,3 & 1,8 & 1,4 & 0 & 7,7 & 9,1 & 85 \\
\hline $\begin{array}{l}L \\
\mathrm{a}\end{array}$ & & 58 & 0,66 & 5,8 & 1,8 & 1,2 & 0 & 8,3 & 9,4 & 88 \\
\hline $\begin{array}{l}t \\
0\end{array}$ & Torta & 70 & 067 & 58 & 16 & 11 & & 00 & 0 & \\
\hline s & --.--- & 10 & 0,01 & J,o & 1,0 & $1,1$. & 0 & 8,0 & 5,1 & 88 \\
\hline $\mathrm{s}$ &  & 50 & 0,70 & 5,4 & 1,6 & $1,2$. & 0 & 7,7 & 8,9 & 87 \\
\hline $\mathrm{V}$ & 2 & 53 & 0,86 & 6,1 & 1,6 & 1,1 & 0 & 8,6 & 9,7 & 89 \\
\hline e & & 51 & 0,62 & $\underline{6,8}$. & $\underline{1,4}$. & $\underline{1,0}$ & 0 & $\underline{8,8}$ & 9,9 & 90 \\
\hline c & 2 & 47 & 0,66 & $\underline{7,5}$ & 1,3 & $\underline{0,9}$ & 0 & $\underline{9,5}$ & 10,4 & 91 \\
\hline $\begin{array}{l}\mathrm{u} \\
\mathrm{r}\end{array}$ & 1 & $\underline{58}$ & 0,59 & $\underline{8,0}$ & $\underline{1,1}$ & $\underline{0,8}$. & 0 & $\underline{9,8}$ & 10,6 & 92 \\
\hline & 2 & 57 & 0,63 & $\underline{8,9}$ & $\underline{0,9}$ & $\underline{0,8}$. & 0 & 10,5 & 11,3 & 93 \\
\hline & C.V. $\left(\frac{\circ}{0}\right)$ & 8,93 & 3,81 & 4,91 & 4,52 & 5,14 & & 4,21 & 3,94 & 0,65 \\
\hline & Test. 0 & 20 & 0,13 & 1,5 & 0,4 & 1,0 & 0 & 2,0 & 3,0 & 67 \\
\hline $\begin{array}{l}A \\
r\end{array}$ & & $\underline{41}$ & 0,16 & 2,4 & 0,5 & 0,9 & 0 & 3,1 & 4,0 & 77 \\
\hline e & Torta & 64 & 0.19 & 2.7 & 0.6 & 0.8 & 0 & 34 & 4,2 & 81 \\
\hline 1 & 2 & 64 & 0,15 & $\frac{2,1}{1}$ & $\underline{0,0}$ & $\underline{0,8}$. & 0 & 3,4 & $\underline{4,2}$ & $\underline{81}$ \\
\hline & & 26 & $\underline{0,26}$ & $\underline{2,2}$ & 0,5 & $\underline{0,8}$. & 0 & $\underline{3,0}$ & 3,8 & 79 \\
\hline $\begin{array}{l}Q \\
u\end{array}$ & C.Iixo & $\underline{33}$ & $\underline{0,38}$ & 2,8 & 0,6 & $0,8$. & 0 & 3,8 & 4,6 & 82 \\
\hline $\begin{array}{l}a \\
r\end{array}$ & & $\underline{49}$ & 0,16 & 3,1 & 0,4 & $\underline{0,8}$. & 0 & 3,6 & 4,4 & $\underline{82}$ \\
\hline$t$ & L. petroq. & & & & & & & & & \\
\hline$z$ & & 68 & $\underline{0,18}$ & $\underline{4,1}$. & 0,4 & $\underline{0,6}$ & 0 & $\underline{4,7}$. & $\underline{5,3}$ & $\underline{89}$ \\
\hline$s$ & 1 & $\underline{48}$ & 0,15 & 4,0 & 0,4 & $\underline{0,6}$ & 0 & 4,5 & $5,1$. & $\underline{88}$ \\
\hline$a$ & $\begin{array}{r}\text { L.esgoto } \\
2\end{array}$ & $\underline{58}$ & 0,14 & $\underline{4,7}$. & 0,3 & $\underline{0,6}$ & 0 & 5,2 & $5,8$. & 90 \\
\hline & C.V. $\left(\frac{\circ}{0}\right)$ & 9,78 & 6,68 & 7,43 & 11,4 & 0,11 & & 7,19 & 5,96 & 1,29 \\
\hline
\end{tabular}


Tabela 8. Teores de nitrogênio total e mineral $\left(\mathrm{NO}_{3}{ }^{-}+\mathrm{NH}_{4}{ }^{+}\right)$, e relação $\mathrm{C} / \mathrm{N}$, em dois solos tratados com quatro diferentes materiais orgânicos.

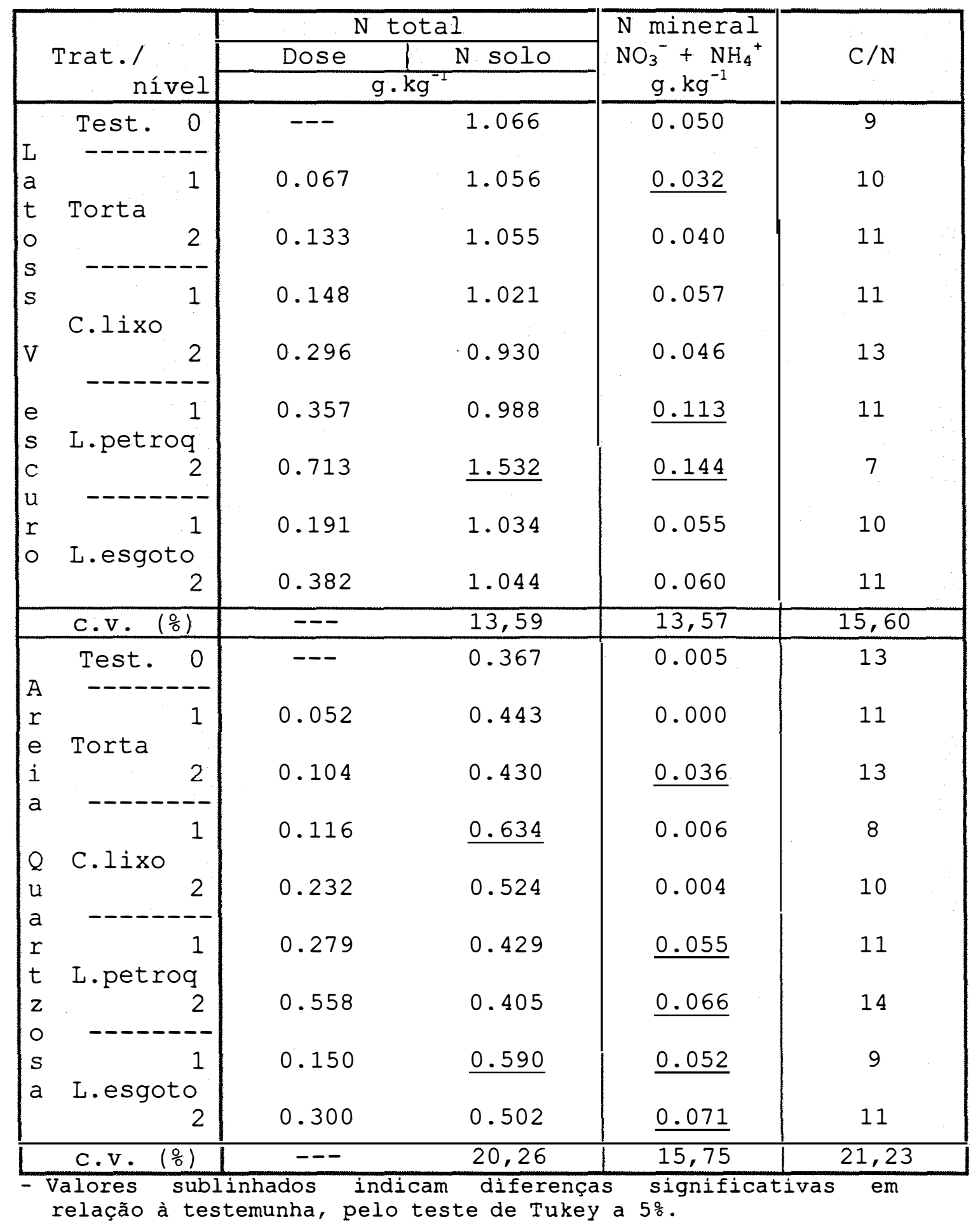




\subsubsection{Efeito na capacidade de troca cationnica dos solos.}

Os dados de CTC determinados a pH7 e ao pH atual dos dois solos estudados são apresentados nas figuras 6 e 7. Diante dos efeitos observados, é importante salientar que, neste estudo, dentro de cada dose, foram aplicadas quantidades idênticas de carbono na forma de diversos residuos, os quais provocaram efeitos diferentes no solo.

No Latossolo Vermelho-escuro, observa-se que a CTC a pH7 apresenta aumentos significativos na dose 1 de torta e lodo de esgoto, em relação à testemunha. Na dose 2, as diferenças são significativas entre a testemunha e os quatro residuos, e ainda, entre as doses 1 e 2 de lodo de esgoto. Quanto à CTC ao pH atual, não se observa nenhuma alteração em decorrência da adição dos resíduos neste solo.

$\mathrm{Na}$ Areia Quartzosa distrófica, a CTC determinada a pH7 apresentou uma significativa elevação em relação à testemunha na dose 1 de lodo de esgoto, e na dose 2, para composto de lixo, lodo petroquímico e lodo de esgoto. Este último mostrou ainda um aumento significativo da dose 1 para a dose 2. Quanto à CTC ao pH atual deste solo, observam-se aumentos, em relação à testemunha, significativos nas duas doses dos quatro residuos, com exceção da dose 1 de torta de filtro. Aumentos na CTC ao pH atual em Areia Quartzosa foram observados também por RODELLA et al. (1995), após a adição de materiais orgânicos de diversas origens. 

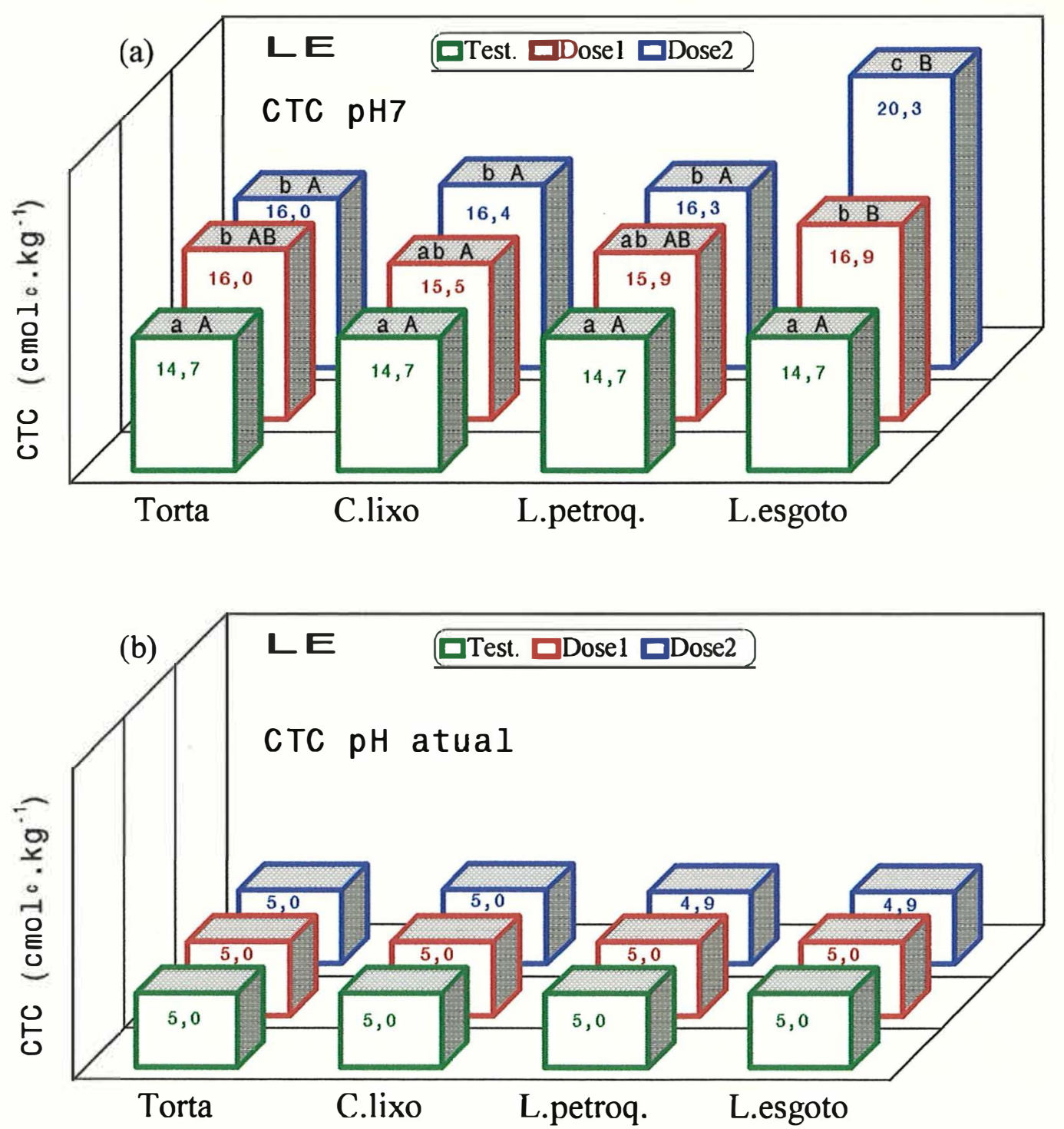

Letras diferentes, indicam existência de diferenças significativas pelo teste de Tukey a 5\%: maiúsculas entre resíduos, minúsculas entre doses.

Figura 6. Valores de CTC de amostras de Latossolo Vermelhoescuro tratadas com quatro diferentes materiais orgânicos em três doses, determinados: (a) a pH7 e (b) ao $\mathrm{pH}$ atual do solo. 

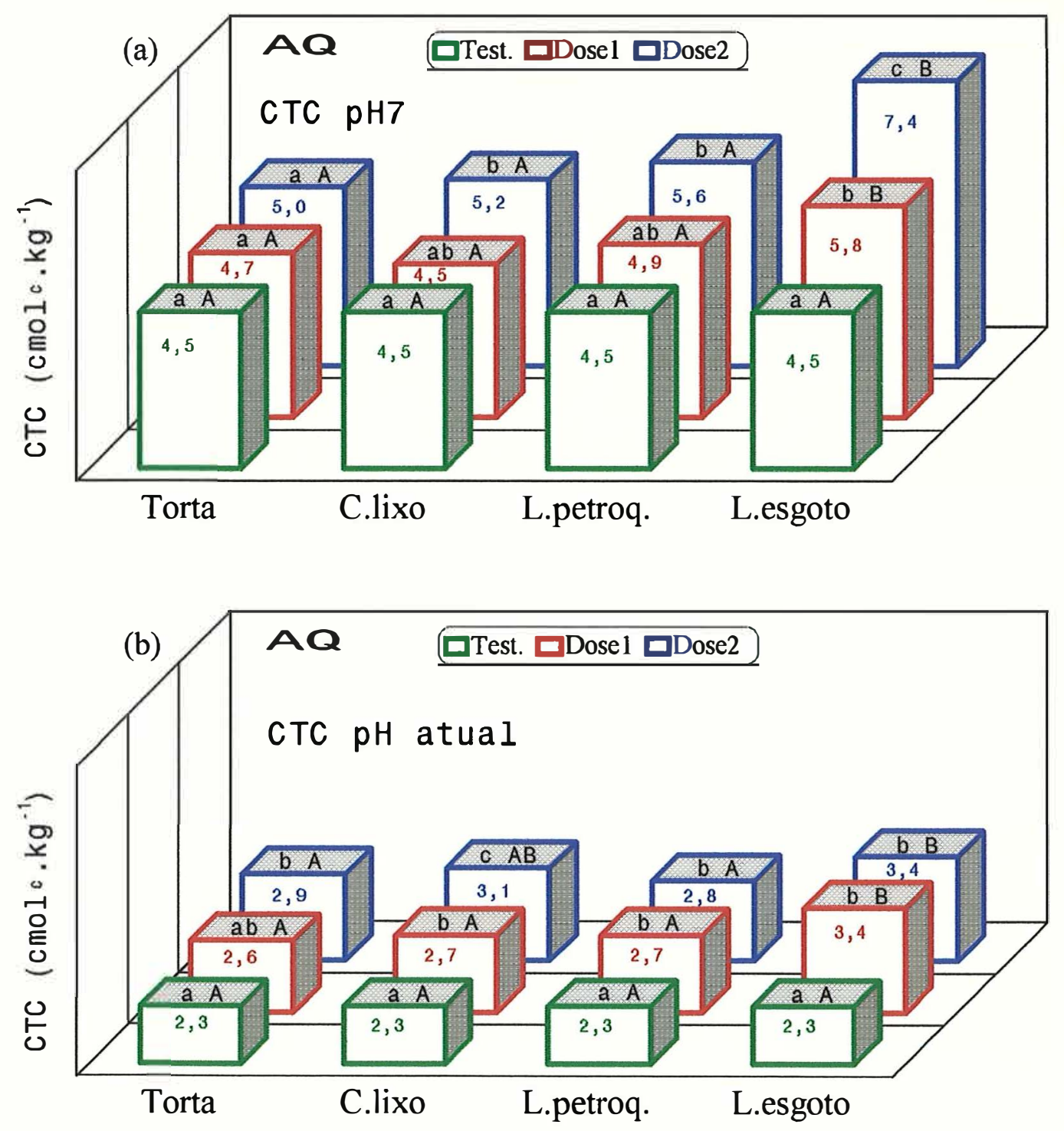

Letras diferentes, indicam existência de diferenças significativas pelo teste de Tukey a 5\%: maiúsculas entre residuos, minúsculas entre doses.

Figura 7. Valores de CTC de amostras de Areia Quartzosa distrófica tratadas com quatro diferentes materiais orgânicos em três doses, determinados: (a) a $\mathrm{pH} 7$ e (b) ao $\mathrm{pH}$ atual do solo. 
Os maiores valores observados para CTC a pH7 dão uma idéia do potencial de liberação de cargas negativas dos solos tratados, enquanto que a CTC ao pH atual reflete uma condição vigente nestes solos, mostrando, neste caso, para o LE, ausência de contribuição da adição dos resíduos.

Um aspecto importante a considerar é a CTC dos materiais aplicados. Na Tabela 9 são apresentadas estimativas de acréscimos na CTC do solo, calculadas em função da CTC a pH7 de cada resíduo e das quantidades aplicadas. Comparando os acréscimos estimados com os valores determinados para CTC a pH7, nos dois solos, observa-se que estes, de maneira geral, não são correspondentes. No caso do lodo de esgoto, por exemplo, nota-se que o aumento da СТC é várias vezes maior que o acréscimo estimado. Por outro lado, examinando os valores $\mathrm{pH}$ dos solos nos diversos tratamentos ao final do ensaio (Tabela 6, p.53), observa-se que os maiores aumentos de CTC ocorreram nos tratamentos que apresentaram as maiores elevações do valor $\mathrm{pH}$.

Tabela 9. Estimativas de acréscimos à CTC dos solos, calculados em função da CTC de quatro materiais orgânicos, quando da sua aplicação em duas doses.

\begin{tabular}{|l|c|c|}
\hline \multirow{2}{*}{ Material } & Acréscimo estimado à CTC do solo \\
\cline { 2 - 3 } & Dose 1 & Dose 2 \\
\hline Torta de Filtro & 0,200 & $\mathrm{cmol}_{\mathrm{c}} \cdot \mathrm{kg}^{-1}$ \\
Composto de lixo & 0,497 & 0,400 \\
Lodo petroquímico & 0,302 & 0,994 \\
Lodo de esgoto & 0,355 & 0,603 \\
& & 0,711 \\
\hline
\end{tabular}


O efeito da elevação do $\mathrm{pH}$ dos solos no aumento da CTC a pH7 fica evidente através do exame da Tabela 10. Nesta, as equações para cálculo da CTC, que têm os valores $\mathrm{pH}$ como variável independente, foram as que apresentaram os maiores coeficientes de determinação. No entanto, os valores de $\mathrm{R}^{2}$, situando-se em torno de 0,70, mostram que o $\mathrm{pH}$ final do solo deixa de explicar parte das observações. Assim, contribuições menores, como as da dose de carbono elou acréscimo estimado de CTC, podem ser levadas em consideração em tentativas de explicação matemática deste fenômeno.

Quanto à CTC ao pH atual do solo já foi reportada, para $O$ LE, a ausência de resposta à aplicação dos resíduos. É interessante salientar que isto ocorreu apesar das alterações observadas no $\mathrm{pH}$ deste solo nos diversos tratamentos. Já no caso do solo $A Q$, que mostrou evidentes respostas para a CTC determinada nesta condição, observa-se, de maneira semelhante ao que ocorreu com a CTC a pH7, que o efeito está relacionado com as alterações de $\mathrm{pH}$ ocorridas neste solo em decorrência da adição dos materiais orgânicos. Regressões Iineares determinadas para este caso (Tabela 11) também apontam $\circ \mathrm{pH}$ ao final da incubação como a variável que mais influiu nos valores determinados para a CTC.

As observações acima permitem concluir que os efeitos da aplicação dos resíduos orgânicos sobre a CTC a pH7 dos dois solos estudados são dependentes das alterações de pH decorrentes desta prática. Esta afirmação é válida também para a CTC ao pH atual para a Areia Quartzosa. 
Tabela 10 Regressões lineares para CTC a pH7 de dois solos tratados com diferentes materiais orgânicos em função de alguns parâmetros relativos ao ensaio.




Tabela 11. Regressões lineares para CTC ao pH atual da Areia Quartzosa distrófica tratada com diferentes materiais orgânicos em função de alguns parâmetros relativos ao ensaio.

\begin{tabular}{|c|c|c|}
\hline $\begin{array}{c}\text { Variável } \\
\text { independente } \\
(\mathrm{x})\end{array}$ & Regressão & $\mathrm{R}^{2}$ \\
\hline $\mathrm{pH} \mathrm{H}_{2} \mathrm{O}$ & $\mathrm{CTC}=-4,3250+1,0011 . x$ & 0,72 \\
\hline $\mathrm{pH} \mathrm{CaCl} 2$ & $\mathrm{CTC}=-0,7045+0,5298 . x$ & 0,73 \\
\hline Dose CTC ${ }^{(*)}$ & $\mathrm{CTC}=2,5459+0,9536 . \mathrm{x}$ & 0,34 \\
\hline Dose de C & $\mathrm{CTC}=2,4704+0,2349 . x$ & 0,33 \\
\hline C solo & $\mathrm{CTC}=1,2324+0,3303 . x$ & 0,16 \\
\hline Relação C/N & $\mathrm{CTC}=3,2045-0,0294 . \mathrm{x}$ & 0,05 \\
\hline
\end{tabular}


65.

\subsubsection{Efeito no conteúdo de metais pesados do solo e na sua fitodisponibilidade.}

As quantidadades de cádmio, níquel e crômio retiradas pelas plantas de arroz e extraídas por soluções de DTPA 0,05 M e de $\mathrm{HCl} 0,1 \mathrm{M}$ dos dois solos estudados encontram-se nas tabelas 12 e 13 . Os dados relativos a cobre e zinco constam das tabelas 14 e 15. Em todas estas, as colunas referentes às doses apresentam quantidades de metais calculadas em função dos teores destes nos residuos empregados.

As extrações feitas com solução de $\mathrm{Ca}\left(\mathrm{NO}_{3}\right)_{2}$ 0,05M, em todos os tratamentos, não resultaram em quantidades detectáveis de nenhum dos metais estudados, razão pela qual não são apresentados dados relativos a estas. Consta, na literatura, que este extrator remove quantidades pequenas de metais, que se encontram na forma livre ou fracamente adsorvida. É provável que, em estudos nos quais os metais são adicionados ao solo na forma de sais, a sua presença nesta condição seja favorecida. Neste trabalho, os metais compareciam como contaminantes de quatro diferentes resíduos $e$, assim sendo, deviam encontrar-se em formas não facilmente liberadas para a solução do solo. Isto, no entanto, não significa ausência de fitodisponibilidade, e sim, que a planta mostrou ser um extrator de metais mais eficiente do que esta solução, conforme se verá a seguir.

Os metais $\mathrm{Cd}, \mathrm{Ni}$, e $\mathrm{Cr}$ foram extraídos pelas plantas em quantidades detectáveis apenas nos tratamentos com lodo de esgoto. É importante salientar que os dados obtidos nos tratamentos-testemunha, para estes metais, apresentavam grande dispersão, tendo sido incluidos nas tabelas 12 e 13 visando apenas fornecer um termo de 
comparação com os tratamentos utilizando lodo de esgoto. Desta forma, a ausência de valores detectáveis nos tratamentos com torta de filtro, composto de lixo e lodo petroquímico, não significa que estes materiais promoveram diminuição dos teores de $\mathrm{Cd}, \mathrm{Ni}$ e $\mathrm{Cr}$ dos solos.

No solo LE (Tabela 12) só a dose 2 de crômio diferiu significativamente da testemunha. Na Areia Quartzosa (Tabela 13), apenas a dose 1 de crômio não diferiu da testemunha, mostrando que, neste solo, os metais $\mathrm{Cd}, \mathrm{Ni}$ e $\mathrm{Cr}$ encontravam-se em formas mais disponíveis.

Em experimentos do tipo Neubauer, as quantidades de elementos extraídas pelas plantas são expressas pelo total removido pelas mesmas. No entanto, caso se pretenda igualar as unidades com vistas a comparações com os teores extraídos pelas soluções, tomando-se os 10 gramas de solo explorados pelas plantas, basta dividir 0 valor observado nestas por 10, para se colocar os dados em $\mathrm{mg}$ de metal por $\mathrm{kg}$ de solo. Desta forma observa-se que, para $\mathrm{Cd}$, $\mathrm{Ni}$ e $\mathrm{Cr}$, nos dois solos, as quantidades retiradas pelas plantas foram muito menores do que as extraídas por DTPA e HCl, com exceção do cádmio, nas testemunhas dos dois solos.

Observando 0 desempenho dos extratores, nota-se que $\bigcirc \mathrm{HCl}$ extraiu praticamente todo $\circ \mathrm{Cd}$ e $\mathrm{Ni}$ adicionados ao solo e grande parte do crômio. O DTPA extraiu todo o cádmio adicionado, cerca de metade do níquel e de 7 a 15\% do crômio nos dois solos.

Em estudo com os mesmos solos e plantas, porém com os metais aplicados na forma de sais, MATTIAzzoPREZOTTO (1994) observou a superioridade do extrator salino $\left(\mathrm{Ca}\left(\mathrm{NO}_{3}\right)_{2}\right)$ para $\mathrm{Cd}, \mathrm{Ni}$, e $\mathrm{Cr}$, indicando a sua presença em formas livres. Contrariamente, no presente trabalho, considerando a afinidade do DTPA por formas ligadas à matéria 
orgânica, conclui-se que $\circ \mathrm{Cd}$ e grande parte do $\mathrm{Ni}$ encontram-se associados a esta. O restante do níquel e a maior parte do crômio encontram-se, provavelmente, adsorvidos a colóides inorgânicos do solo, conforme demonstram as diferenças entre as quantidades extraídas por HCl e DTPA.

o comportamento do cobre e do zinco nas plantas revela que estas, em geral, retiraram quantidades de metais muito menores do que as extraidas por DTPA e $\mathrm{HCl}$. Como exceção, apresenta-se o zinco na testemunha e doses 1 e 2 de torta, nas quais as plantas retiraram quantidades semelhantes ao DTPA e cerca de metade das extraídas com HCl no LE (Tabela 14) e no solo AQ (Tabela 15). Estes fatos estão relacionados com os teores iniciais no solo e com as pequenas doses de zinco adicionadas através da torta de filtro, encontrando-se, provavelmente, próximos da demanda do elemento por parte das plantas, fazendo com que estas retirassem as quantidades disponíveis no solo. Estas quantidades, pelos dados em DTPA, encontravam-se associadas à matéria orgânica. Ainda quanto ao zinco, observa-se que o $\mathrm{HCl}$ extraiu mais que $O$ DTPA no LE, porém com valores próximos, e quantidades praticamente idênticas na Areia Quartzosa.

A afinidade do cobre com a matéria orgânica do solo é demonstrada pelas quantidades removidas com DTPA nos dois solos estudados. Subtraindo-se os valores observados nas testemunhas daqueles determinados nos diversos tratamentos, nota-se que todo o cobre adicionado foi retirado por este extrator, que apresentou dados superiores aos das extrações feitas com $\mathrm{HCl}$. Nota-se ainda que os dois extratores e a planta mostraram um comportamento crescente das quantidades retiradas em função das doses de cádmio, níquel, crômio e cobre. 


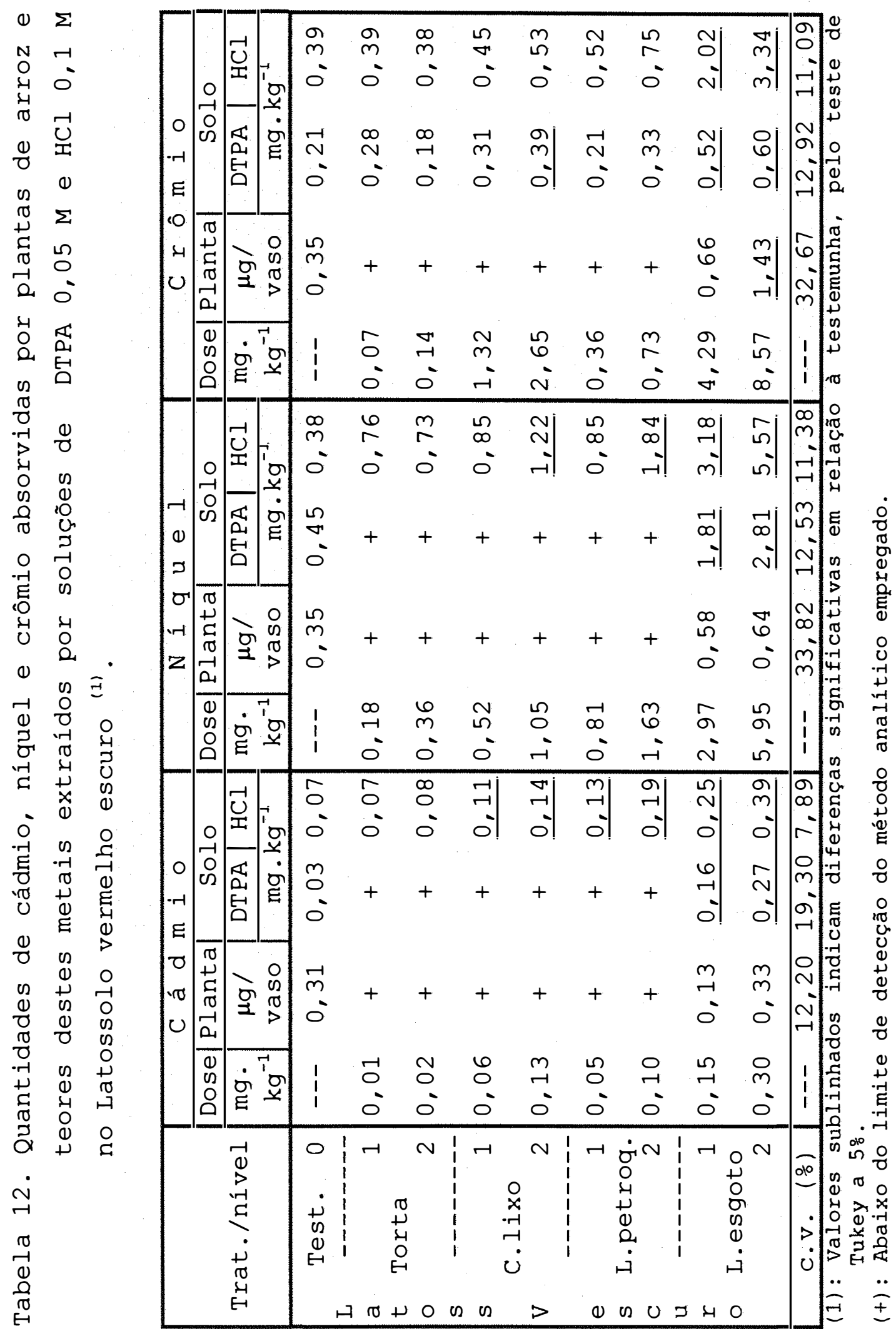









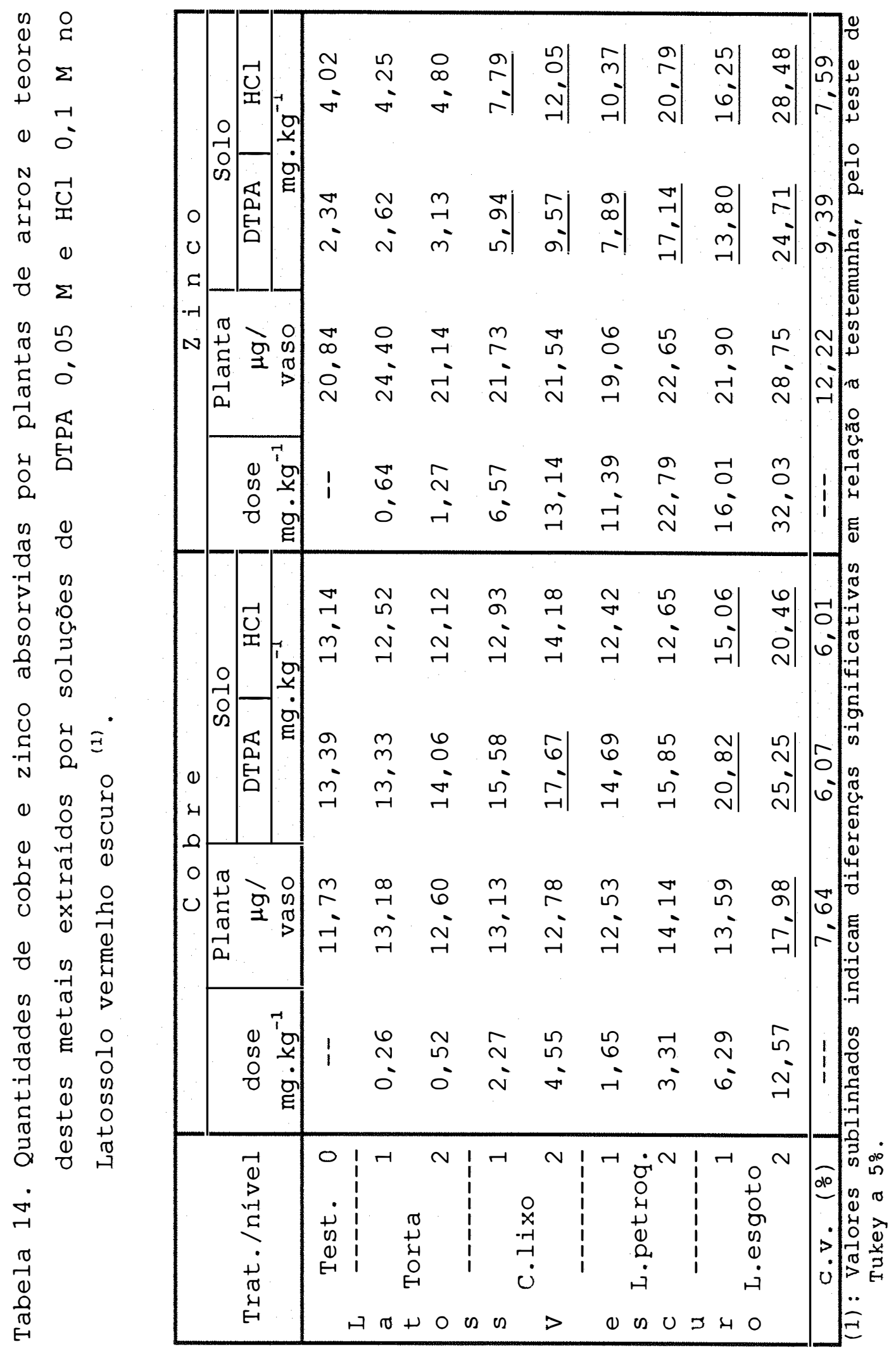







O Zinco apresentou um comportamento crescente, em função das doses, apenas com relação aos dois extratores, não mostrando correspondência com os dados em planta, fato confirmado pelas equações da Tabela 16. Nesta, observa-se que os coeficientes de determinação das regressões para quantidades totais do cobre na planta em função dos seus teores no solo apresentam valores razoáveis para DTPA e HCl. Já para o zinco, em nenhum dos casos observa-se uma relação estreita entre estas variáveis, mostrando que as plantas não responderam ao zinco aplicado via resíduos orgânicos.

Tabela 16. Regressões lineares para cobre e zinco na planta em função dos seus teores nos solos, extraídos por soluções de DTPA 0,05 M e Hcl 0,1 M.

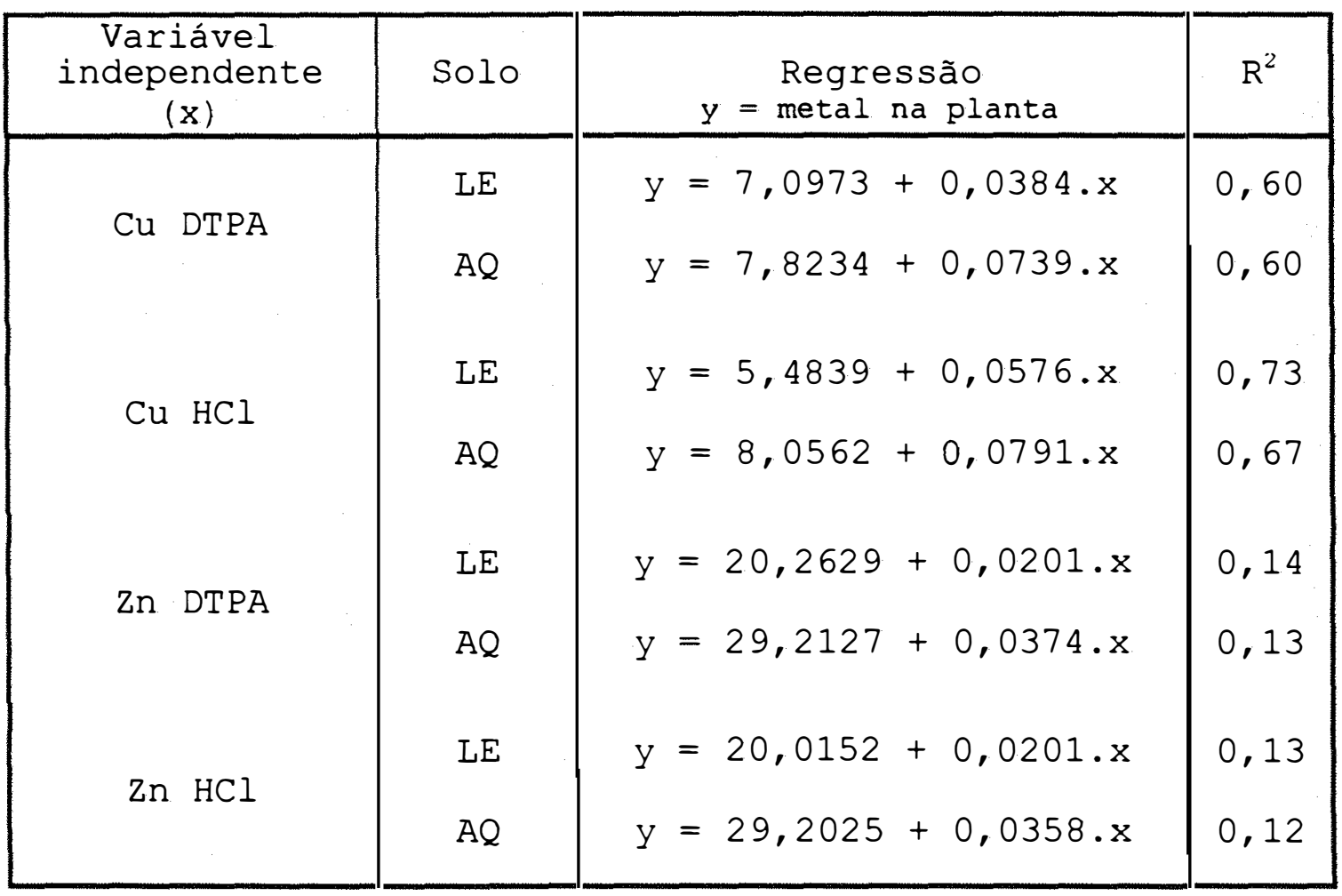


Regressões polinomiais não foram determinadas para $\mathrm{Cd}, \mathrm{Ni}$ e $\mathrm{Cr}$ devido a só ter ocorrido absorção pelas plantas nos tratamentos com lodo de esgoto, uma vez que se pretendia analisar a disponibilidade dos metais provenientes dos diversos residuos de forma conjunta.

De uma forma geral os dados mostram, para os cinco metais estudados, que o DTPA 0,05 M foi eficiente na extração de formas ligadas à matéria orgânica e que o $\mathrm{HCl}$ $0,1 \mathrm{M}$ retirou quantidades semelhantes às totais. Os extratores mostraram ainda capacidade de deteç̧ão do metal em função da dose aplicada. Na previsão de quantidades fitodisponíveis estes mostraram-se eficientes, exceto para para o zinco. A ausência de teores detectáveis no extrator salino indica a não ocorrência, no solo, de formas livres de metais neste estudo.

A absorção de cádmio níquel e crômio pela plantas ocorreu em valores detectáveis a partir de adições, ao LE, de respectivamente $0,15,2,97$ e 4,29 $\mathrm{mg}$ por $\mathrm{kg}$ de solo e, na $A Q$, a partir de $0,12,2,33 \mathrm{e} 3,35 \mathrm{mg} \cdot \mathrm{kg}^{-1}$. Estes valores merecem ser destacados por serem relativamente baixos em relação a taxas de aplicação recomendadas na literatura, tendo, mesmo assim, expressado a sua fitodisponibilidade. 


\subsubsection{Efeito na capacidade de retenção de água dos solos.}

As curvas de umidade versus tensão aplicada em amostras de solos tratadas com os residuos utilizadas neste estudo são apresentadas nas figuras 8 e 9, referindose, respectivamente, aos solos $L E$ e $A Q$. Os valores médios observados constam da Tabela 21 do APENDICE.

É importante salientar que a faixa de tensão empregada neste trabalho representa um intervalo muito pequeno da curva característica de umidade do solo, referindo-se, portanto, à água retida a baixos níveis de energia, não permitindo inferências a respeito do que possa ocorrer a maiores tensões. Por outro lado, situa-se em faixa de umidade considerada na literatura como próxima à capacidade de campo dos solos estudados e apresenta a utilidade de analisar o comportamento da água mais facilmente perdida por drenagem, que pode carregar, através do perfil de solo, elementos ou compostos indesejáveis.

A adição de materiais orgânicos revelou, no IE, aumento da capacidade de retenção de água nos tratamentos com torta de filtro e lodo de esgoto na dose 1 e com os quatro resíduos na dose 2. Estas alterações de comportamento expressam-se principalmente às tensões de 10 e $15 \mathrm{kPa}\left(1,0\right.$ e $\left.1,5 \mathrm{~m} \mathrm{H} \mathrm{H}_{2} \mathrm{O}\right)$. Melhoria de atributos físicos tais como agregação e porosidade refletem-se, entre outras, em propriedades hídricas do solo. A conhecida eficácia da matéria orgânica como agente cimentante, aliada certamente ao teor de argila deste solo, produziu os efeitos observados. Os diferentes comportamentos ocorridos quando da aplicação dos diversos resíduos, sabendo-se que as doses eram idênticas em carbono, demonstram que a natureza destes é fator determinante deste comportamento. 


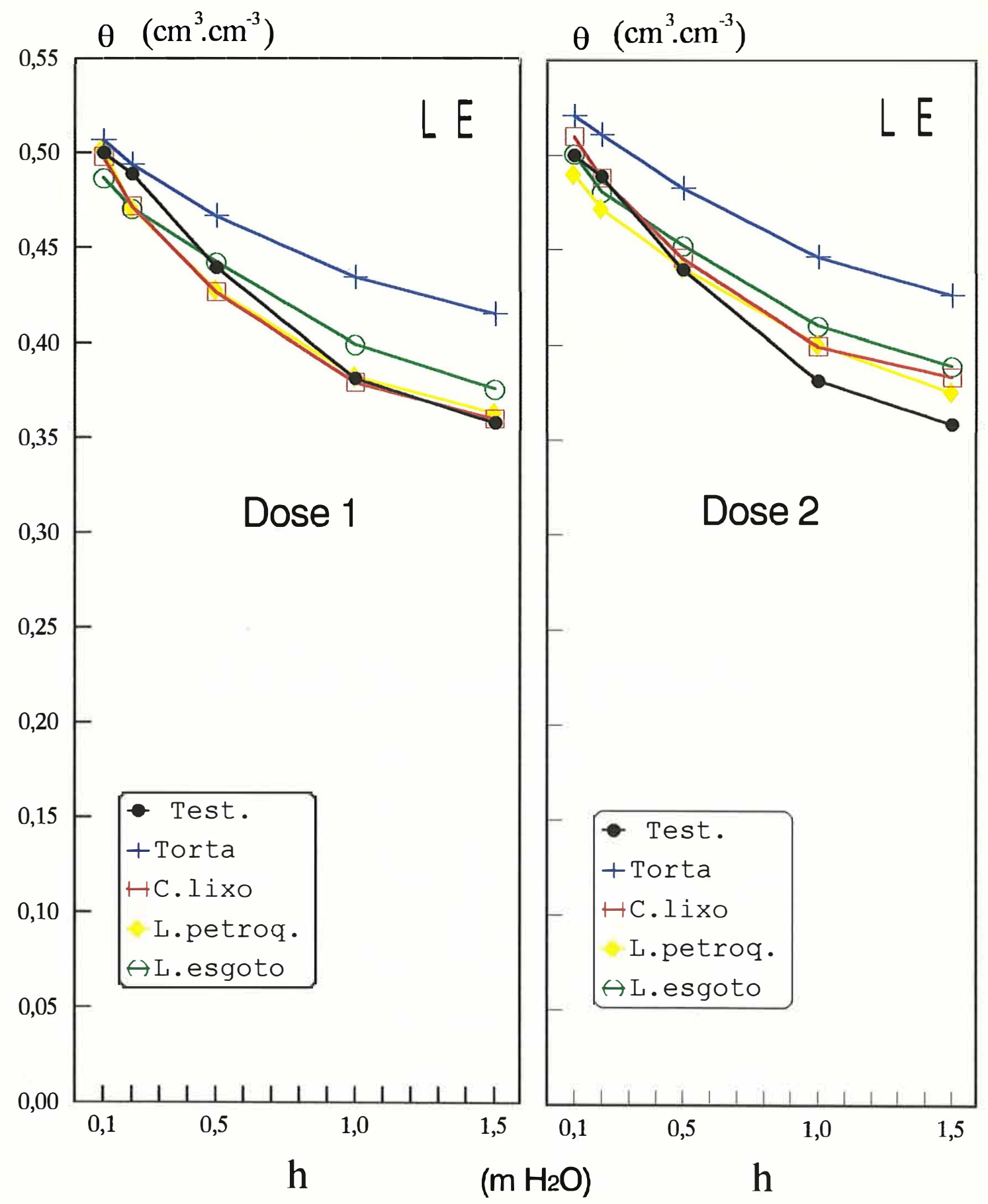

Figura 8. Curvas de umidade volumétrica $(\theta)$ em função da tensão aplicada a amostras de Latossolo Vermelho-escuro incubadas com quatro diferentes materiais orgânicos em duas doses. 


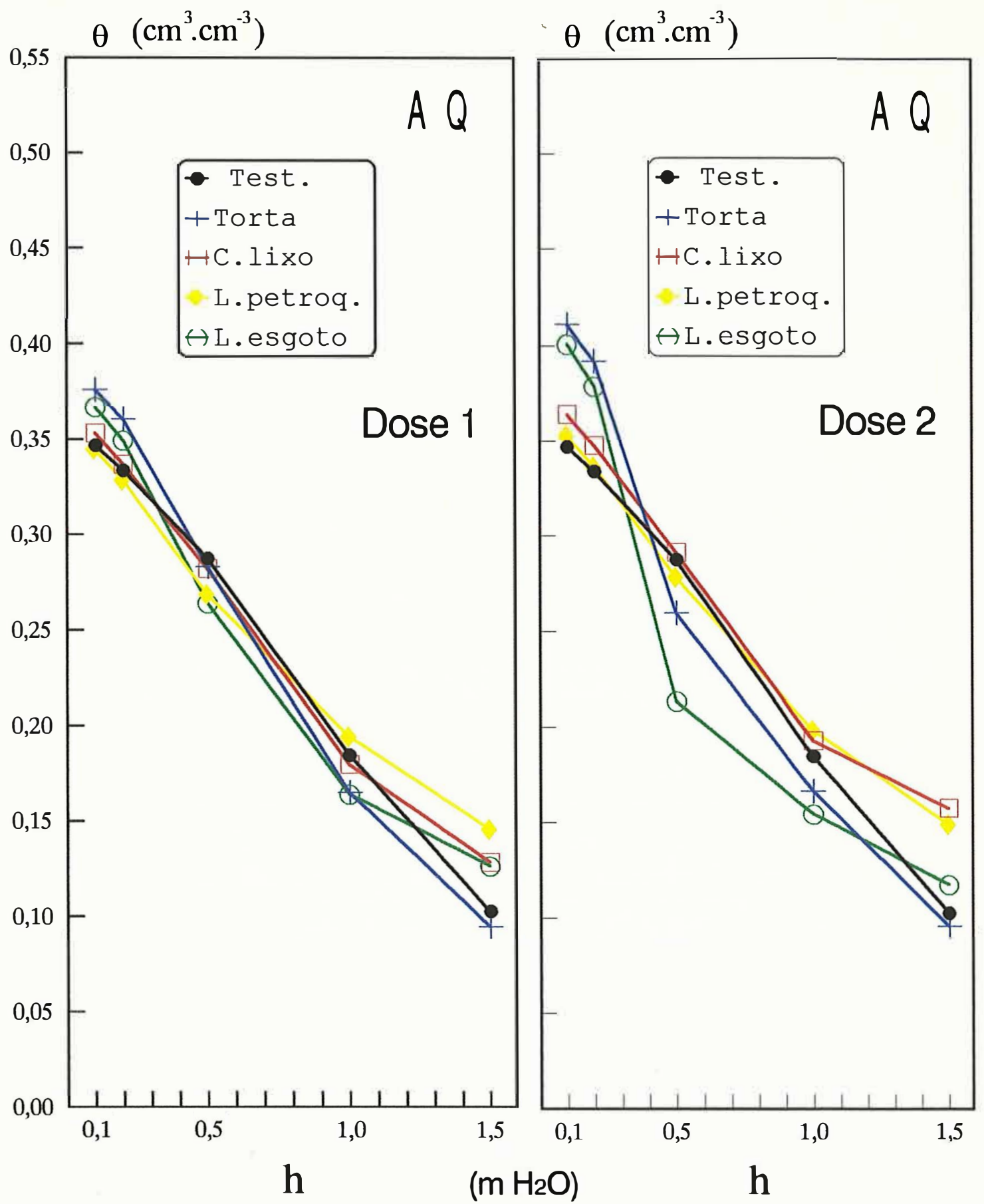

Figura 9. Curvas de umidade volumétrica $(\theta)$ em função da tensão aplicada a amostras de Areia Quartzosa distrófica incubadas com quatro diferentes materiais orgânicos em duas doses. 
Na Areia Quartzosa observa-se uma grande diversidade de comportamentos, sendo, para torta de filtro e lodo de esgoto, inverso ao observado no solo argiloso, no qual estes materiais mostraram as maiores contribuições. Este efeito negativo expressa-se principalmente entre os pontos a 0,5 e $1,0 \mathrm{~m}$ de $\mathrm{H}_{2} \mathrm{O}$. No entanto, as curvas para 0 lodo de esgoto mostraram tendência de alteração deste comportamento, entre 1,0 e $1,5 \mathrm{~m}$, enquanto a testemunha $\mathrm{e} a$ torta de filtro apresentavam as maiores perdas de água com - aumento das tensões aplicadas. O lodo petroquímico e o composto de lixo mostraram os melhores resultados neste solo. Mais importante que a observação de efeitos pontuais, é a avaliação das curvas relativas a cada material e, desta forma, nota-se que o composto de lixo, o lodo petroquímico e o lodo de esgoto tendem a superar o tratamento testemunha, e, a torta de filtro, aproxima-se desta tendendo a igualar-se.

Apesar de efeitos apresentados a um único valor de tensão não fornecerem uma idéia da dinâmica do comportamento da água no solo, pode-se tentar observar se estes relacionam-se com a capacidade de retenção de água dos materiais orgânicos. Visando avaliar a utilidade de observaões deste tipo são apresentadas, na Tabela 17, correlações lineares determinadas entre a umidade volumétrica dos solos à tensão de $10 \mathrm{kPa}\left(1 \mathrm{~m} \mathrm{H}_{2} \mathrm{O}\right.$ ) e a água retida pelos resíduos em duas condições (Tabela 2, p.29), separando-se as duas doses resíduos empregadas. Pelas equações obtidas, os dados no LE revelaram uma correspondência com o atributo original do material orgânico. Nota-se ainda que a umidade determinada nos resíduos, em equilíbrio com a pressão atmosférica (CR) e à tensão de $10 \mathrm{kPa}$, resultaram em coeficientes de regressão semelhantes, revelando ausência de vantagens das medidas 
efetuadas a esta tensão. No solo AQ observa-se um efeito negativo, fato devido aos dados obtidos nos tratamentos com torta de filtro e lodo de esgoto serem inferiores aos da testemunha neste nível de tensão. Os baixos coeficientes de determinação neste caso mostram que estas equações não explicam o fenômeno satisfatoriamente. Acentua-se ainda que, as regressões determinadas para o solo arenoso, fariam previsões inversas às que seriam obtidas caso se tomasse, como variável dependente, as medidas efetuadas à tensão de $1,5 \mathrm{~m}$.

Tabela 17. Regressões lineares para umidade volumétrica $(\theta)$, à tensão de $10 \mathrm{kPa}$, de dois solos tratados com quatro resíduos orgânicos, em função da capacidade de retenção de água destes residuos(1).

\begin{tabular}{|c|c|c|c|}
\hline $\begin{array}{c}\text { Variável } \\
\text { independente } \\
(\mathrm{x})\end{array}$ & $\begin{array}{l}\text { Solo } / \\
\text { dose }\end{array}$ & Regressão & $\mathrm{R}^{2}$ \\
\hline $\mathrm{CR}$ & $\begin{array}{l}1 \\
2\end{array}$ & $\begin{array}{l}\theta=0,3728+0,000009 . x \\
\theta=0,3831+0,000009 . x\end{array}$ & $\begin{array}{l}0,74 \\
0,75\end{array}$ \\
\hline $\mathrm{CR}$ & $\begin{array}{l}1 \\
2\end{array}$ & $\begin{array}{l}\theta=0,1880-0,000004 . \mathrm{x} \\
\theta=0,1924-0,000005 . \mathrm{x}\end{array}$ & $\begin{array}{l}0,33 \\
0,31\end{array}$ \\
\hline $\mathrm{U} 10 \mathrm{kPa}$ & $\begin{array}{l}1 \\
2\end{array}$ & $\begin{array}{l}\theta=0,3714+0,000016 . x \\
\theta=0,3810+0,000017 . x\end{array}$ & $\begin{array}{l}0,68 \\
0,72\end{array}$ \\
\hline $\mathrm{U} 10 \mathrm{kPa}$ & $\begin{array}{l}1 \\
2\end{array}$ & $\begin{array}{l}\theta=0,1884-0,000007 . x \\
\theta=0,1934-0,000009 . x\end{array}$ & $\begin{array}{l}0,29 \\
0,30\end{array}$ \\
\hline
\end{tabular}


Todos os resíduos empregados possuem elevada capacidade de retenção de água e, apesar disto, nem sempre contribuiram com este atributo na $\mathrm{AQ}$, ocorrência contrária à observada no solo argiloso. Estes fatos indicam que é a interação de fatores relacionados com a natureza dos resíduos e dos solos, que irá determinar o comportamento resultante, ou seja, apenas atributos relativos ao material orgânico são insuficientes para previsões desse tipo. Desta forma, caso se pretenda obter uma explicação matemática deste comportamento deve ser testada a contribuição de outros parâmetros, como, por exemplo, o teor de argila do solo.

A Tabela 18 apresenta valores relativos a alguns atributos físicos dos solos tratados com os quatro resíduos. Para densidade do solo e densidade de partículas não foram observados efeitos dignos de nota. A porosidade total, calculada pela relação entre estas densidades, também não mostra grandes diferenças. Para se observar efeitos na distribuição de poros do solo elegeu-se a tensão de $10 \mathrm{kPa}\left(\mathrm{h}=1,0 \mathrm{~m} \mathrm{H}_{2} \mathrm{O}\right) \quad \mathrm{e}$, a partir da fórmula apresentada no ítem 3.3.3, determinou-se o diâmetro máximo dos poros que retiam a água determinada nesta condição, chegando-se ao valor de $30 \mathrm{\mu m}$. Calculou-se então que percentagens da porosidade total correspondiam a poros de diâmetros menores que o valor calculado.

Com estes dados, observa-se que no LE houve um aumento, em relação à testemunha, na percentagem de poros menores que $30 \mu \mathrm{m}$ nas dose 1 e 2 de torta de filtro e na dose 2 de composto de lixo, lodo petroquímico e lodo de esgoto. Isto revela um aumento na quantidade de água retida a tensões maiores que $1 \mathrm{~m}$, 0 que pode ser benéfico por dificultar a perda de água através do perfil do solo. 
Tabela 18. Valores de densidade, porosidade total e de percentagem desta porosidade com diâmetro menor ou igual a $30 \mu \mathrm{m}$, em amostras de dois solos tratados com quatro diferentes materiais orgânicos.

\begin{tabular}{|c|c|c|c|c|}
\hline \multirow{3}{*}{$\begin{array}{r}\text { Trat. / dose } \\
\end{array}$} & \multicolumn{2}{|c|}{ Densidade } & \multicolumn{2}{|c|}{ Porosidade } \\
\hline & solo & partículas & total & $<30 \mathrm{um}$ \\
\hline & \multicolumn{2}{|c|}{$\mathrm{Mg} \cdot \mathrm{m}^{-3}$} & \multicolumn{2}{|c|}{$\left(\frac{\circ}{0}\right)$} \\
\hline Test. 0 & 1260 & 2700 & 53,40 & 71,5 \\
\hline $\begin{array}{lr}\mathrm{L} & -------- \\
\mathrm{a} & 1\end{array}$ & 1300 & 2750 & 52,91 & 82.3 \\
\hline t Torta & & & & \\
\hline & 1260 & 2780 & 54,77 & 81,6 \\
\hline $\begin{array}{cr}s & -------- \\
s & 1\end{array}$ & 1270 & 2780 & $54 \quad 40$ & 690 \\
\hline C.Iixo & & & & ( \\
\hline $\mathrm{V} \quad 2$ & 1310 & 2800 & 53,13 & 75,3 \\
\hline e & 1260 & 2790 & 54,90 & 69,8 \\
\hline s L.petroq & & & & \\
\hline $\begin{array}{lr}\mathrm{C} & 2 \\
\mathrm{u} & --------\end{array}$ & 1290 & 2770 & 53,51 & 74,9 \\
\hline$r$ & 1260 & 2940 & 56,88 & 70,4 \\
\hline $\begin{array}{r}0 \\
\text { L.esgoto } \\
2\end{array}$ & 1260 & 2840 & 55,46 & 74,0 \\
\hline C.V. ( $\left(\frac{\circ}{0}\right)$ & 2,79 & 3,15 & 3,79 & 6,42 \\
\hline Test. 0 & 1660 & 2680 & 38,10 & 48,5 \\
\hline A $\quad---\cdots--$ & & & & \\
\hline 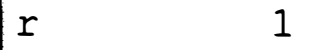 & 1610 & 2680 & 40,01 & 41,4 \\
\hline $\begin{array}{ll}\text { e } & \text { Torta } \\
i & \end{array}$ & 1600 & 2740 & 41,49 & 40,3 \\
\hline a $\quad-------$ & 1610 & 2680 & & 5 \\
\hline Q C.Iixo & & & & 40,0 \\
\hline$u$ & 1630 & 2640 & 38,19 & 50,6 \\
\hline-------- & 1620 & $? 6 ? 0$ & $r$ & 50 \\
\hline $\begin{array}{ll}I & \text { L.petrog }\end{array}$ & $16<0$ & $\angle 6<0$ & 38,36 & 50,8 \\
\hline$z$ & 1660 & 2640 & 37,14 & 53,5 \\
\hline -ー-ーーーーー & & & & \\
\hline 1 & 1610 & 2630 & 38,86 & 42,4 \\
\hline 2 & 1550 & 2630 & 41,12 & 37,7 \\
\hline C.V. (잉 & 2,33 & 1,03 & 4,1 & 7,40 \\
\hline
\end{tabular}


No solo AQ observa-se um decréscimo desta fração da porosidade, nas dose 1 e 2 de torta de filtro e de lodo de esgoto. Este comportamento revela um aumento na quantidade de poros de maior calibre, nos quais a água encontra-se retida com menor energia.

Uma outra maneira de interpretar os efeitos dos tratamentos é observar diferenças entre teores de água disponível no solo. Para tanto pode-se fazer a subtração entre pontos da curva de retenção e, multiplicando-se este resultado de umidade por uma determinada profundidade, chega-se a valores de diferenças de armazenagem de água do solo, expressas em milímetros. Valores referentes a estes cálculos são apresentados na Tabela 19. Para a sua obtenção as curvas das figuras 8 e 9 foram divididas em dois intervalos, correspondentes às tensões situadas entre 0,1 e $1,0 \mathrm{~m}$, e entre 1,0 e $1,5 \mathrm{~m}$ de coluna de água. A profundidade adotada foi a de uma camada de $10 \mathrm{~cm}$ de solo.

Comparando com o tratamento testemunha, observa-se que, no LE, houve uma diminuição na quantidade de água disponível entre as tensões de 0,1 e 1,0 m com a aplicação de torta de filtro e lodo de esgoto na dose $1 . \mathrm{Na}$ dose 2 este efeito ocorre também para o lodo petroquímico. No intervalo de tensão de 1,0 a $1,5 \mathrm{~m}$, nesta dose, os valores apresentam-se próximos à testemunha, nos tratamentos com torta, lodo petroquímico e lodo de esgoto. Observa-se, portanto, decréscimo na faixa de 0,1 a $1,0 \mathrm{~m}$ e valores semelhantes entre 1,0 e $1,5 \mathrm{~m}$. O comportamento do LE quanto a este aspecto não significa que houve diminuição de disponibilidade de água para as plantas, visto que estas têm capacidade de retirar água do solo a tensões muito mais elevadas do que as empregadas neste estudo. Revela, no entanto, que uma fração da água mais facilmente perdida em 
um perfil de solo passou a ser retida mais fortemente, o que pode ser um aspecto positivo deste efeito.

Tabela 19. Diferenças de armazenagem de água $(\Delta h)$ calculadas para uma camada de $10 \mathrm{~cm}$ de solo, entre as tensões de 0,1 e $1,0 \mathrm{~m}$ e de 1,0 a $1,5 \mathrm{~m}$ de coluna de água, em dois solos incubados com quatro materiais orgânicos em diferentes doses.



Quanto à areia quartzosa, a aplicação de torta e lodo de esgoto nas duas doses provocou um sensível acréscimo de água disponível entre as tensões de 0,1 e 1,0 $\mathrm{m} \mathrm{H}_{2} \mathrm{O}$. Já entre 1,0 e $1,5 \mathrm{~m} \circ$ decréscimo apresentado confirma, neste caso, o aumento na quantidade água mais 
fracamente retida. Embora este efeito possa facilitar o consumo de água pelas plantas, esta água pode se movimentar mais facilmente através do perfil de solo, fato indesejável, caso se esteja adicionando a este, materiais contendo substâncias tóxicas. O composto de lixo e o lodo petroquímico, nas duas doses, apresentaram comportamento semelhante à testemunha na faixa de 0,1 a $1,0 \mathrm{~m}$ e um decréscimo no intervalo de 1,0 a $1,5 \mathrm{~m}$, revelando um aumento da quantidade de água retida mais fortemente, aspecto este interessante, quanto a uma possível diminuição do risco de poluição de camadas mais profundas do solo.

Os dados apresentados mostram, de uma forma geral, que o solo argiloso respondeu positivamente à aplicação de resíduos orgânicos, quanto aos parâmetros observados, enquanto que no solo arenoso os efeitos foram até desfavoráveis em alguns casos. É importante que sejam salientados os estreitos limites dentro dos quais o estudo foi desenvolvido, o que torna necessário que trabalhos em faixas mais abrangentes sejam feitos no sentido de se coletar informações mais completas.

Com relação às respostas apresentadas pela Areia Quartzosa, deve ser ressaltado que não significam, necessariamente, uma ausência de benefícios da aplicaçào de materiais orgânicos, já que isto foi observado para um pequeno número de parâmetros. Com relação à retenção de água, ficou claro que, caso se aplique uma mesma quantidade de energia ao solo arenoso tratado ou não com os resíduos estudados, este vai reter água de maneira semelhante. Por outro lado, a forma de aquisição desta energia pode ocasionar comportamentos diferentes conforme o caso. 0 elevado calor específico da materia orgânica faz com que solos que a contenham em grande quantidade se aqueçam mais lentamente. Deste modo, perdas de água por evaporação serão 
retardadas, permitindo que a água contida no solo permaneça neste por mais tempo. Trabalhos como o de TESTER (1990), no qual observaram-se valores de umidade de um solo muito arenoso, no campo, mais elevados em parcelas tratadas com resíduos, mostram um benefício da adição de matéria orgânica, quanto à conservação da umidade. Assim sendo, estudos abordando outros parâmetros, por exemplo, alterações no calor específico de solos onde se aplicou resíduos, poderão trazer informações que conduzam a uma compreensão mais ampla dos fenômenos relacionados com esta prática.

\subsection{Considerações finais.}

Os resultados apresentados mostraram que a capacidade de troca catiônica e a capacidade de retenção de água, como parâmetros de caracterização de resíduos orgânicos, não são suficientes para prever comportamentos resultantes da sua adição ao solo quanto a estes atributos. Isto sugere que, para estimar com segurança estes efeitos, são imprescindíveis os estudos de incubação dos resíduos nos solos onde serão utilizados.

- estudo dos efeitos da aplicação de materiais orgânicos a solos, realizado neste trabalho, contemplou diversos outros parâmetros, dos quais se pode lançar mão para a previsão de comportamentos decorrentes desta adição. Estes parâmetros, tendo sido coletados dentro de condições bem específicas, são úteis, tão somente, para indicar tendências de respostas às intervenções promovidas. 
Deste modo, inferências que venham a ser feitas, embora possam contribuir com a busca de procedimentos seguros para - manejo de resíduos na agricultura, não dispensam o monitoramento em condições reais, visto que serão estas, de fato, que determinarão as conseqüências destas intervenções no ambiente. 


\section{CONCLUSÕES.}

a) Quanto à determinação das quantidades de $\mathrm{CO}_{2}$ emanadas do solo, os sistemas dinâmico e fechado são equivalentes, desde que, neste último, mantenham-se intervalos de aeração adequados a cada fase do estudo.

b) Dos resíduos adicionados aos solos, o que apresenta a maior velocidade de decomposição é a torta de filtro, seguida do lodo de esgoto, composto de lixo e lodo petroquímico.

c) O aumento das doses dos resíduos estudados provoca o decréscimo da sua taxa de decomposição no solo.

d) O método de respirometria possui maior sensibilidade do que a determinação de carbono do solo para a observação da cinética de decomposição de materiais orgânicos.

e) Mudanças na CTC a pH7 dos solos, pela adição de materiais orgânicos, ocorrem principalmente em função de. alterações no $\mathrm{pH}$ decorrentes desta prática. 
f) As soluções de DTPA $0,05 \mathrm{M}$ e $\mathrm{HCl} 0,1 \mathrm{M}$ mostram-se eficientes na deteç̧ão da fitodisponibilidade de cádmio, níquel, crômio e cobre, não se revelando eficazes com relação ao zinco.

g) Os metais cádmio, níquel e crômio expressam fitodisponibilidade mesmo em pequenas taxas de aplicação, como as empregadas neste estudo.

h) Dentro dos limites considerados neste estudo, a adição de materiais orgânicos promove $\circ$ aumento da capacidade de retenção de água do solo argiloso. Já no solo arenoso, este efeito não é evidente.

i) A CTC e a capacidade de retenção de água, como parâmetros de caracterização de resíduos orgânicos, não são suficientes para prever comportamentos resultantes da sua adição ao solo quanto a estes atributos. 


\section{REFEREANCIAS BIBLIOGRÁFICAS}

ADRIANO, D.C. Trace elements in the terrestrial environment. New York, Springer-Verlag, 1986. 533p.

BACHE, B.W. The measurement of cation exchange capacity of soils. Journal of the Science of Food and Agriculture, London, $27(3): 273-80,1976$.

BARTHA, R. $\mathcal{E}$ PRAMER, D. Features of a flask and method for measuring the persistense and biological effects of pesticides in soil. Soil science, Baltimore, 100(1): 68-70, 1965.

BASCOMB, C.I. Rapid method for the determination of cation-exchange capacity of calcareous and noncalcareous soils. Journal of the science of Food and Agriculture, London, 15: 821-3, 1964.

BAVER, L.D.; GARDNER, W.H.; GARDNER, W.R. Soil physics. 4.ed. New York, John Wiley, 1972. 498p.

BEVAQUA, R.F. $\mathcal{E}$ MELLANO, V.J. Cumulative effects of sluge compost on crop yields and soil properties. Communications in Soil Science and Plant Analysis, New York, 25(3/4): 395-406, 1994. 
BoUYoUCOS, G.J. Effect of organic matter on the waterholding capacity and the wilting point of mineral soils. Soil science, Baltimore, 47: 377-83, 1939.

BOWER, C.A.; HARPER, W.G.; MOODIE, C.D.; OVERSTREET, R.; RICHARDS, L.A. Apparatus for studiyng biochemical transformations in incubated soils. Soil science Society of America Proceedings, Madison, 22(3): 270-1, 1958 .

BOYLE, M. $\mathcal{E}$ PAUL, E.A. Carbon and nitrogen mineralization kinetics in soil previously amended with sewage sludge. Soil Science Society of America Journal, Madison, 53(1): 99-103, 1989 .

BRAMS, E. E ANTHONY, W. Residual cadmium in a soil profile and accumulation to wheat grain. Plant and soil, The Hague, $109(1): 3-8,1988$.

BROWN, J.R. $\mathcal{E}$ BRUSH, L. Lime stabilized sludge treatment of acid soils relative to soil acidity minimuns for sludge application. Communications in soil science and Plant Analysis, New York, 23(11/12): 1257-73, 1992.

BUCHANAN, M. E GLIESSMAN, S. How compost fertilization affects soil nitrogen and crop yield. Biocycle, Emmaus, $32(12): 72-7,1991$.

CASARINI, D.C.P.; MACEDO, R.M.; CUNHA, R.C.A.; MAUGER, J.C.O. The development of assessment techniques to evaluate the biodegradation of oily sludge in a 
landfarming system. Water Science and Technology, London, 20(10): 231-6, 1988.

CATANI, R.A. E BERGAMIN FILHO, H. Sobre uma modificação no método de NEUBAUER. Anais da Escola Superior de Agricultura "Luiz de Queiroz", Piracicaba, 18:193-204, 1961 .

CAVALLARO, N.; PADILLA, N.; VILLARRUBIA, J. Sewage sludge effects on chemical properties of soils. Soil science, Baltimore, 156(2): 62-70, 1993.

CERRI, C.C.; ANDREUX, F.; EDUARDO, B.P.; CHONE, T.; PICCOLO, M.C. Incubador para estudos sobre decomposição de material orgânico no solo. Revista Brasileira de Ciência do Solo, Campinas, 18(1): 1-5, 1994.

CHANG, A.T.; GRANATO, T.C.; PAGE, A.L. A metodology for stablishing phytotoxicity criteria for chromium, copper, nickel, and zinc in agricultural land application of municipal sewage sludges. Journal of Environmental Quality, Madison, 21(4): 521-36, 1992.

COSTA, M.P. Efeito da matéria orgânica em alguns atributos do solo. Piracicaba, 1983. 137p. (Doutorado - Escola Superior de Agricultura "Luiz de Queiroz"/USP).

EPENIBU, O. $\mathcal{E}$ NWADIALO, B. Predicting soil water availability from texture and organic matter content for nigerian soils. Communications in Soil Science and Plant Analysis, New York, 24(7/8): 633-40, 1993. 
EPSTEIN, E.; TAYLOR, J.M.; CHANEY, R.L. Effects of sewage sludge compost applied to soil on some soil physical and chemical properties. Journal of Environmental Quality, Madison, 5(4): 422-6, 1976.

FINE, P.; MINGELGRIN, U.; FEIGIN, A. Incubation studies of the fate of organic nitrogen in soils amended with activated sludge. Soil Science Society of America Journal, Madison, 53(2): 444-50, 1989.

FONTES LIMA, F. $\varepsilon$ ALVES PEREIRA, F. Advances in residual processing, treatment and disposal for chemical and petrochemical industries - a brasilian case study. Water Science and Technology, Oxford, 25(3): 173-81, 1992.

FORTUN, A.; FORTUN, C.; ORTEGA, C. Effect of farmyard manure and its humic fractions on the aggregate stability of a sandy loam soil. Journal of soil Science, Oxford, 40(2): 293-8, 1989.

GILLMAN, G.P. A proposed method for the measurement of exchange properties of highly weathered soils. Autralian Journal of Soil Research, Melbourne, 17(1): 129-39, 1979.

GIUSQUiAnI, P.L.; MARUCChINI, C. ; BUSINELli, M. Chemical properties of soils amended with compost of urban waste. Plant and Soil, The Hague, 109(1): 73-8, 1988. 
GIUSQUIANI, P.L.; PAGLIAI, M.; GIGLIOTTI, G.; BUSINELLI, D.; BENETTI, A. Urban waste compost: Effects on physical, Chemical and biochemical soil properties. Journal of Environmental Quality, Madison, 24(1): 175$82,1995$.

GLÓRIA, N.A. Residuos Industriais Como Fonte de Matéria Orgânica. In: ENCONTRO SOBRE MATÉRIA ORGÂNICA NO SOLO: PROBLEMAS E SOLUÇÕES, Botucatu, 1992. Anais. Botucatu: UNESP/Faculdade de Ciências Agronômicas, 1992. p.129-48

GLÓRIA, N.A.; CATANI, R.A.; MATUO, T. Determinação da Capacidade de troca de cátions, do solo por fotometria de chama. Anais da Escola Superior de Agricultura "Iuiz de Queiroz", Piracicaba, 22:3-9, 1965.

GRISI, B.M. Metodologia de determinação de biomassa microbiana de solo. Revista Brasileira de Ciência do Solo, Campinas, 8(2): 167-72, 1984.

GUPTA, S.C.; DOWDY, R.H.; LARSON, W.E. Hydraulic and thermal properties of a sandy soil as influenced by incorporation of sewage sludge. Soil science society of America Journal, Madison, 41(3): 601-5, 1977.

HADAS, A. E PORTNOY, R. Nitrogen and carbon mineralization rates of composted manures incubated in soil. Journal of Environmental Quality, Madison, 23(6): 1184-9, 1994.

HADDAD, K.S. E EVANS, J.C. Assessment of chemical methods for extracting zinc, manganese, copper, and iron from 
New South Wales soils. Communications in Soil science and Plant Analysis, New York, 24(1/2): 29-44, 1993.

HÄNI, H. $\varepsilon$ GUPTA, S. Reasons to use neutral salts solutions to assess the metal impact on plant and soils. In: LESCHBER, R.; DAVIES, R.D.; L'HERMITÉ, P., ed. Chemical methods for assessing bioavailability. London, Elsevier, 1985. p.42-8.

HAYES, A.R.; MANCINO, C.F.; PEPPER, I.L. Irrigation of turfgrass with secondary sewage effluent: $I$. Soil and leachate water quality. Agronomy Journal, Madison, 82: $939-43,1990$.

HELLING, C.S.; CHESTERS, G.; COREY, R.B. Contribution of organic matter and clay to soil cation-exchange capacity as affected by the $\mathrm{pH}$ of the saturating solution. Soil Science Society of America Proceedings, Madison, 23(4): $517-20,1964$.

HERNANDEZ, T.; COSTA, F.; LAX, A.; CEGARRA, J.; ROIG, A.; MORENO, J.I. Transformations of carbon and nitrogen in a Calciorthid soil amended with a range of organic residues. Plant and Soil, The Hague, 105(2): 205-11, 1988 .

HERNANDEZ, T.; GARCIA, C.; COSTA, F.; VALERO, J.A.; AYUSO, M. Utilizacion de residuos urbanos como fertilizantes orgânicos. Suelo Y Planta, Madrid, 2(3): 373-83, 1992.

JENKINSON, D.S. E POWLSON, D.S. The effects of biocidal treatments on metabolism in soil - 1. Fumigation of 
chloroform. Soil Biology and Biochemistry, Oxford, $8(1): 167-77,1976$.

JENKINSON, D.S. Studies on the decomposition of plant material in soil. IV. The effect of rate of addition. Journal of Soil Science, Oxford, 28: 417-23, 1977.

JING, J. $E$ LOGAN, T.J. Effects of sludje cadmium concentration on chemical extractability and plant uptake. Journal of Environmental Quality, Madison, $21(1): 73-81,1992$.

KHALEEL, R.; REDDY, K.R.; OVERCASH, M.R. Changes in soil physical properties due to organic waste application: A review. Journal of Environmental Quality, Madison, $10(2): 133-41,1981$.

KIHEL, E.J. Fertilizantes orgânicos. São Paulo, Agronômica Ceres, 1985. 492p.

KING, L.D. E HAJJAR, L.M. The residual effect of sewage sludje on heavy metal content of tobacco and peanut. Journal of Environmental Quality, Madison, 19(4): 73848,1990 .

KIRKHAM, M.B. Disposal of sludge on land: Effect on soils, plants, and ground water. Compost Science, Emmaus, $15(1): 6-10,1974$.

KLUTE, A. E JACOB, W.C. Physical properties of sassafras silt loam as affected by long-time organic matter 
additions. Soil Science Society of America Proceedings, Madison, 14: 24-8, 1949.

LIBARDI, P.L. Dinâmica da água no solo. Piracicaba, 0 autor, 1995. 497p.

LIBARDI, P.L. E SAAD, A.M. Balanço hídrico em cultura de feijão irrigada por pivô central em Latossolo Roxo. Revista Brasileira de Ciência do Solo, Campinas, 18(3): $529-32,1994$.

LINDSAY, W.L. $E$ NORVELL, W.A. Development of a DTPA soil test for zinc, iron, manganese an copper. Soil science Society of America Journal, Madison, 42:421-8, 1978.

MANAHAN, S.E. Environmental chemistry. 4.ed. Chelsea, Lewis Publ., 1990. 612p.

MATTIAZZO-PREZOTTO, M.E. Comportamento de cobre, cádmio, crômio, níquel e zinco adicionados a solos de clima tropical em diferentes valores de pH. Piracicaba, 1994. 197p. (Livre-docência - Escola Superior de Agricultura "Luiz de Queiroz"/USP).

MATTIAZZO, M.E. E GLÓRIA N.A. Effect of vinasse on soil acidity. Water Science and Technology, London, 19(7): $1293-6,1987$.

MATTIAZZO, M.E. E GLÓRIA, N.A. Parâmetros para adição a solos de resíduos contendo metais. I: Estudos com soluções. In: CONGRESSO BRASILEIRO DE CIÊNCIA DO SOLO, 
25., Viçosa, 1995. Anais. Viçosa, SBCS, 1995. v.4., p. 2315-17.

MBAGWU, J.S.C. Effects of organic amendments on some physical properties of a tropical ultisol. Biological Wastes, Essex, 28(1): 1-13, 1989.

MCBRIDE, M.B. Toxic metal accumulation from agricultural use of sludge: Are USEPA regulations protective? Journal of Environmental Quality, Madison, 24(1): 5-18, 1995.

MCLAUGHLIN, M.J. $\varepsilon$ CHAMPION, L. Sewage sludge as a phosphorus amendment for sesquioxic soils. Soil Science, Baltimore, 143(2): 113-9, 1987.

MINHONI, M.T.A.; EIRA, A.F.; CARDOSO, E.J.B.N. Efeitos da adição de $\mathrm{N}$ e $\mathrm{P}$ sobre a decomposiçào de diferentes tipos de material orgânico no solo. Revista Brasileira de Ciência do Solo, Campinas, 14(3): 297-304, 1990.

MULCHI, C.L.; ADAMU, C.A.; BELL, P.F.; CHANEY, R.L. Residual heavy metal concentration in sludge-amended coastal plain soils - I. Comparison of extractants. Communications in Soil science and plant Analysis, New York, 22(9/10): 919-41, 1991.

NAGANAWA, T.; KYUMA, K.; H., YAMAMOTO, Y.; YOKOI, H.; TATSUYAMA, K. Measurement of soil respiration in the field: influence of temperature, moisture level, and application of sewage sludge compost and agro-chemicals. 
Soil Science and Plant Nutrition, Tokyo, 35(4): 509-16, 1989 .

NDAYEGAMIE, A. E CÔTÉ, D. Effect of long-term pig slurry and solid cattle manure application on soil chemical and biological properties. Canadian Journal of Soil Science, Otawa, 69(1): 39-47, 1989.

OBI, M.E. E EBO, P.O. The effects of organic and inorganic amendments on soil physical properties and maise production in a severely degraded sandy soil in Southern Nigeria. Bioresource Technology, Essex, 51(2/3): 11723, 1995 .

OBREZA, T.A. E REEDER, R.K. Municipal solid waste compost use in tomato/watermelon successional cropping. Soil and Crop Science Society of Florida, Gainesville, 53(1): 13-9, 1994 .

PETRUZZELLI, G.; LUBRANO, L.; GUIDI. Uptake by corn an chemical and chemical extractability of heavy metals from a for year compost treated soil. Plant and Soil, The Hague, $116(1): 23-7,1989$.

RAIJ, B. van. A capacidade de troca de cátions das frações orgânica e mineral em solos. Bragantia, Campinas, $28(8): 85-112,1969$.

RAIJ, B. van; QUAGGIO, J.A.; CANTARELLA, H. FERREIRA, M.E.; LOPES, A.S.; BATAGLIA, O.C. Arálise química do solo para fins de fertilidade. Campinas, Fundação Cargill, 1987. 170p. 
REICHARDT, K. Capacidade de campo. Revista Brasileira de Ciência do Solo, Campinas, 12(3): 211-6, 1988.

RICCI, M.S.F.; CASALI, V.W.D.; RUIZ, H.A.; CARDOSO, A.A. Características físicas e químicas de solos mediante a utilização de vermicomposto. In: CONGRESSO BRASILEIRO DE CIÊNCIA DO SOLO, 24., Goiânia, 1993. Anais. Goiânia, SBCS, 1993. v.3., p.263.

ROCA, J. $\varepsilon$ POMARES, F. Prediction of available heavy metals by six chemical extractants in a sewage sludgeamended soil. Communications in Soil science and plant Analysis, New York, $22(19 / 20)$ : 2119-36, 1991.

RODELLA, A.A E ALCARDE, J.C. Avaliação de materiais orgânicos empregados como fertilizantes.

Scientia Agricola, Piracicaba, 51(3): 556-62, 1994.

RODELLA, A.A.; FISCHER, K.R.; ALCARDE, J.C. Cation exchange capacity of an acid soil as influenced by different sources of organic matter. Communications in Soil Science and Plant Analysis, New York, 26(17/18), 1995. (no prelo).

SARKIS, K. Evaluating land application effects - Results on Philadelphia sludge application program on corn and soybean fields provide useful data on heavy metal and PCB accumulation. Biocycle, Emmaus, 28(1): 27-8, 1987.

SAUERBECK, D.R. $E$ STYPEREK, P. Evaluation of chemical methods for assessing the $\mathrm{Cd}$ and $\mathrm{Zn}$ availability from 
diferent soils and sources. In: LESCHBER, R.; DAVIES, R.D.; L'HERMITÉ, P., ed. Chemical methods for assessing bioavailability. London, Elsevier, 1985. p.49-66.

SIKKA, R. $\mathcal{E}$ KANSAL, B.D. Effect of fly-ash application on yield and nutrient composition of rice, wheat, and on $\mathrm{pH}$ and available nutrient status of soils. Bioresource Technology, Essex, 51(2/3): 199-203, 1995.

SMILDE, K.W. $E$ LUIT, B. van. The extraction by soil and absorption by plants of applied zinc and cadmium. Plant and Soil, The Hague, 143(2): 233-8, 19.92.

SIMS, J.T. Nitrogen mineralization and elemental availability in soils amended with cocomposted sewage sludge. Journal of Environmental Quality, Madison, 19(4): 66975,1990 .

SMITH, S.R. $E$ HADLEY, P. Carbon and nitrogen mineralization characteristics of organic nitrogen fertilizers in a soil-less incubation system. Fertilizer Research, The Hague, 23(2): 97-103, 1990.

SOMMERFELDT, T.G.; CHANG, C.; ENTZ, T. Long-term annual manure applications increase soil organic matter and nitrogen, and decrease carbon to nitrogen ratio. soil Science Society of America Journal, Madison, $52(6)$ : $1668-72$, 1988 .

SPARLING, G.P. Ratio of microbial biomass carbon to soil organic carbon as a sensitive indicator of changes in 
soil organic matter. Australian Journal of Soil Research, Melbourne, 30: 195-207, 1992.

SPOSITO, G. The chemistry of soils. New York, Oxford University Press. 1989, 277p.

TAYLOR, R.W.; IBEABUCHI, I.O.; SISTANI, K.R.; SHUFORD, J.W. Accumulation of some metals by legumes and their extractability from acid mine spoils. Journal of Envirommental Quality, Madison, 21(2): 176-80, 1992.

TEDESCO, M.J., coord. Efeito da aplicação do lodo da estação de tratamento do SITEL/CORSAN nas plantas e no solo ( $5^{\circ}$ e $6^{\circ}$ anos); relatório final. Porto Alegre, UFRGS/Depto. de Solos, 1991. 149p.

TESTER, C.F. Organic amendment effects on physical and chemical properties of a sandy soil. Soil science Society of America Journal, Madison, 54(3): 827-31, 1990 .

TIESSEN, J.W.; STEWART, W.B.; HUNT, H.W. Concepts of soil organic matter transformations in relation to organomineral particle size fractions. Plant and soil, The Hague, $76(1 / 3): 287-95,1984$.

VALDARES, J.M.A.S.; GAL, M. ; MINGELGRIN, U.; PAGE, A.L. Some heavy metals in soils treated with sewage sludje, their effects on yield, and their uptake by plants. Journal of Environmental Quality, Madison, 12 (1): 49-57, 1983 . 
VEIHMEYER, F.J. $\varepsilon$ HENDRICKSON, A.H. The moisture equivalent as a measure of the field capacity of soils. Soil Science, Baltimore, 22: 181-95, 1931.

VIVEKANANDAN, M.; BROWN, J.R.; WILLIAMS, J.; CLEVENGER, T.; BELYEA, R.; TUMBLESON, M.E. Tolerance of forage legumes to lime-stabilized sludje. Communications in soil Science and Plant Analysis, New York, 22(5/6): 449-63, 1991 .

WALLACE, A.W. $E$ WALLACE, G.A. A possible flaw in EPA'S 1993 new sludge rule due to heavy metal interactions. Communications in Soil Science and plant Analysis, New York, 25(1/2): 129-35, 1994 .

WEIL, R.R. E KROONTJE, W. Physical condition of a Davidson Clay loam after five years of heavy poultry manure applications. Journal of Environmental Quality, Madison, 8(3): 387-92, 1979.

WILLIAMS, R.J.B.E COOKE, G.W. Some effects of farmyard manure and grass residues on soil structure. Soil Science, Baltimore, 92: 30-9, 1961.

WILLIAMS, S. (Ed.) Official methods of analysis of the Association of Official Analytical Chemists. 14.Ed. Arlington, AOAC, 1984. 1141p.

ZIBILSKE, L.M. Dynamics of nitrogen and carbon in soil during papermill sludge decomposition. Soil science, Baltimore, 143(1): 26-33, 1987 . 
APENDICE 
Tabela 20. Perdas de carbono por produção de $\mathrm{CO}_{2}$ em dois solos incubados durante 60 dias com quatro diferentes materiais orgânicos.




Tabela 20. Perdas de carbono por produção de $\mathrm{CO}_{2}$ em dois solos incubados durante 60 dias com quatro diferentes materiais orgânicos (Continuação).

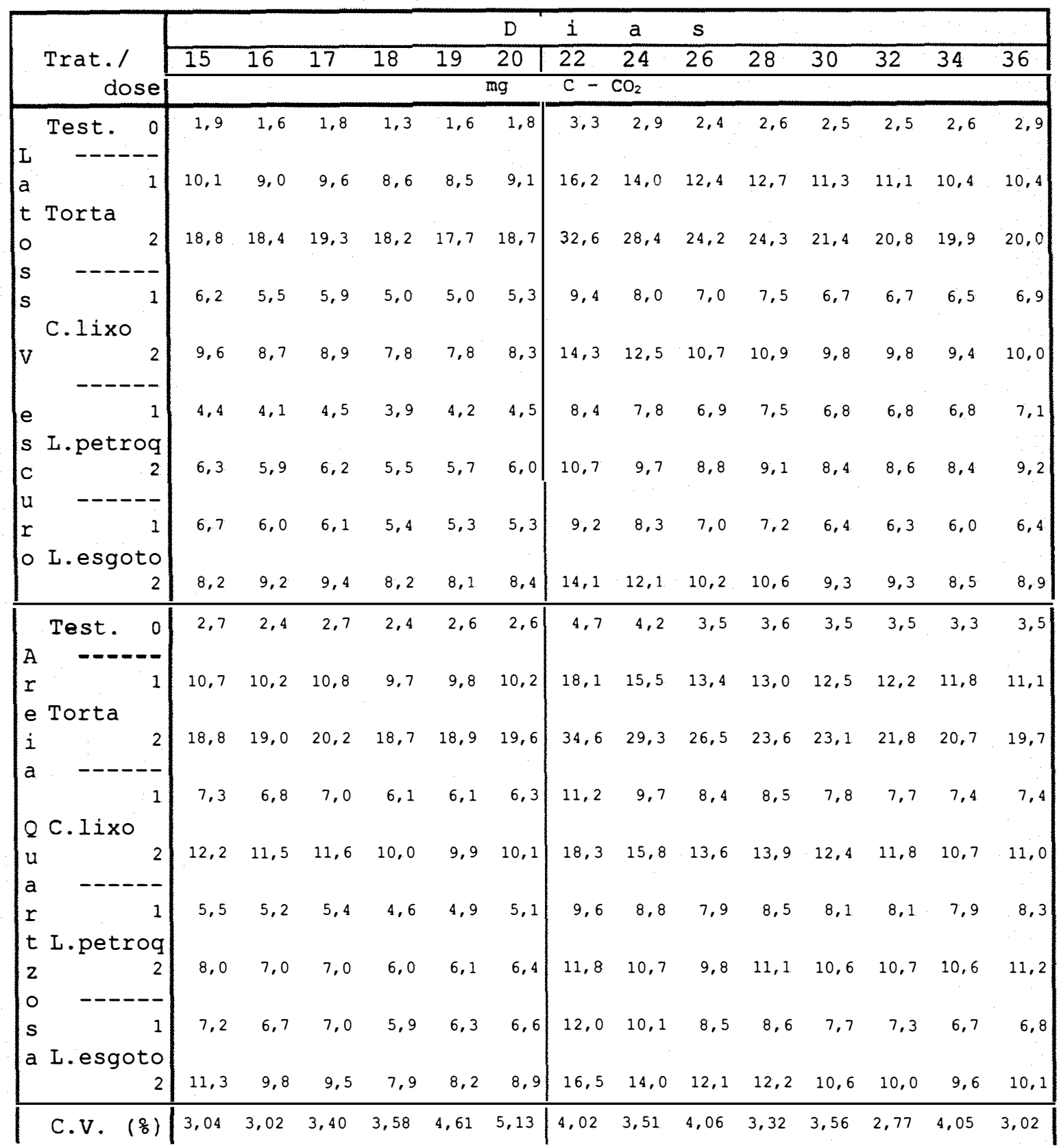


Tabela 20. Perdas de carbono por produção de $\mathrm{CO}_{2}$ em dois solos incubados durante 60 dias com quatro diferentes materiais orgânicos (Continuação) ${ }^{*}$.

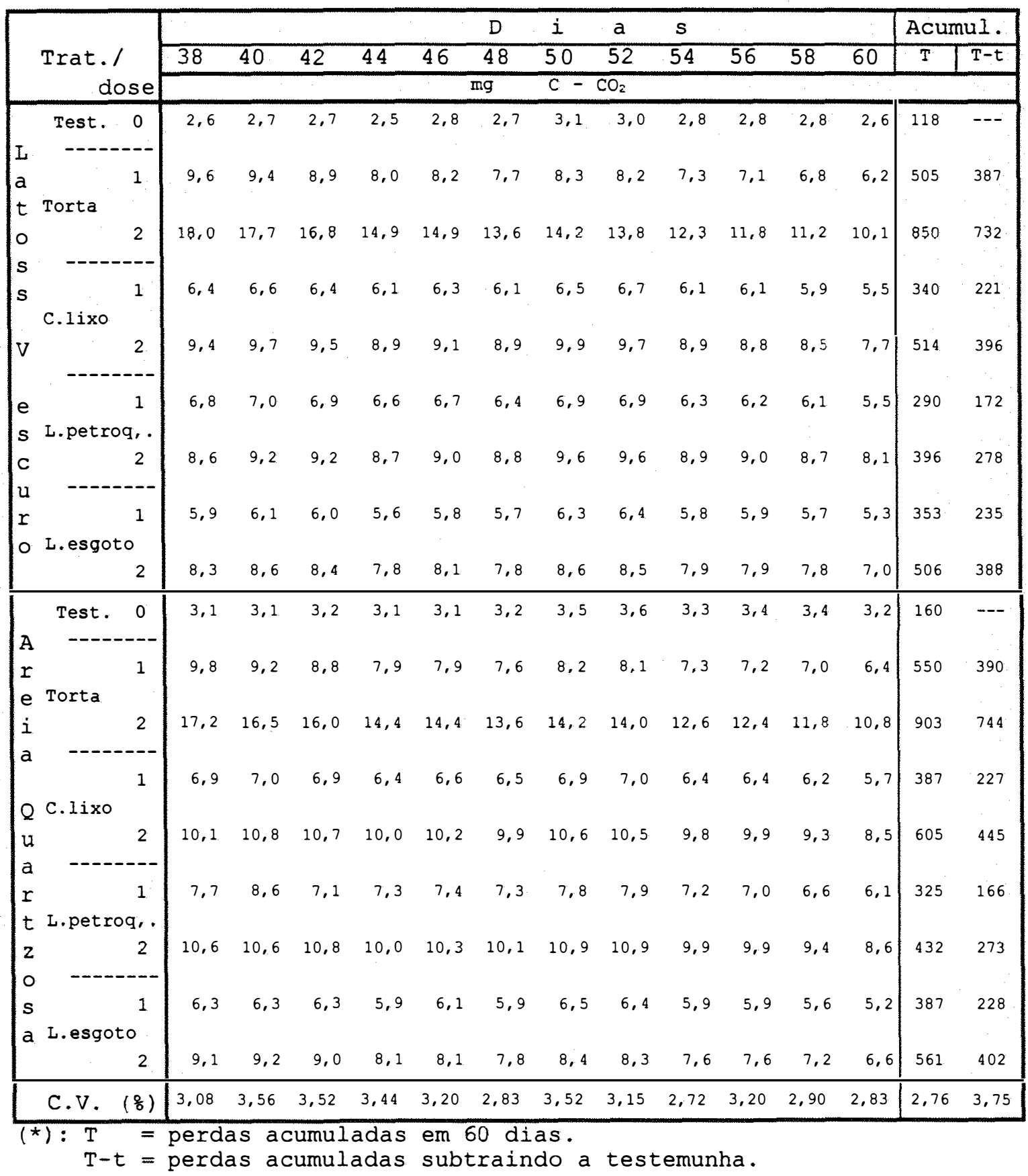


Tabela 21. Valores de umidade volumétrica em amostras de dois solos tratados com quatro diferentes materiais orgânicos submetidas a variadas tensões.

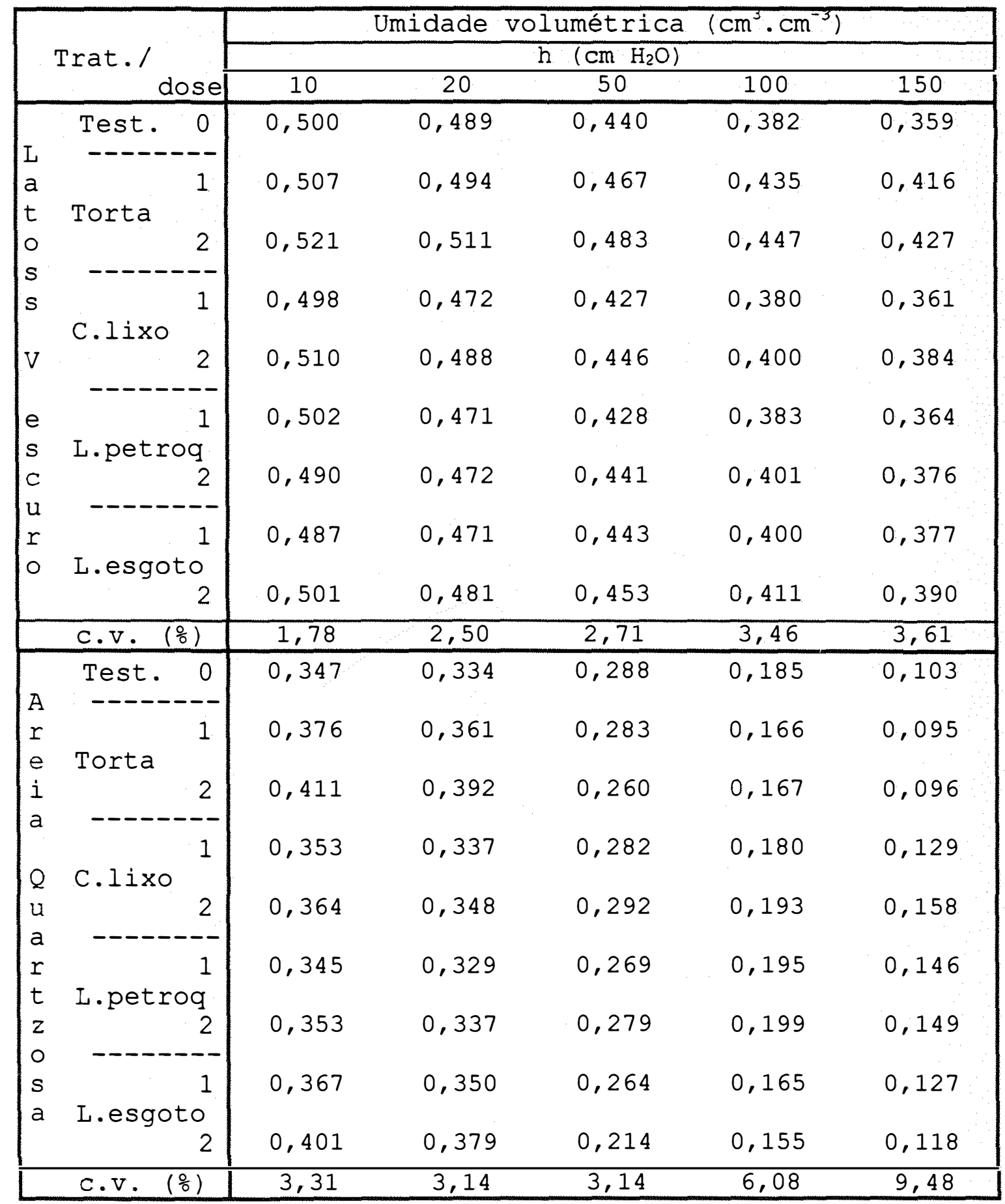

